GILBERTO ALVES PEREIRA

\title{
SISTEMA EXPERIMENTAL DE MONITORAMENTO E CONTROLE PARA CASAS DE VEGETAÇÃO BASEADO EM REDES DE CONTROLE DISTRIBUÍDO LONWORKS ${ }^{\circledR}$
}

Dissertação apresentada à Escola Politécnica da Universidade de São Paulo para obtenção do Título de Mestre em Engenharia.

São Paulo

2006 


\section{GILBERTO ALVES PEREIRA}

\section{SISTEMA EXPERIMENTAL DE MONITORAMENTO E CONTROLE PARA CASAS DE VEGETAÇÃO BASEADO EM REDES DE CONTROLE DISTRIBUÍDO LONWORKS ${ }^{\circledR}$}

Dissertação apresentada à Escola Politécnica da Universidade de São Paulo para obtenção do Título de Mestre em Engenharia.

Área de Concentração:

Sistemas Digitais

Orientador:

Prof. Livre-Docente

Carlos Eduardo Cugnasca

São Paulo 
FICHA CATALOGRÁFICA

Pereira, Gilberto Alves

Sistema experimental de monitoramento e controle para casas de vegetação baseado em redes de controle distribuído LonWorks ${ }^{\circledR}$ / Gilberto Alves Pereira -- São Paulo, 2006. $125 \mathrm{p}$.

Dissertação (Mestrado) - Escola Politécnica da Universidade de São Paulo. Departamento de Engenharia de Computação e Sistemas Digitais.

1. Estufas (Automação) 2. Agricultura (Automação) 3. Engenharia agrícola I. Universidade de São Paulo. Escola Politécnica. Departamento de Engenharia de Computação e Sistemas Digitais II.t 
À minha esposa Silvana e meus filhos Victor e Sophia. 


\section{AGRADECIMENTOS}

Ao meu orientador, Prof. Dr. Carlos Eduardo Cugnasca pela oportunidade, confiança, pelo constante incentivo, apoio e por tudo que aprendi com ele, não apenas no campo científico, mas também no ético e no humano.

Ao Prof. Dr. Sérgio Tadeu Meirelles do Departamento de Ecologia do Instituto de Biociências da Universidade de São Paulo por possibilitar a utilização da casa de vegetação.

Ao Prof. Dr. Antônio Mauro Saraiva pela oportunidade.

Ao doutorando Miguel dos Santos Alves Filho pelo apoio e incentivo.

Aos colegas do LAA, Sergio Roberto de Mello Canovas, Marlon Gripp Chermont, Gabriela Werner Ceschini, Marcelo Jorge Parente Burdelis, Jacinto Carlos Ascencio Cansado, João Israel, Rafael de Aquino Cunha e Rodrigo Alvite Romano pelos incontáveis auxílios.

Ao colega Fernando Keisuke Tani pelas longas horas de trabalho e estudo compartilhadas e principalmente pela sua solicitude.

Ao colega Jésus Franco Bueno pelas palavras de incentivo.

A Nivaldo Guerreiro e seu filho Bruno, pelo auxílio na obtenção de componentes para a ligação em rede dos módulos.

Às empresas TAC, Schneider Electric, PureChoice e Conceito Tecnologia pelo fornecimento dos módulos e componentes utilizados neste trabalho.

Á Escola Politécnica da USP pela oportunidade e ao Instituto de Biociências da USP pela cessão da casa de vegetação utilizada neste trabalho. 
À Elisabeth Adriana Dudziak pela ajuda na revisão do texto desta dissertação.

Aos meus amigos Reinaldo Burian e José Henrique Fernandez pelas orientações na revisão e em muitos detalhes deste trabalho.

A todos que, direta ou indiretamente, contribuíram para este trabalho e que não foram citados. 


\section{RESUMO}

PEREIRA, G.A. Sistema experimental de monitoramento e controle para casas de vegetação baseado em redes de controle distribuído LonWorks. 2006. $125 \mathrm{f}$. Dissertação (Mestrado) - Escola Politécnica, Universidade de São Paulo, São Paulo, 2006.

O cultivo protegido em casas de vegetação possibilita produção vegetal de maior qualidade e em qualquer época do ano. A tecnologia tem papel preponderante no controle desses ambientes, embora nem sempre seja satisfatoriamente empregada. Soluções convencionais, como as que utilizam Controladores Lógicos Programáveis, ou sistemas com tecnologia proprietária predominam nas soluções oferecidas. A evolução da tecnologia de comunicação vem possibilitando a difusão do uso da tecnologia de redes de computadores em outras aplicações, as chamadas redes de controle, possibilitando a mudança de paradigmas na concepção de sistemas de monitoramento e controle. Os sistemas com arquitetura centralizada tendem a dar lugar aos com arquitetura distribuída, e o uso da Internet possibilita a supervisão e operação de qualquer lugar. Este trabalho discute a adoção da tecnologia de redes de controle em casas de vegetação, envolvendo aspectos de sua arquitetura, distribuição da inteligência, crescimento incremental, flexibilidade e custos. Ele foi aplicado a uma casa de vegetação do Instituto de Biociências da Universidade de São Paulo, dotada de sistema de automação convencional, para a implantação e avaliação de um sistema experimental baseado na rede de controle com a tecnologia LonWorks®. Utilizaram-se nós inteligentes comercialmente disponíveis e um nó desenvolvido em laboratório. A implementação permitiu a verificação experimental das vantagens e desvantagens da utilização da abordagem distribuída em relação à centralizada. Constatou-se a facilidade de implementação, redução no cabeamento, flexibilidade e interoperabilidade da solução. Contudo, os custos tendem a ser mais elevados na abordagem distribuída, no que se refere às ferramentas de apoio e nós inteligentes. Além da avaliação de aplicação da nova tecnologia, propõe-se uma sequiência de passos a se seguir na migração de um sistema convencional para um sistema de controle distribuído, e apresenta-se a disponibilização do sistema desenvolvido como um Web Lab, que possibilita a realização de experimentos remotamente.

Palavras-chave: estufas, agricultura, engenharia agrícola 


\begin{abstract}
PEREIRA, G.A. Experimental greenhouse monitoring and control system based on LonWorks distributed control network. 2006. 125 f. Master's thesis - Escola Politécnica, Universidade de São Paulo, São Paulo, 2006.

Protected agriculture using greenhouses allows high quality crops and in any time of the year. The technology has a preponderant role in the control of these environments, although no always successfully. Conventional solutions, such as Programmable Logic Controllers, or systems with proprietary technology are predominant. The evolution of the communication technology is making possible the diffusion of computer networks use in other applications: control networks start to awake the interest of both researchers and users, changing the paradigm of monitoring and control systems conception. The traditional systems with centralized architecture tend to be replaced by distributed technology, and the Internet use makes possible the supervision and control from anywhere. This work discusses the control networks technology applied to greenhouses, involving architecture aspects, intelligence distribution, incremental growth, flexibility and costs. For the implementation and assessment of an experimental system based on LonWorks ${ }^{\circledR}$ technology, a greenhouse at Instituto de Biociências at Universidade de São Paulo was used. Off the shelf intelligent nodes were used and an experimental node was developed. The implementation made possible the experimental verification of advantages and disadvantages of the use of distributed and centralized approach. It was evidenced easiness of implementation, cabling reduction, flexibility and interoperability of the solution. However, the costs tend to be raised in the distributed approach, referring to support tools and intelligent nodes. Besides the new technology application evaluation, a step-by-step sequence is proposed for the migration from a conventional system to a control system, and presents a Web Lab system that enables remote experimentation.
\end{abstract}

Keywords: greenhouse, agriculture, agricultural engineering 


\section{SUMÁRIO}

LISTA DE FIGURAS

LISTA DE TABELAS

LISTA DE ABREVIATURAS E SIGLAS

1 INTRODUÇÃ

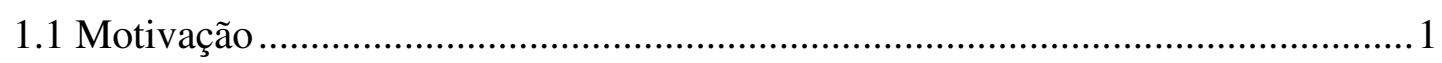

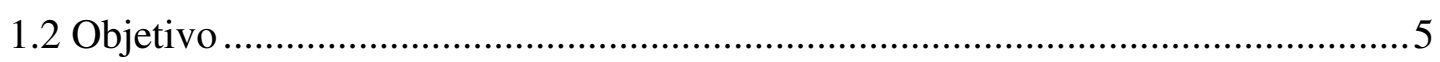

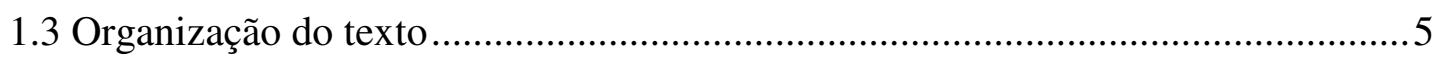

2 CASAS DE VEGETAÇÃO - FATORES DE CONTROLE ...................................7

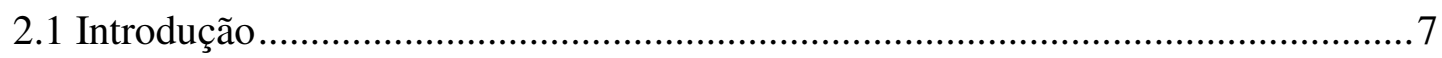

2.2 Fatores controlados numa casa de vegetação ................................................... 8

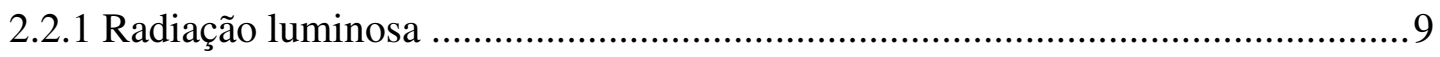

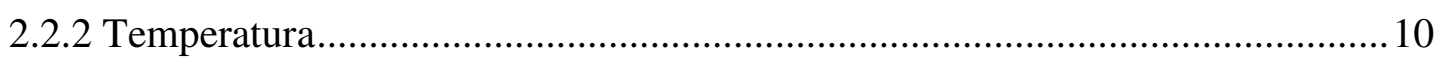

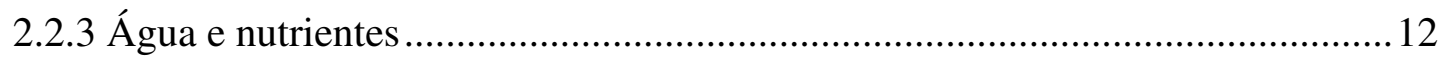

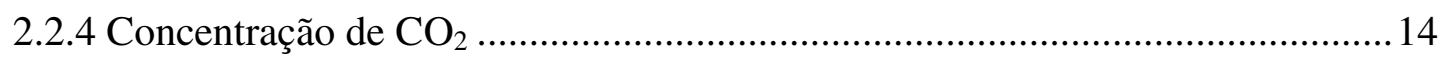

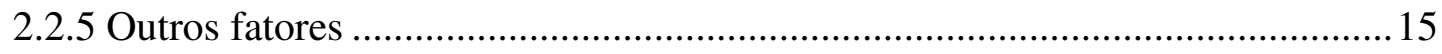

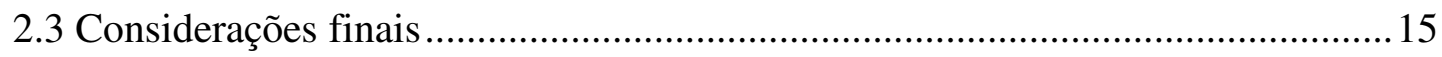

3 SISTEMAS DE CONTROLE CENTRALIZADOS E DISTRIBUÍDOS..........17

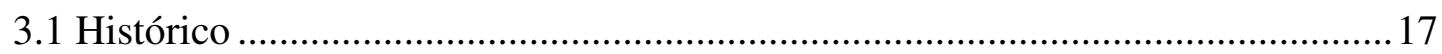

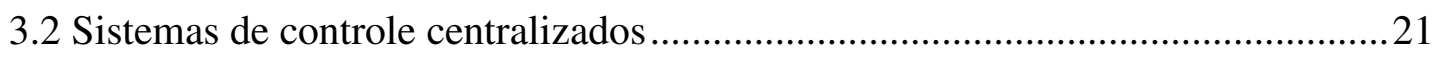

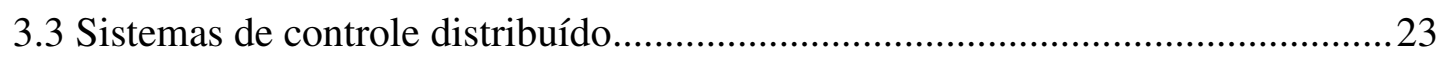

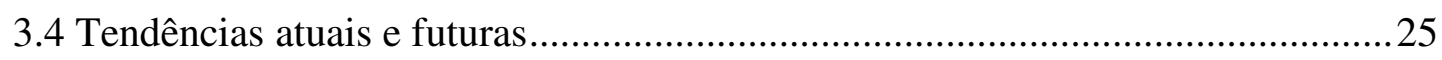

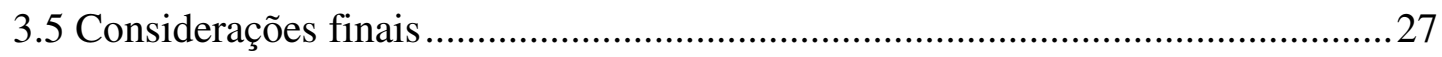

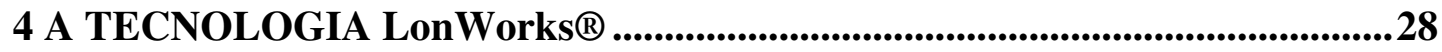

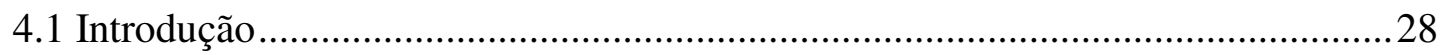

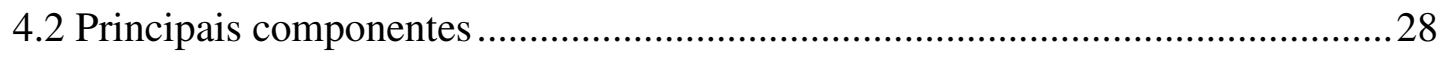

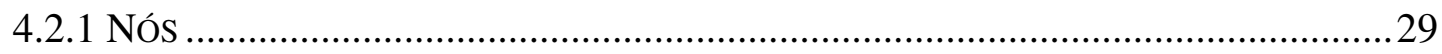

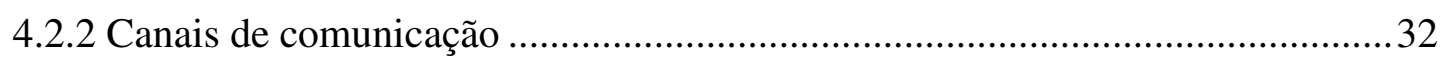

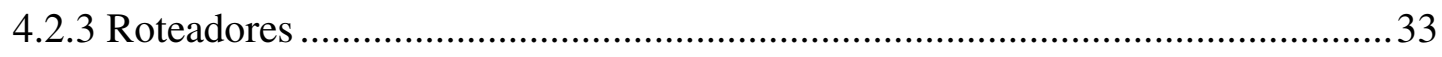

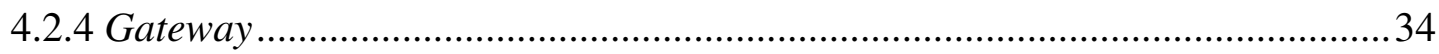


4.2.5 Topologias de rede 34

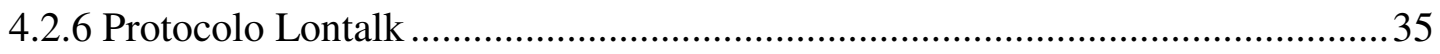

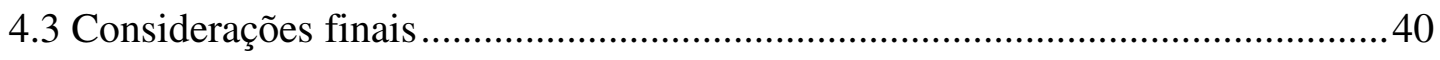

\section{PROPOSTA E IMPLEMENTAÇÃO DE UMA REDE DE CONTROLE} DISTRIBUÍDO EM UMA CASA DE VEGETAÇÃO............................................42

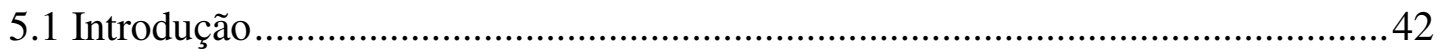

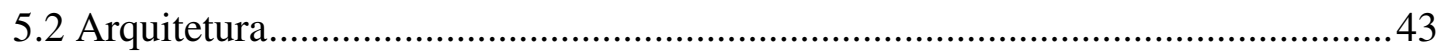

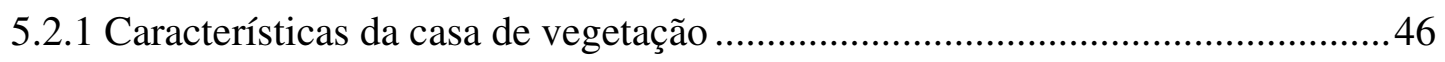

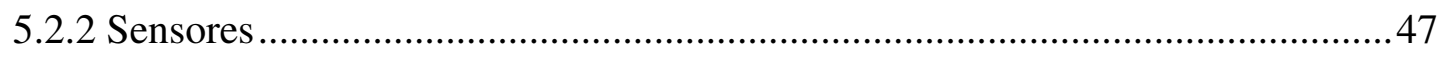

5.2.2.1 Sensor de temperatura - PT-100 …......................................................... 47

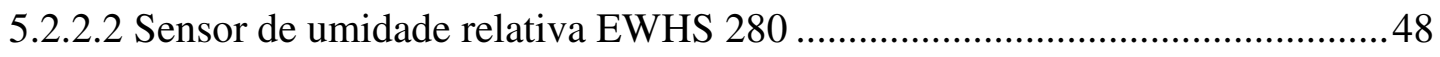

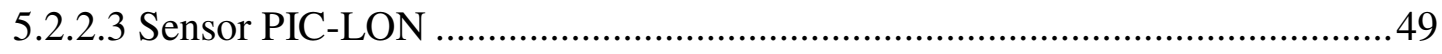

5.2.2.4 Sensor múltiplo NOSE da PureChoice …...................................................52

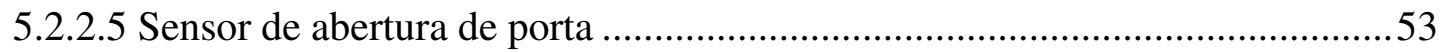

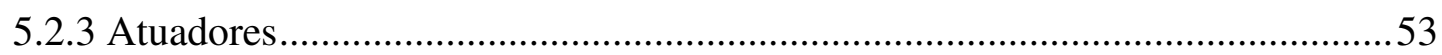

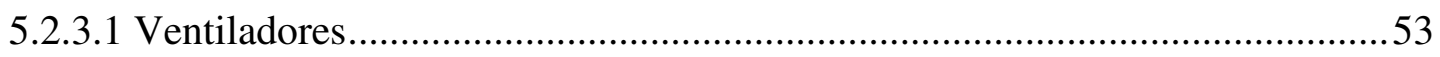

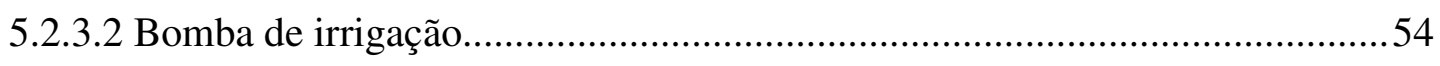

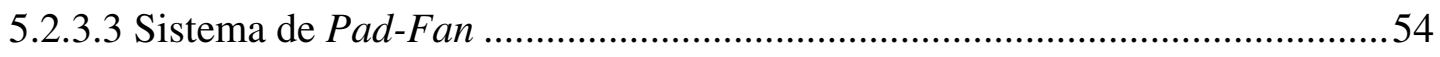

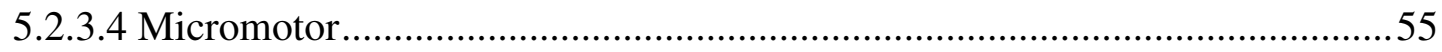

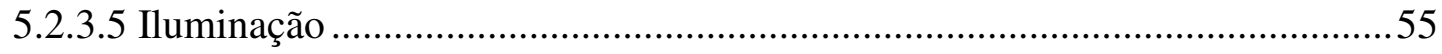

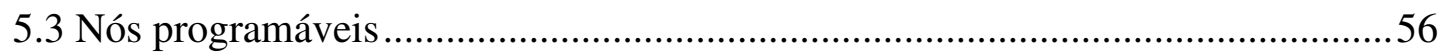

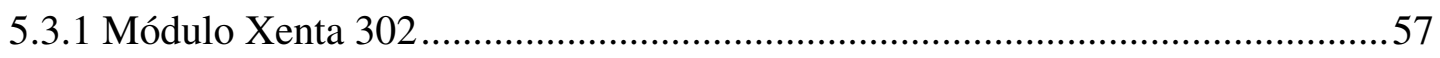

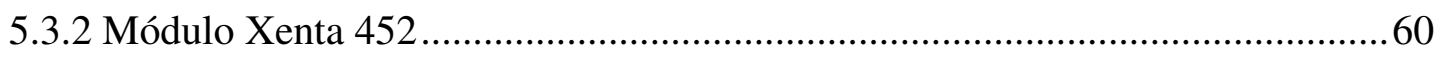

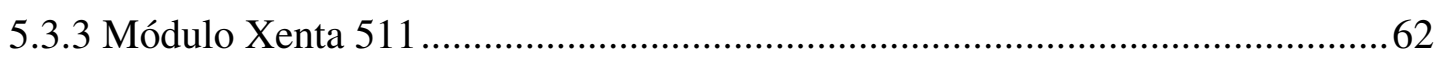

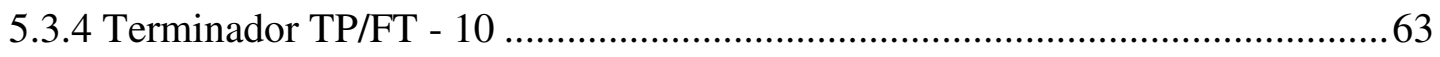

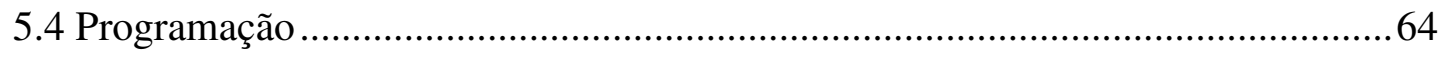

5.4.1 Programas de desenvolvimento e configurações básicas ..................................64

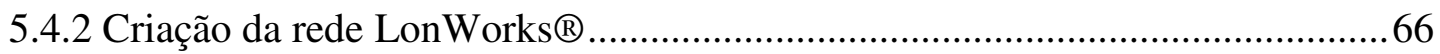

5.4.3 Inclusão dos nós Nose e PIC-LON na rede LonWorks® .................................67

5.4.4 Tratamentos de sinais e cálculos Implementados.............................................6 68

5.4.4.1 Tratamento das medidas de temperatura e umidade......................................68

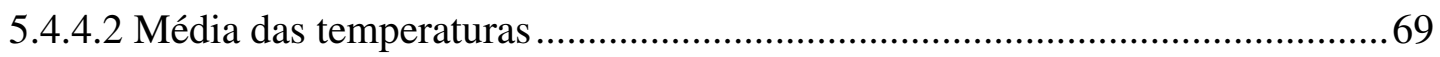




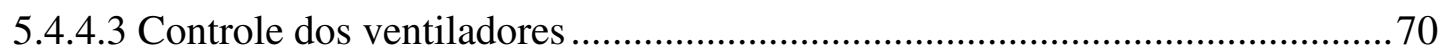

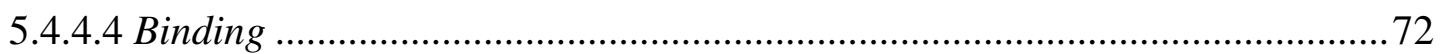

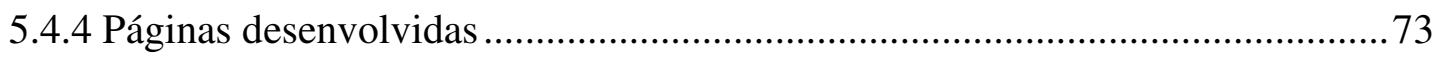

5.4.4.1 Site Web para monitoramento e controle ................................................... 73

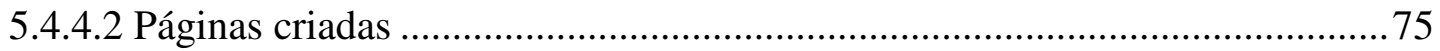

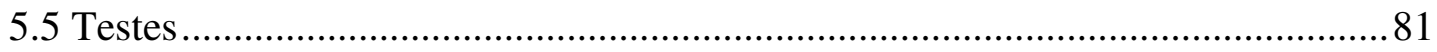

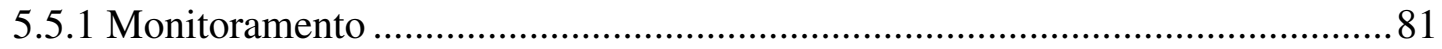

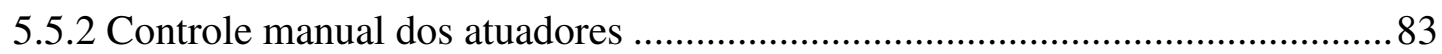

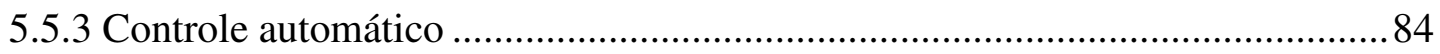

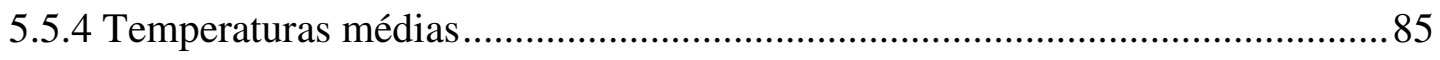

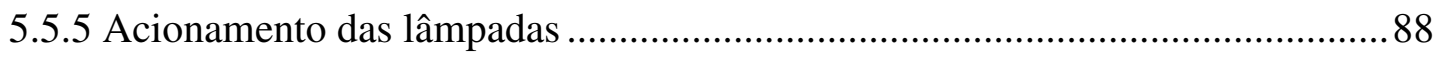

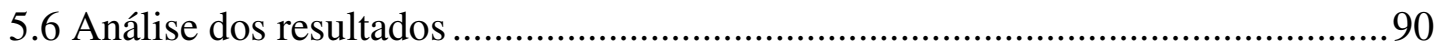

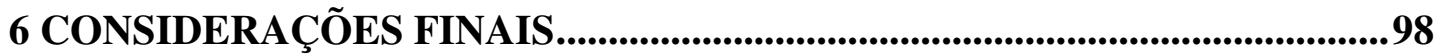

REFERÊNCIAS ..........................................................................................109

APÊNDICE A - CIRCUITOS CONDICIONADORES DE SINAL ...................116 APÊNDICE B - ESTUDO SOBRE A REDUÇÃO NO CABEAMENTO NA CASA DE VEGETAÇÃ APÊNDICE C - MEDIDAS DE TEMPERATURA COLETADAS....................122 


\section{LISTA DE FIGURAS}

Figura 1 - Efeito do acréscimo da temperatura diurna (DT) a uma temperatura noturna constante $(\mathrm{NT})$ de $22^{\circ} \mathrm{C}$ comparada com o acréscimo da NT a uma DT constante de $22^{\circ} \mathrm{C}$

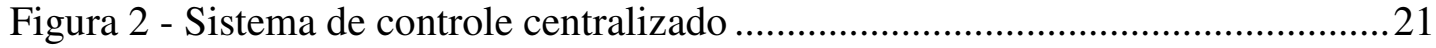

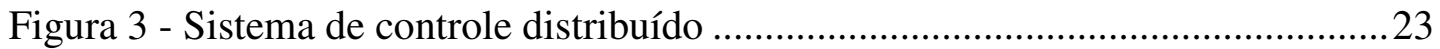

Figura 4 - Evolução dos sistemas computacionais e de controle. ..............................26

Figura 5 - Exemplo de uma rede utilizando a tecnologia LonWorks® ${ }^{\circledR}$......................2 29

Figura 6 - Configuração típica de um nó LonWorks ${ }^{\circledR}$................................................ 30

Figura 7 - Comunicação entre os processadores do Neuron Chip.............................. 31

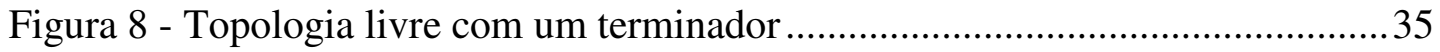

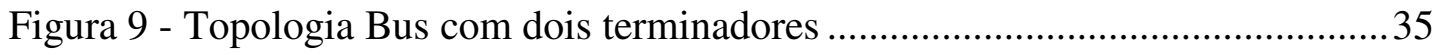

Figura 10 - Tipos de binding a) um para um b) um para muitos c) muitos para um d) muitos para muitos (mesmo grupo de nós) e e) muitos para muitos (grupos de

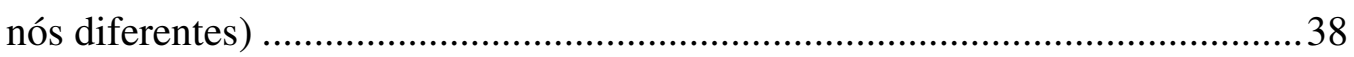

Figura 11 - Arquitetura do sistema implementado ................................................45

Figura 12 - Vista externa da casa de vegetação do IB-USP .......................................46

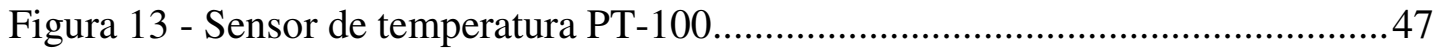

Figura 14 - Vista superior da casa de vegetação com o posicionamento dos sensores e atuadores 48

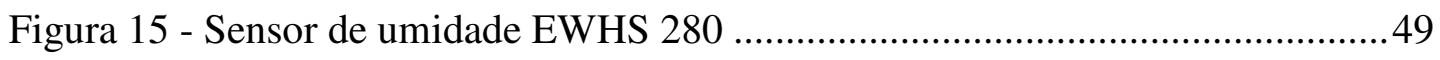

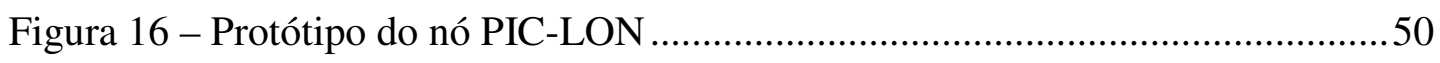

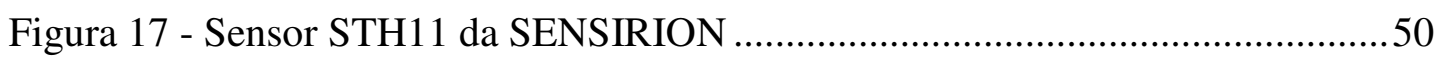

Figura 18 - Módulo LTM-10 utilizado no experimento ….........................................51

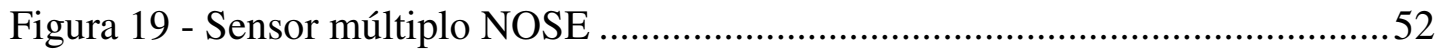

Figura 20 - Sensor de abertura utilizado na porta da casa de vegetação .....................53

Figura 21 - Ventilador utilizado na casa de vegetação...............................................53

Figura 22 - Bico aspersor utilizado no sistema de irrigação ......................................54

Figura 23 - Parede evaporativa do sistema Pad-Fan .................................................5

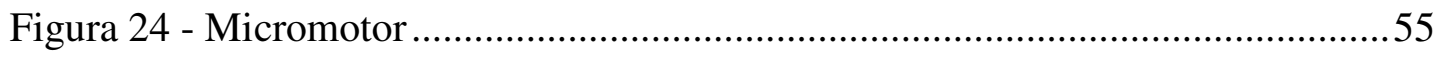

Figura 25 - Disposição das lâmpadas da casa de vegetação.........................................55 
Figura 26 - Conjunto de componentes utilizados na rede experimental

Figura 27 - Placa condicionadora de sinais dos sensores PT-100 e EWHS 280........58

Figura 28 - Caixa de relés acionadores dos atuadores.............................................5

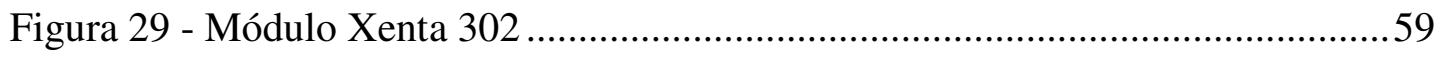

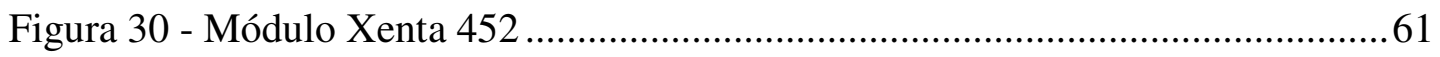

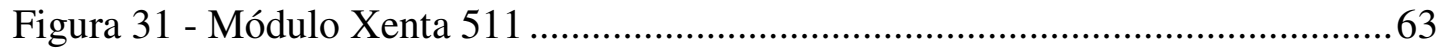

Figura 32 - Terminador TP/FT -10 utilizado na montagem da rede LonWorks ${ }^{\circledR}$....66

Figura 33 - Fluxo de processamento utilizado na ferramenta Menta

Figura 34 - Blocos funcionais usados para tratamento dos valores de temperatura do sensor PT100_3

Figura 35 - Blocos funcionais usados para tratamento dos valores de umidade do sensor EWHS_1

Figura 36 - Blocos funcionais usados para cálculo da média de temperatura dos sensores PT100_3, PT100_4, e PIC-LON utilizadas no módulo programável $302 \_1$

Figura 37 - Blocos funcionais usados para cálculo da média de temperatura dos sensores PT100_1, PT100_2, e NOSE utilizadas no módulo programável 302_2 .70

Figura 38 - Gráfico exemplificando o funcionamento do algoritmo two-step 71

Figura 39 - Gráfico da saída em função dos valores de referência para o bloco HYST

Figura 40 - Blocos funcionais usados para acionamento do ventilador 1 utilizando o algoritmo two-step .72

Figura 41 - Nós LonWorks ${ }^{\circledR}$ com as ligações entre as suas variáveis de rede ...........73

Figura 42 - Sistema de monitoramento e controle - página inicial..............................75

Figura 43 - Página de monitoramento das temperaturas ...........................................76

Figura 44 - Página de monitoramento da umidade relativa........................................77

Figura 45 - Página de monitoramento do controle do ventilador 1 .............................78

Figura 46 - Página de monitoramento do controle do ventilador 2 ...........................78

Figura 47 - Página de monitoramento de temperatura média....................................79

Figura 48 - Página de monitoramento do estado dos atuadores e porta ......................80

Figura 49 - Página de monitoramento das medidas .................................................. 80 
Figura 50 - Página de acionamento manual dos atuadores

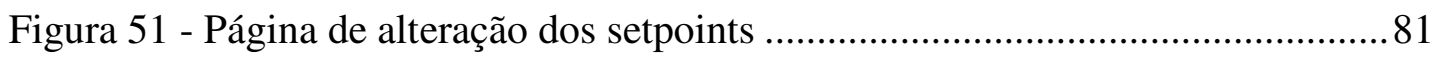

Figura 52 - Gráfico do comportamento da leitura das temperaturas .......................... 82

Figura 53 - Gráfico do comportamento da leitura da umidade .................................82

Figura 54 - Resultado do teste de acionamento dos relés...........................................83

Figura 55 - Estado dos contatores dos atuadores e relé da iluminação durante

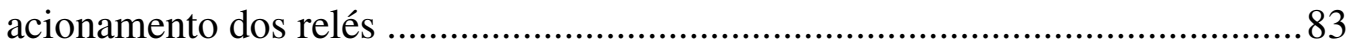

Figura 56 - Resultado do teste de acionamento do ventilador 1 ............................... 84

Figura 57 - Resultado do teste de acionamento do ventilador 2 ...............................85

Figura 58 - Temperatura média calculada pelo módulo 302_1 ................................. 86

Figura 59 - Temperatura média calculada pelo módulo 302_2 ….............................86

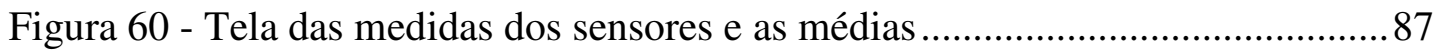

Figura 61 - Resultado do teste de acionamento do fotoperíodo através do fechamento

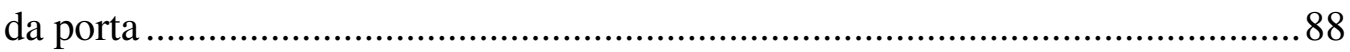

Figura 62 - Circuito condicionador utilizado para o sensor de temperatura PT-100116 Figura 63 - Circuito condicionador utilizado para o sensor de umidade EWHS 280

Figura 64 - Dimensões da casa de vegetação e posicionamento dos sensores e atuadores utilizadas no cálculo do tamanho do cabeamento necessário 120 


\section{LISTA DE TABELAS}

Tabela 1 - Elementos normalmente considerados como essenciais para o crescimento

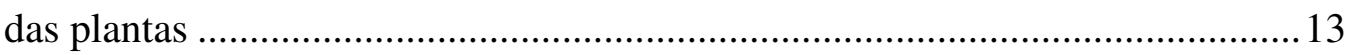

Tabela 2 - Tipos de transceptores e taxas de velocidade...........................................33

Tabela 3 - Exemplo de alguns tipos de variáveis de rede (SNVT) da tecnologia

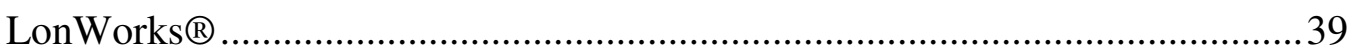

Tabela 4 - Ligações dos módulos Xenta 302 aos atuadores e sensores......................60

Tabela 5 - Verificação da média de temperaturas calculada pelo módulo 302_1 ......87

Tabela 6 - Verificação da média de temperaturas calculada pelo módulo 302_2 _.....87

Tabela 7 - Comprimentos dos cabos dos sensores e atuadores até o quadro de CLP

Tabela 8 - Distância dos componentes para o caso de ser montada uma rede de controle

Tabela 9 - Dados de temperatura coletados na casa de vegetação 


\section{LISTA DE ABREVIATURAS E SIGLAS}

\begin{tabular}{|c|c|}
\hline A & Ampère (unidade de medida de corrente) \\
\hline $\mathrm{A} / \mathrm{D}$ & Analógico/Digital \\
\hline $\mathrm{AC}$ & Alternate Current \\
\hline ANSI & American National Standards Institute \\
\hline ASI & Actuator Sensor Interface \\
\hline $\mathrm{C}$ & Carbono (elemento químico) \\
\hline CAN & Controller Area Network \\
\hline CD-ROM & Compact Disc - Read Only Memory \\
\hline CLP & Controlador Lógico Programável \\
\hline $\mathrm{CO}_{2}$ & Gás Carbônico \\
\hline CSMA/CD & Carrier Sense Multiple Access Collision Detection \\
\hline DC & Direct Current \\
\hline DeviceNet & Device Network \\
\hline DIF & Diferença entre a temperatura diurna e a temperatura noturna \\
\hline DHCP & Dynamic Host Configuration Protocol \\
\hline DT & Day Temperature \\
\hline EIA & Electronic Industries Alliance \\
\hline EIB & European Installation Fieldbus \\
\hline EPUSP & Escola Politécnica da Universidade de São Paulo \\
\hline FBD & Function Block Diagram \\
\hline FF & Fieldbus Foundation \\
\hline GAP & Grupo de estudos de Ambientes Protegidos \\
\hline GSM & Global System of Mobile Telecommunication \\
\hline HART & Highway Addressable Remote Transducer \\
\hline HP & Horse Power (unidade física de potência) \\
\hline HTML & HyperText Markup Language \\
\hline $\mathrm{Hz}$ & Hertz (unidade física de freqüência) \\
\hline
\end{tabular}




\begin{tabular}{|c|c|}
\hline IB & Instituto de Biociências \\
\hline IHC & Interface Homem-Computador \\
\hline IP & Internet Protocol \\
\hline IR & Infra Red \\
\hline ISO & International Organization for Standardization \\
\hline ISP & Interoperable System Project \\
\hline kbps & 1000 bits por segundo \\
\hline LAA & Laboratório de Automação Agrícola \\
\hline LAN & Local Área Network \\
\hline LDP & Long Day Plant \\
\hline LED & Light Emitting Diode \\
\hline LON & Local Operating Network \\
\hline LTA & LontTalk Adapter \\
\hline MAC & Media Access Control \\
\hline Mbps & 1.000 .000 bits por segundo \\
\hline MMC & MultiMedia Card \\
\hline $\mathrm{mV}$ & milivolt \\
\hline $\mathrm{nm}$ & Nanômetro $\left(10^{-9} \mathrm{~m}\right)$ \\
\hline NT & Night Temperature \\
\hline OSI & Open System Interconnection \\
\hline PAR & Photosynthetically Active Radiation \\
\hline PC & Personal Computer \\
\hline $\mathrm{PC}$ & Personal Computer \\
\hline $\mathrm{PH}$ & Potencial de hidrogênio iônico \\
\hline P-NET & Process Net \\
\hline ppm & partes por milhão \\
\hline Profibus & Process Fieldbus \\
\hline $\mathrm{Pt}$ & Platina (elemento químico) \\
\hline PWM & Pulse Width Modulation \\
\hline
\end{tabular}




\begin{tabular}{|c|c|}
\hline RAM & Random Access Memory \\
\hline $\mathrm{RF}$ & Rádio-frequência \\
\hline RPM & Rotações por Minuto \\
\hline RTD & Resistance Temperature Detector \\
\hline SDP & Short Day Plant \\
\hline SDS & Smart Distributed Systems \\
\hline SMTP & Simple Mail Transfer Protocol \\
\hline SNVT & Standard Network Variable Type \\
\hline SSL & Secure Sockets Layer \\
\hline TCP/IP & Transmission Control Protocol / Internet Protocol. \\
\hline TEDS & Transducer Electronic Data Sheets \\
\hline TIDIA & $\begin{array}{l}\text { Tecnologia da Informação para o Desenvolvimento da Internet } \\
\text { Avançada }\end{array}$ \\
\hline URL & Uniform Resource Location \\
\hline USP & Universidade de São Paulo \\
\hline $\mathrm{V}$ & Volts (unidade de medida de tensão) \\
\hline VAC & $\begin{array}{l}\text { Volts - Alternate Current (unidade de medida de tensão, em corrente } \\
\text { alternada) }\end{array}$ \\
\hline VDC & $\begin{array}{l}\text { Volts - Direct Current (unidade de medida de tensão, em corrente } \\
\text { contínua) }\end{array}$ \\
\hline ViNCES & Virtual Networking Center of Ecosystem Services \\
\hline WEB & World Wide Web ou www \\
\hline WLAN & Wireless Local Area Network \\
\hline WorldFIP & World Factory Instrumentation Protocol \\
\hline
\end{tabular}




\section{INTRODUÇÃ̃O}

\subsection{Motivação}

O ser humano, na sua busca insaciável para tornar o ambiente em que vive mais adequado à sua sobrevivência, cria mecanismos para manipular a natureza a seu favor. Aos poucos, foi desenvolvendo técnicas e utensílios que viabilizavam e facilitavam o cultivo. $\mathrm{O}$ cultivo protegido é fruto dessa necessidade. Procura manter o controle de algumas características do ambiente que circunda as plantas. Tem a finalidade de obtenção de melhorias na qualidade e produtividade das culturas, permitindo o aumento de produtividade nos períodos de entressafra (RATTIN, ANDRIOLO e WITTER, 2003) e é utilizado para aumentos de produção quando muitas vezes as tentativas de obtenção de incrementos pelos métodos tradicionais se esgotaram (VIDA, 2004). Auxilia também na adaptação de culturas ao clima tropical e ajuda no florescimento, sendo normalmente usado em culturas de maior valor agregado (CANSADO, 2003).

No Brasil, o cultivo protegido com a utilização de casas de vegetação (comercialmente conhecidas como estufas) é adotado principalmente na produção de certas culturas como as hortaliças e leguminosas, assim como na produção de flores. Nos últimos anos, alguns fatores têm contribuído no sentido de auxiliar o aumento da participação desse tipo de cultivo. Em primeiro lugar, ao avanço e barateamento da tecnologia, que permite maior disseminação dessa forma de cultivo; aliado a isso, segundo Cansado (2003), observa-se que há um interesse cada vez maior por qualidade e produtividade dos produtos hortifrutigranjeiros, o que estimula o movimento das empresas em atender a tal necessidade. Nesse sentido, duas tendências podem ser notadas: o espaço cada vez maior tomado pelos produtos da “agricultura orgânica" e os produtos hidropônicos que, em certas épocas do ano, têm seus preços muito competitivos em relação ao cultivo tradicional.

No entanto, segundo dados obtidos na feira Hortitec (2003) e segundo relatos de Cansado (2003), a maioria dos expositores que comercializavam casas de 
vegetação não ofereciam nenhum tipo de controle automatizado; os poucos sistemas de controle oferecidos eram elementares. Nota-se ainda que o cultivo de hortaliças em casas de vegetação no Brasil é muito pequeno comparativamente aos países da Europa (VECCHIA e KOCK, 1999 apud CANSADO, 2003). Esses pontos destacam a grande oportunidade de incremento, tanto da utilização desse ambiente, quanto da utilização de tecnologia nesse tipo de cultivo, o que motiva o desenvolvimento de trabalhos nessa área.

Por outro lado, com a evolução e barateamento da tecnologia, novas formas de controle das condições climáticas e de automação dos processos passaram a ser adotados. Deixando para trás os controles manuais, passou-se a utilizar controles automatizados baseados em microprocessadores, que proporcionam flexibilidade de programação e reutilização: os chamados Controladores Lógicos Programáveis (CLPs). Foi o primeiro marco nos projetos de controle de processos e automação trazendo significativas vantagens aos usuários, que passaram a implementar seus projetos com a tecnologia baseada em CLPs, em substituição aos dispendiosos e inflexíveis painéis com muitos relés e lógica fixa de controle (ALVES FILHO, 2001).

Nesses sistemas todas as decisões de controle, assim como todas as entradas e saídas, são centralizadas, o que traz uma série de desvantagens, tais como: a falha no CLP causa a parada de todo o sistema, o grande volume de cabos de entradas e saídas convergindo para um único local e a necessidade de amplificação de sinal para sensores distantes do CLP, degradando o sinal devido à amplificação dos ruídos.

Com o progresso e barateamento do desenvolvimento de semicondutores surge a tendência em se utilizar a topologia de decisão distribuída, o que permite facilmente o incremento da confiabilidade, redução no cabeamento, diminuição no custo de instalação e escalabilidade. Com isso, a comunicação entre os elementos necessariamente torna-se mais complexa. 
No esteio desta evolução, no início da década de 90, começa a ganhar destaque, a tecnologia LonWorks ${ }^{\circledR}{ }^{1}$. Criada pela empresa americana Echelon Corporation (ECHELON, 2005a), LonWorks® é uma tecnologia aberta, que permite o desenvolvimento de dispositivos interoperáveis e sistemas flexíveis que operam através de redes de controle distribuído. Esta tecnologia suporta uma diversidade de meios físicos de comunicação. Cabos de par-trançado, rede elétrica, radiofreqüência e fibra ótica são exemplos de meios físicos disponíveis.

LonWorks® é um padrão aberto desenvolvido para ser usado em automação industrial, residencial e predial $^{2}$. Trata-se de uma tecnologia para automação e controle que utiliza inteligência distribuída. Sua idéia, assim como do padrão BACnet (FISCHER, 1996;GOLDSHMIDT, 1998) é propor um padrão de comunicação entre seus componentes chamados "nós". Muito utilizada na automação predial, embora adequada a diversos setores de aplicação, essa tecnologia envolve não apenas um módulo que permite flexibilidade e facilidade de implementação, mas a utilização de múltiplos módulos inteligentes (que se comunicam através de um protocolo de comunicação com padrão aberto); as mensagens trocadas entre os módulos são padronizadas, permitindo com isso que fabricantes diferentes possam produzir módulos compatíveis.

A utilização da tecnologia LonWorks ${ }^{\circledR}$ possibilita aos projetistas a concentração de esforços somente na camada de aplicação da rede. Todo o restante, desde o acesso ao meio físico, até o roteamento de mensagens e endereçamento, é tratado pelo firmware já existente. A utilização das conexões lógicas entre as variáveis de rede permite uma visão de alto nível do sistema, reduzindo a necessidade de conhecimento do funcionamento das camadas básicas de sua infraestrutura.

\footnotetext{
${ }^{1}$ Tenologia de redes de controle distribuídos que envolve uma família de produtos em hardware e software, dispostos em rede e comunicando-se através de um protocolo padronizado chamado LonTalk e ferramentas de gerenciamento de rede.

${ }^{2}$ Segue a norma americana ANSI EIA 709.1 que possibilita a criação de redes de controle distribuído.
} 
Essa tecnologia simplifica o projeto de sistemas de controle, que se torna cada vez mais um processo de integração de componentes e a sua adaptação aos requisitos específicos da aplicação.

A tecnologia LonWorks® foi escolhida para a implementação de uma aplicação de rede de controle por ser uma solução aberta, por existir uma similaridade no controle ambiental de um edifício e de uma casa de vegetação, e devido ao fato de que, embora essa tecnologia já esteja consolidada em diversos campos como automação predial, encontram-se poucos relatos de trabalhos envolvendo sua aplicação em casas de vegetação. Diversas de suas características são importantes para a aplicação em questão, como por exemplo, aceitar vários tipos de meio físicos, o que possibilita um grau adequado de flexibilidade ao sistema.

Este trabalho dá prosseguimento ao trabalho de pesquisa realizado na casa de vegetação do Instituto de Biociências da Universidade de São Paulo (IBUSP) por pesquisadores do Laboratório de Automação Agrícola (LAA) da Escola Politécnica (EP-USP). Cansado (2003) desenvolveu um sistema de controle para a casa de vegetação utilizando um CLP, que foi utilizado como comparativo a este trabalho. Parte da infra-estrutura já desenvolvida foi utilizada.

Finalmente, pretende-se que o resultado deste trabalho sirva de base para futura disponibilização da infra-estrutura disponível, para a realização de experimentos à distância, que faz parte do projeto Tecnologia de Informação para o Desenvolvimento da Internet Avançada (TIDIA-Kyatera), subprojeto Virtual Networking Center of Ecosystem Services (ViNCES) (TIDIA, 2005; KYATERA, 2005; VINCES, 2005). Nesse projeto serão interligados alguns laboratórios de pesquisa do Estado de São Paulo com redes de alta velocidade, possibilitando que sejam feitas pesquisas remotamente. O projeto ViNCES é um consórcio de três instituições: Escola Politécnica da USP (EPUSP), Instituto de Biociências da USP (IB) e Instituto de Botânica da Secretaria do Meio Ambiente do Estado de São Paulo. Seu objetivo é atuar em serviços ambientais, tais como fotossíntese e polinização, promovendo um melhor entendimento desses serviços, sua importância, grandeza e impactos sob diversos pontos de vista: científico, econômico e social. 


\subsection{Objetivo}

O objetivo deste trabalho é a implementação de um sistema experimental de supervisão e controle para a casa de vegetação do Instituto de Biociências da USP, seguindo uma nova abordagem: adoção de arquitetura do sistema de controle distribuída, baseada na rede de controle LonWorks ${ }^{\circledR}$, e compará-la com o controle centralizado baseado em CLP. Pretende-se que o sistema implementado seja utilizado em novas pesquisas, envolvendo técnicas de controle e monitoração de ambientes de cultivo protegido.

\subsection{Organização do texto}

Esta dissertação é composta por sete capítulos, referências bibliográficas e apêndices.

O segundo capítulo apresenta uma breve descrição de uma casa de vegetação, destacando as principais variáveis envolvidas no seu monitoramento e controle.

O terceiro capítulo discute a questão dos sistemas de controle centralizados e distribuídos evidenciando suas diferenças.

O quarto capítulo provê uma introdução às redes de controle LonWorks ${ }^{\circledR}$, apresentando os conceitos básicos e suas principais características.

O quinto capítulo descreve o sistema implementado, mostra a arquitetura idealizada, as características da casa de vegetação, ferramentas e testes efetuados, assim como discute os resultados desses testes.

O sexto capítulo apresenta as conclusões, onde é feita uma análise crítica do trabalho, apontando suas contribuições e perspectivas de melhoria e continuidade. 
O Apêndice A apresenta uma descrição detalhada da placa de circuitos de condicionamento de sinais implementada e suas ligações com os componentes da casa de vegetação. No Apêndice B é apresentado um estudo sobre a redução do cabeamento e no apêndice C são apresentados, a título de exemplo, uma lista de dados de temperatura coletados, tanto do ambiente interno como externamente ao ambiente controlado. 


\section{CASAS DE VEGETAÇÃO - FATORES DE CONTROLE}

Este capítulo tem por objetivo apresentar e descrever os principais fatores passíveis de controle em casas de vegetação, servindo como base ao estudo e desenvolvimento de sistemas de monitoramento e controle. Como referências principais relacionadas ao assunto tem-se Hanan (1998).

\subsection{Introdução}

As casas de vegetação são estruturas montadas com a finalidade de proteger a cultura e criar um ambiente mais propício ao seu desenvolvimento. $\mathrm{O}$ simples fato de proteger todas as plantas através de uma estrutura que as envolva, já melhora a qualidade da colheita em muitos casos, principalmente em países onde não existem variações muito grandes entre as estações do ano, como acontece em muitas partes do Brasil.

No entanto, quando se deseja obter maior controle do desenvolvimento da cultura, é preciso atuar sobre as principais variáveis que a influenciam. Deste modo, o controle e supervisão dessas variáveis se faz necessário.

Segundo Hanan (1998), uma casa de vegetação é uma estrutura que cobre a terra para crescimento de um cultivo, que retornará um lucro para o proprietário do risco e capital. A função primordial da casa de vegetação é criar um ambiente mais favorável ao cultivo de determinada cultura do que o ambiente externo a ela. Deste modo, um aspecto importante é a parte física da casa de vegetação, que tem a função de proteger (ou encapsular) a cultura do ambiente externo. Assim, o envoltório tem a função de efetuar esse isolamento. No entanto, a colocação da cultura dentro de uma 
casa por si só não cria necessariamente esse ambiente favorável. Claro que isso protege a cultura de intempéries externas, ventos (até um certo ponto), excesso de água, etc. Mas também pode causar vários problemas, como o excesso de umidade e a proliferação de fungos, temperaturas internas excessivamente altas, falta de umidade no ar e no solo devido à inexistência das chuvas, etc.

Os mecanismos de controle do ambiente de uma casa de vegetação são recursos de grande importância. Eles podem ter um grau maior ou menor de complexidade e atuar em uma ou mais variáveis que afetam o desenvolvimento da cultura. Aplicado de forma manual ou automática, sempre estão presentes numa casa de vegetação.

Quanto melhor o controle, maior será a qualidade e a produtividade, menor o desperdício de insumos, assim como o risco atribuído ao negócio. Havendo redução dos custos de produção, e devido à melhor qualidade do produto, é possível alcançar maior preço na venda, o que necessariamente aumenta a lucratividade para o produtor. Este é também um ponto importante que leva a otimizar cada vez mais os processos de controle e estimula a estudar e propor diversas formas de se obter essa redução de custos e melhoria do produto.

\subsection{Fatores controlados numa casa de vegetação}

A seguir são descritos os fatores normalmente envolvidos em algum tipo de controle numa casa de vegetação. Deve-se observar, no entanto, que apesar desses fatores serem analisados separadamente, eles são intrinsecamente inter-relacionados. Todos eles participam dos processos metabólicos da planta e a alteração de um fator pode influenciar o comportamento de outro. Por exemplo, a maior presença de energia luminosa pode catalisar a fixação de Carbono que, por sua vez, consome $\mathrm{CO}_{2}$ 
do ambiente, diminuindo sua concentração e reduzindo a fixação de Carbono. Aqui também pode ser aplicada a lei do mínimo de Liebig. ${ }^{3}$

\subsubsection{Radiação luminosa}

A radiação luminosa é determinante na produção das casas de vegetação. $\mathrm{Na}$ prática, dois aspectos são normalmente observados: intensidade e duração, embora alguns autores como Hanan (1998), citem outros pontos (qualidade, direção e polarização). Ela é o componente fundamental para ocorrência da fotossíntese, processo que possibilita a fixação do Carbono (C) e geração de carboidratos, utilizando-se $\mathrm{CO}_{2}$ e água nas plantas clorofiladas.

O Sol é a principal fonte de radiação luminosa para a Terra. A radiação emitida pelo Sol encontra-se no domínio de $300 \mathrm{~nm}$ a $3000 \mathrm{~nm}$ de comprimentos de onda. Existe uma faixa do espectro de freqüência da luz na qual ocorre o processo de fotossíntese, conhecida como Photosynthetically Active Radiation (PAR) que vai de $400 \mathrm{~nm}$ a $700 \mathrm{~nm}$

A intensidade luminosa influencia o crescimento da planta, enquanto as durações do período luminoso e do período escuro influenciam seu metabolismo. A floração é um exemplo: é através desta característica que, em algumas plantas, as flores só aparecem em determinadas épocas do ano. Hanan (1998) cita que existem dois tipos de plantas: Short Day Plant (SDP), cuja floração ocorre ou é acelerada em dias curtos e Long Day Plant (LDP) onde a floração ocorre ou é acelerada por dias longos.

\footnotetext{
3 O máximo da produção depende do fator de crescimento que estiver à disposição da planta em menor quantidade
} 


\subsubsection{Temperatura}

A temperatura influencia principalmente os aspectos de crescimento e desenvolvimento das plantas. Funciona como agente catalisador dos seus processos químicos. Todas as culturas possuem uma faixa de temperaturas necessárias para o alcance de determinadas fases, como a floração e a frutificação. Fora dessas faixas não há o desenvolvimento correto da cultura, podendo mesmo vir a definhar, ter má formação de frutos, despedaçamento de flores, etc. Segundo Hanan (1998) para a maioria das espécies, a escala de temperaturas para produção em casas de vegetação é relativamente estreita: entre 10 e $30^{\circ} \mathrm{C}^{4}$. Outra medida importante relatada por vários autores (BLOM, 2002; HANAN, 1998; NELSON, 1991) é a diferença de temperatura entre o dia e a noite onde normalmente se utiliza o termo "DIF" (diferença entre a temperatura diurna e a temperatura noturna). Caso a temperatura diurna seja menor do que a noturna, tem-se um valor negativo do DIF, caso contrário, um valor positivo.

Através de experimentos, constatou-se que algumas espécies apresentam um pequeno desenvolvimento (pequena elongação do caule) para valores de DIF negativos e um bom desenvolvimento para valores de DIF positivos. Esta medida pode ser utilizada para controlar o desenvolvimento de algumas espécies (Figura 1).

\footnotetext{
${ }^{4}$ Graus Celsius
} 

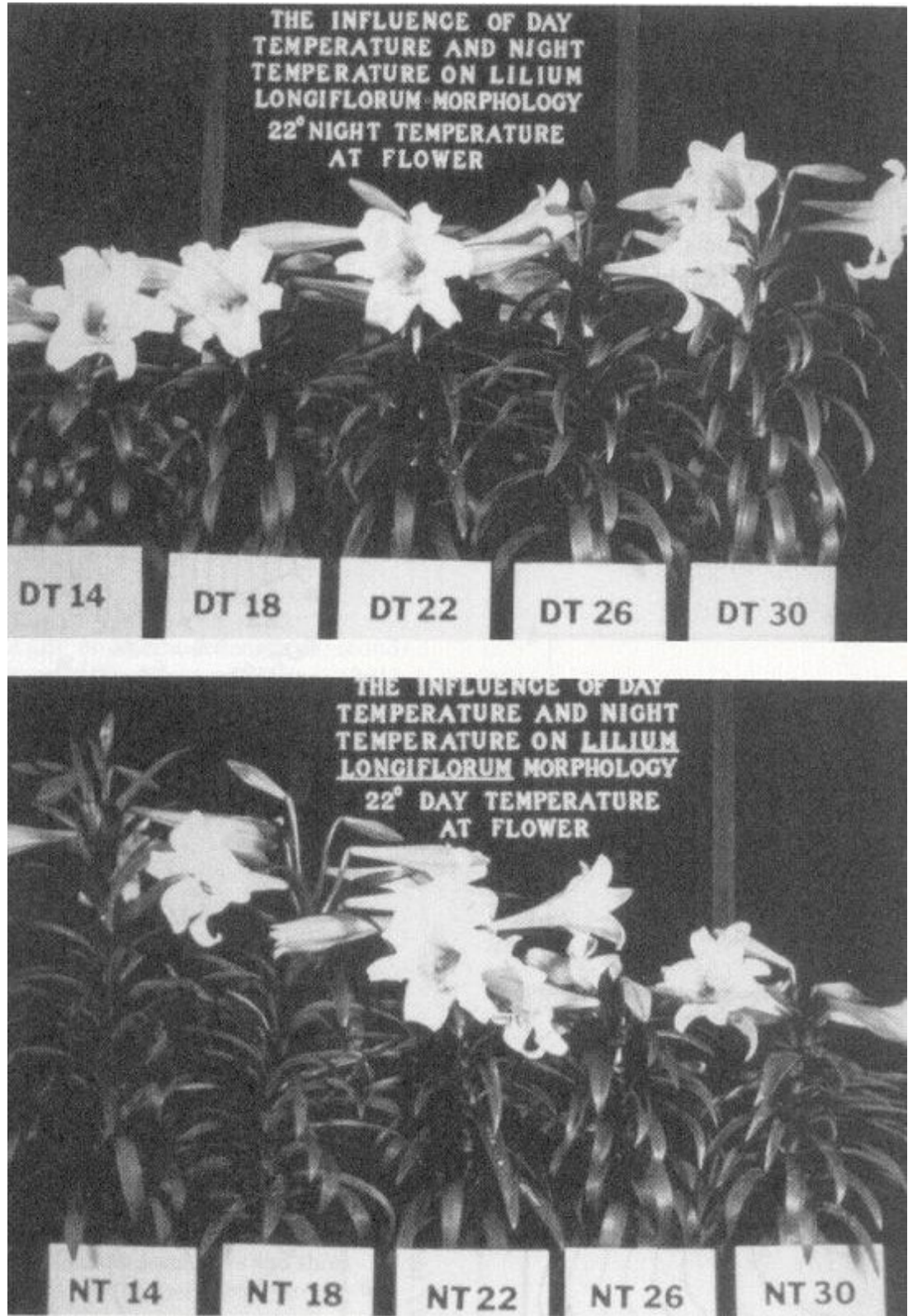

Figura 1 - Efeito do acréscimo da temperatura diurna (DT) a uma temperatura noturna constante (NT) de $22^{\circ} \mathrm{C}$ comparada com o acréscimo da NT a uma DT constante de $22^{\circ} \mathrm{C}$ (Fonte: Hanan, 1998) 


\subsection{3 Água e nutrientes}

Grande parte da radiação solar recebida por uma planta bem irrigada acaba contribuindo para a evaporação de água. Isto significa que o consumo de água pelas culturas em uma casa de vegetação está muito relacionado com a radiação incidente. As plantas podem sofrer de dois males em relação à água: o excesso e a falta. No primeiro caso, não há o comprometimento do crescimento da cultura, sendo que até pode auxiliar. No entanto, torna a planta mais frágil, mais sensível à luz solar e causa danos irreparáveis à sua raiz. Já a falta de água ocasiona a diminuição da fotossíntese e crescimento, deixa folhas e caules menores, assim como a aparência de debilitada (HANAN, 1998).

A planta absorve ou perde água através de mecanismos fisiológicos como transpiração, respiração, processo da fotossíntese (que consome água) e absorção pela raiz. Existem basicamente dois fatores que influenciam nesse processo: a umidade do ar e do solo. A umidade do ar influencia os processos de transpiração e a do solo os processos de absorção pela raiz e fotossíntese. O excesso de umidade reduz a transpiração, diminuindo o crescimento da planta. Também pode desencadear uma série de enfermidades causadas por fungos, bactérias e algas, que têm seu desenvolvimento acelerado em ambientes quentes e úmidos. Já no caso da baixa umidade, ocorre o aumento da transpiração levando as plantas a graus diferenciados de desidratação.

Os elementos nutrientes podem ser divididos em micronutrientes e macronutrientes. As concentrações necessárias dos macronutrientes são de 10 a 1000 vezes maiores dos que as necessárias para os micronutrientes (em mol/l). A Tabela 1 mostra os elementos comumente considerados como essenciais para o crescimento da planta. 
Tabela 1 - Elementos normalmente considerados como essenciais para o crescimento das plantas (Fonte: Hanan, 1998)

\begin{tabular}{llll}
\hline Elemento & $\begin{array}{l}\text { Símbolo } \\
\text { Químico }\end{array}$ & $\begin{array}{l}\text { Formas disponíveis } \\
\text { plantas }\end{array}$ & $\begin{array}{c}\text { para Concentração } \\
(\mathbf{p p m})\end{array}$ \\
\hline Micronutrientes & & & \\
Níquel & $\mathrm{Ni}$ & $\mathrm{Ni}^{2+}$ & 0,06 \\
Molibidênio & $\mathrm{Mo}$ & $\mathrm{MoO}_{4}{ }^{2-}$ & 0,1 \\
Cobre & $\mathrm{Cu}$ & $\mathrm{Cu}^{+}, \mathrm{Cu}^{2+}$ & 6 \\
Zinco & $\mathrm{Zn}$ & $\mathrm{Zn}^{2+}$ & 20 \\
Manganês & $\mathrm{Mn}$ & $\mathrm{Mn}^{2+}, \mathrm{Mn}^{3+}, \mathrm{Mn}^{4+}$ & 50 \\
Boro & $\mathrm{B}$ & $\mathrm{H}_{3} \mathrm{BO}_{3}{ }^{0}, \mathrm{BO}_{3}{ }^{3-}$ & 20 \\
Ferro & $\mathrm{Fe}$ & $\mathrm{Fe}^{2+}, \mathrm{Fe}^{3+}$ & 100 \\
Cloro & $\mathrm{Cl}$ & $\mathrm{Cl}^{-}$ & 100 \\
Macronutrientes & & & \\
Enxofre & $\mathrm{S}$ & $\mathrm{SO}_{4}{ }^{2-}$ & 1000 \\
Fósforo & $\mathrm{P}$ & $\mathrm{H}_{2} \mathrm{PO}_{4}{ }^{-}, \mathrm{HPO}_{4}{ }^{2-}, \mathrm{PO}_{4}{ }^{3-}$ & 2000 \\
Magnésio & $\mathrm{Mg}$ & $\mathrm{Mg}^{2+}$ & 2000 \\
Cálcio & $\mathrm{Ca}$ & $\mathrm{Ca}^{2+}$ & 5000 \\
Potássio & $\mathrm{K}$ & $\mathrm{K}^{+}$ & 10000 \\
Nitrogênio & $\mathrm{N}$ & $\mathrm{NO}^{+}{ }^{-}, \mathrm{NH}_{4}{ }^{+}, \mathrm{NO}_{2}{ }^{-}$ & 15000 \\
\hline & & & \\
\hline
\end{tabular}

Nos cultivos hidropônicos, esses são os únicos elementos considerados.

Os nutrientes são importantes nos processos metabólicos das plantas, afetando diretamente seu crescimento e desenvolvimento saudável alterando, portanto, a qualidade da cultura.

Normalmente, a aplicação dos nutrientes aproveita o processo de irrigação. Em hidroponia, é feito um ciclo fechado de uma solução de água e nutrientes e não se utiliza terra. Existem alguns tipos de fertilizantes que liberam 
gradualmente os nutrientes no ambiente. Eles se apresentam no formato orgânico e inorgânico como superfosfatos, potássio, metafosfatos, etc.

Outros indicadores que ainda podem ser classificados como nutrientes, por serem direta ou indiretamente afetados por eles, são: salinidade, acidez e concentração de cátions.

Muito embora os nutrientes sejam fundamentais no desenvolvimento da cultura, pouco ou nenhum controle automático normalmente é exercido sobre eles numa casa de vegetação. Pontos onde poderia haver alguma atuação seriam no controle da salinidade nas fontes de água da cultura, preparação e manutenção das soluções para o cultivo hidropônico e controle de concentrações de nutrientes em irrigação.

Muito pouco se tem dito sobre controle nutricional. Medições de $\mathrm{pH}$ e condutividade podem ser aplicadas na otimização do consumo de água. Segundo Hanan (1998), sensores de concentração iônica estão sendo desenvolvidos. Outros tipos de sensores seriam os de mistura de solo.

\subsubsection{Concentração de $\mathrm{CO}_{2}$}

Segundo Hanan (1998) 90\% do peso vivo das plantas produzidas em casas de vegetação é composto de água e $5 \%$ de carbono. Isso demonstra a sua importância no metabolismo da planta. Esse carbono é derivado do $\mathrm{CO}_{2}$ do ar que tem uma concentração muito baixa $(340$ ppm). A principal reação metabólica da planta é a fotossíntese. Ela utiliza água, carbono e energia (radiação solar) para gerar os carboidratos componentes da planta. No período noturno, onde não há radiação solar, ocorre o processo inverso, denominado respiração. Para haver crescimento, o carbono absorvido pela planta durante o período luminoso deve ser maior que o carbono consumido no período da respiração (noturno). Caso a fixação de carbono seja menor do que o consumo pela respiração, a planta entra num processo de inanição. De acordo com Hanan (1998), estudos comprovam que sem $\mathrm{CO}_{2}$, o crescimento não ocorre. Se o ar for enriquecido com gás carbônico durante o dia, a 
fixação de carbono aumentará - considerando-se que não haja outros fatores limitantes (baixa temperatura, baixa radiação solar, interrupção do fornecimento de água, nutrição inadequada). Existe uma concentração mínima que faz com que a fixação de Carbono (fotossíntese) seja maior do que o seu consumo (respiração).

Para cada cultura existe uma concentração ideal de $\mathrm{CO}_{2}$. Segundo Cansado (2003), a maioria das culturas tem esse ponto ideal entre 1000 e 1500 ppm. Altas taxas de gás carbônico deixam o ambiente tóxico.

\subsubsection{Outros fatores}

Outros fatores de importância secundária também podem ser citados, embora não seja comum serem considerados pelos sistemas de controle atuais:

- velocidade do vento, que tem uma forte interação com a temperatura;

- pressão, usado em ambientes que necessitam de um certo grau de isolamento.

\subsection{Considerações finais}

Os fatores que influenciam o crescimento e desenvolvimento das plantas foram mostrados neste capítulo e agrupados em cinco categorias: radiação luminosa, temperatura, água, nutrição e concentração de $\mathrm{CO}_{2}$. Apesar dessa separação, nota-se que a alteração de um fator afeta outros fatores numa casa de vegetação. Assim, muitas vezes ao se aumentar a radiação luminosa, aumenta-se também a temperatura. O aumento da temperatura faz com que haja aumento da transpiração das plantas. Com o aumento da transpiração, há um aumento da umidade e um aumento do consumo de água pela raiz. Esse simples exemplo mostra como essas variáveis são interligadas. Demonstra também como o processo de controle desses fatores é complexo.

Geralmente quando se fala em controle de uma casa de vegetação, fala-se em controle ambiental (climático). Assim, o fator nutrição geralmente não é alvo de 
controles, apesar da sua importância. No entanto, há espaço para o seu controle, embora seja mais complexo, como por exemplo, o controle de nutrientes em hidroponia. 


\title{
3 SISTEMAS DE CONTROLE CENTRALIZADOS E DISTRIBUÍDOS
}

\author{
Este capítulo traz um breve histórico da evolução dos sistemas de \\ controle e descreve as principais características dos sistemas centralizados e \\ distribuídos, encerrando com a avaliação de tendências futuras. Ele fornece uma base \\ para os próximos capítulos.
}

\subsection{Histórico}

Relata-se entre o final do século XVIII e início do século XIX as primeiras implementações de automação e controle. O regulador de Watt foi desenvolvido em 1784; há registros de uma moenda automática por esteiras desenvolvida em 1791; e em 1804, Joseph Marie Jacquard inventou a máquina de tear baseada em cartões perfurados. Outras invenções que auxiliaram os sistemas de controle foram o eletroímã, inventado por Joseph Henry em 1836, a álgebra de Boole em 1854, e a calculadora eletrônica a base de relés em 1936 por George Stiblitz (MIYAGI, 1996).

Em meados do século XX, os controles dos sistemas de automação consistiam em painéis eletro-mecânicos, concebidos para executar tarefas com aplicações específicas, tais como, linhas de montagem de veículos e acionamentos de máquinas industriais. Eram formados por relés e contatores, e seu funcionamento, assim como eventuais falhas, podiam ser visualmente observados. Tinham como vantagens sua robustez e simplicidade de manutenção (ALVES FILHO, 2001).

As décadas de 60 e 70 foram caracterizadas pela evolução para sistemas de controle centralizados de grande porte. Com a evolução tecnológica, viabilizou-se a partir de 1960, o desenvolvimento de circuitos eletrônicos e chaveamentos sem 
contatos físicos, implementados por transistores. Isso permitiu a redução do espaço ocupado e o aumento da sua confiabilidade; entretanto fez surgir um novo problema que era o mau funcionamento do sistema devido a ruídos elétricos induzidos. No final da década de 60, a utilização dos circuitos integrados permitiu a criação dos minicomputadores e possibilitou a geração de sistemas de controle on-line de processos industriais.

Em 1968, surgia um critério de especificação técnica para o primeiro controlador programável, elaborado pela General Motors. Seu principal objetivo era eliminar os altos custos associados com os inflexíveis controles baseados em relés. Incluíam os seguintes itens (BRYAN; BRYAN, 1997):

- Seu preço deveria ser competitivo com sistemas baseados em relés;

- Deveria estar adequado ao ambiente industrial;

- As interfaces de entrada e saída deveriam poder ser facilmente trocadas;

- O controlador deveria ser formado por módulos que permitissem facilidade de substituição;

- O sistema deveria ser reutilizável;

- O método usado para a programação do controle deveria ser simples, de tal forma que ele fosse facilmente entendido pelos profissionais da área técnica;

- Deveria ter capacidade de enviar dados para um sistema central.

Iniciou-se então a era dos Controladores Lógicos Programáveis (CLPs). Os primeiros CLPs substituíam os painéis de relés, conseguindo satisfazer os requisitos de modularidade, expansibilidade, facilidade de programação e uso no ambiente industrial. Esses controles eram instalados com facilidade, necessitando de menores espaços e podiam ser reutilizados. Em pouco tempo o uso dos controladores programáveis começou a ser adotado em outras indústrias. 
O CLP é, portanto, um equipamento eletrônico baseado em microprocessadores, usado em aplicações industriais e executa funções como operações lógicas, seqüencialização, temporização, cálculos numéricos, com capacidade de armazenamento das informações em memória e processamento de sinais de entrada/saída, analógicos ou digitais. Os CLPs apresentam-se como uma solução muito mais flexível no processo de controle, pois com algumas alterações nos programas de aplicação na memória do controlador, altera-se o projeto básico.

$\mathrm{Na}$ década de 70, os sistemas utilizando CLP's continuavam centralizados, implementando as funções de coleta e tratamentos dos sinais além da execução dos algoritmos de controle. Com o aumento da sofisticação dos processos de manufatura e a crescente necessidade de sua supervisão e controle, gerou-se a necessidade de um grande número de pontos de coleta de dados e atuação. Num sistema convencional de controle seria necessária a interligação de cada um dos pontos até o centro de processamento do controle, e, conseqüentemente grande quantidade de cabos e horas de instalação. Com o objetivo de reduzir esses inconvenientes, os sensores foram conectados a módulos de entrada/saída, que tinham a função de centralizar um conjunto de sensores e atuadores e efetuar a comunicação com o módulo CLP de forma digital (SHICKHUBER, 1997).

Através desta solução, chamada de barramento de campo (fieldbus), pôde-se racionalizar o uso dos equipamentos e reduzir o tempo de instalação, facilitando a manutenção e reduzindo o custo do sistema de controle. No entanto, a comunicação desses módulos de entrada e saída com o CLP central gerou a necessidade da definição de um protocolo de comunicação. A padronização do protocolo também pôde permitir um avanço na interoperabilidade desses sistemas. Devido à forte demanda por soluções deste tipo e à demora na determinação deste padrão, foram surgindo uma série de protocolos e formas de comunicação concorrentes como, por exemplo, Actuator Sensor Interface (ASI), Bitbus, Controller Area Network (CAN), Device Network (DeviceNet), European Installation Fieldbus (EIB), Fieldbus Foundation (FF), Highway Addressable Remote Transducer (HART), InterBus-S, Interoperable System Project (ISP SP50), Local Operating Network (LonWorks $\left.{ }^{\circledR}\right)$, Process Fieldbus (Profibus), Process Net (P-NET), Smart 
Distributed Systems (SDS), World Factory Instrumentation Protocol (WorldFIP), entre outros. Segundo Mahalik (2002) existem mais de 30 padrões de barramentos de campo.

A utilização destes barramentos começava a mudar o paradigma tradicional, no qual existia um elemento central que executava todo o tratamento e processamento do sistema e delegava a digitalização dos sinais para os módulos de entrada e saída, e dispositivos de campo. No início, os barramentos de campo favoreceram o surgimento sistemas hierarquizados.

A partir da década de 90, essa solução ganhou força com o aparecimento dos dispositivos inteligentes microprocessados, onde cada vez mais os dispositivos vão agregando processamento, não apenas digitalizando, mas também efetuando o tratamento dos sinais lidos (por exemplo, a linearização) e emitindo o seu estado de funcionamento (SCHIMANSKI, 1996).

O progresso industrial no desenvolvimento da tecnologia dos semicondutores, aliado ao crescimento da demanda do usuário final pelo controle da performance do sistema, impulsionaram o avanço dos sistemas de controle para os chamados barramentos de campo distribuídos e sistemas de rede de controles (SHICKHUBER, 1997). Esses sistemas têm como principais características: a distribuição da inteligência através da utilização de microcontroladores na implementação de nós da rede, e da distribuição do software de controle nesses nós; a utilização mais completa do modelo de referência de redes OSI que, dentre outros aspectos, contribui para o aumento da confiabilidade do crescimento da rede; e o uso de topologias de rede em configuração livre (qualquer formato).

As redes de controle distribuído permitiram o surgimento de um novo paradigma no desenvolvimento de sistemas de controle, aplicados com sucesso em alguns setores, como a automação predial. Os itens a seguir definem e destacam as vantagens e desvantagens dos sistemas de controle centralizado e distribuído. 


\subsection{Sistemas de controle centralizados}

Sistemas de automação com controle centralizado são sistemas onde tanto o processamento das informações como a ligação entre todos os elementos estão centralizados em um único elemento de processamento central. Assim, a unidade central deve executar a coleta de informações das entradas, digitalização e trata os dados coletados, executar a lógica de controle e alterar adequadamente o estado das saídas. As informações de entradas e saídas podem estar em formato analógico ou digital (Figura 2).

Os sistemas centralizados, devido à sua simplicidade, em geral são mais baratos, sendo indicados para automação de pequenos sistemas e também para aplicações de tempo crítico, entradas e saídas altamente acopladas, e sincronizadas com grande fluxo de dados (de tal forma a gerar um fluxo muito grande de informações entre os elementos do sistema).

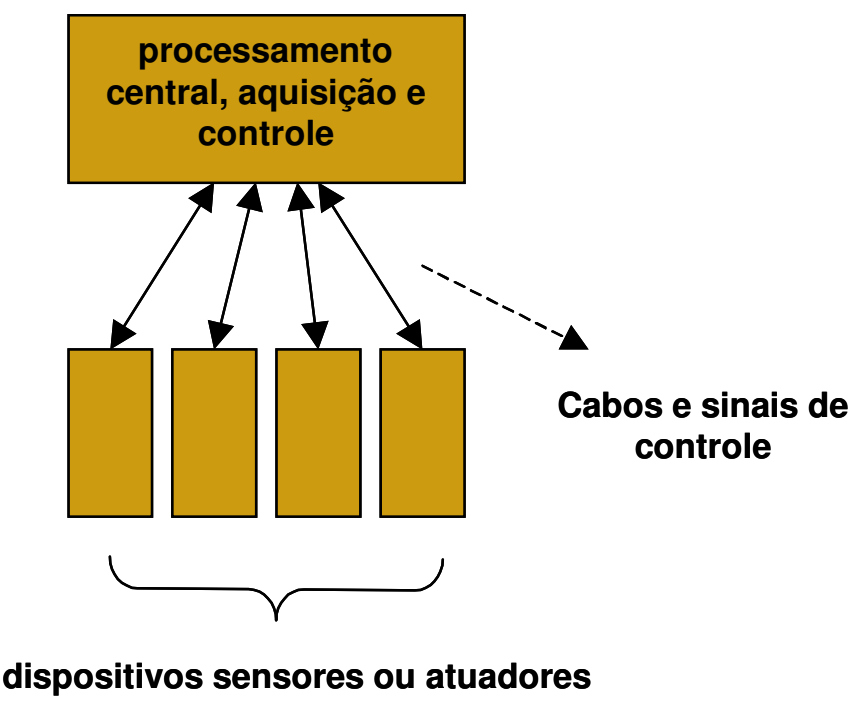

Figura 2 - Sistema de controle centralizado

Uma das vantagens desse tipo de configuração é que a unidade de processamento e o dispositivo de aquisição e controle podem ser instalados em um ambiente separado do processo. Isso é indicado para ambientes considerados 
inadequados para equipamentos eletrônicos, principalmente devido ao calor, umidade, poeira, poluição e produtos químicos. Para maior durabilidade dos equipamentos é aconselhável que os mesmos sejam colocados em ambiente protegido dessas adversidades. Seguem outras vantagens:

- Simplicidade do hardware utilizado, sendo composto essencialmente dos seguintes elementos: sensores, atuadores, cabeamento e unidade central de processamento (GUIMARÃES; SARAIVA, 2002);

- Todos os dados ficam disponíveis à unidade central durante toda a operação do sistema.

Como desvantagens pode-se citar:

- Necessidade de utilização de grande quantidade de cabos de entradas e saídas até um único local, muitos deles blindados devido à interferência eletromagnética, pois conduzem sinais da ordem de milivolts, sendo muito influenciados por eventuais ruídos eletrônicos.

- Necessidade de amplificação de sinal para sensores distantes da unidade de processamento central, o que degrada o sinal devido à amplificação dos ruídos;

- Maior possibilidade de danificação de cabos, problemas de contato e aterramento devido à distância.

- Limitação das possibilidades de expansão do sistema (GUIMARÃES; SARAIVA, 2002);

- Baixa tolerância a falhas: uma falha na unidade de processamento central causa a parada de todo o sistema, assim como mau funcionamento de um sensor pode comprometer significativamente o sistema;

- Em implementações com muitos sensores e atuadores pode haver um gargalo no processador. 


\subsection{Sistemas de controle distribuído}

Os sistemas de controle distribuído ou redes de controle distribuído são aqueles onde tanto as ligações entre seus elementos quanto o processamento de informações encontram-se distribuídos. Os elementos estão conectados a um barramento de dados por onde é feita a comunicação digital através de um protocolo, enquanto que a inteligência do controle, ou seja, o processamento das informações, é distribuída em vários locais do sistema através da utilização de microcontroladores que executam programas. Os circuitos de condicionamento e o tratamento dos sinais coletados são feitos em cada elemento da rede chamados de nós. Tipicamente, os elementos sensores e atuadores do sistema executam tarefas simples de sensoreamento, monitoração e atuação, mas quando trabalham juntos podem executar tarefas bastante complexas (Figura 3).

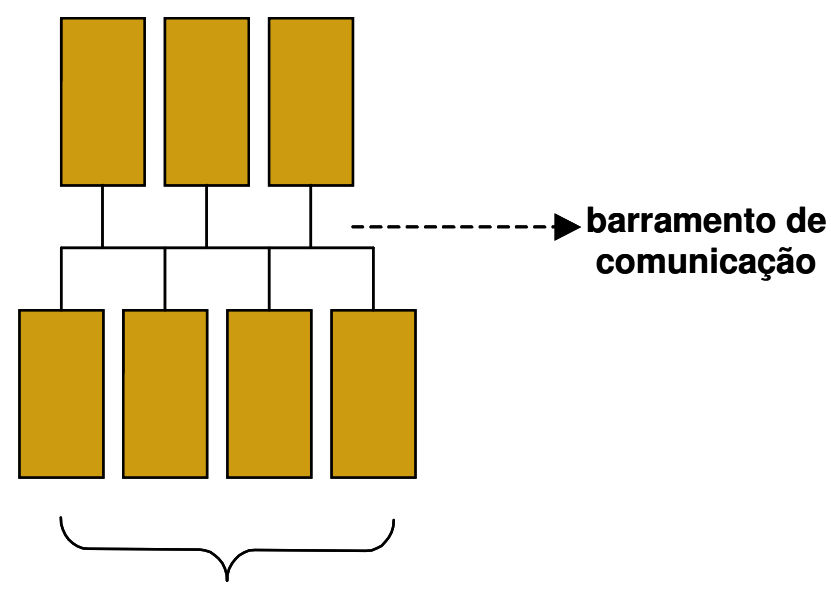

dispositivos inteligentes

Figura 3 - Sistema de controle distribuído

Como vantagens desses sistemas pode-se citar (FRANCO, 2006):

- Autodiagnóstico de cada instrumento: através desta funcionalidade pode-se prever problemas nos dispositivos antes que eles causem danos ao sistema; 
- Transmissão de informação e não de dados: o dispositivo inteligente envia o dado coletado já com o devido tratamento diretamente para os outros dispositivos que utilizam a informação coletada. Isto evita que o dispositivo que recebe esta grandeza tenha que convertê-la antes de usá-la, para descobrir quanto ela equivale, poupando sua capacidade de processamento para executar outras funções;

- Transmissão digital de dados: a transmissão de dados digital é mais confiável e imune a ruídos, não necessitando de cabeamento especial (blindado) como requer o tráfego de informações analógicas.

- Programação dos dispositivos e diagnósticos de correção de problemas à distância;

- Verificação dos dados: são adicionados às variáveis transmitidas, bits que ajudam a verificar a correta recepção dos dados transmitidos;

- Programação de cada dispositivo para trabalhar numa faixa diferente, conforme desejado, num determinado processo;

- Redução do cabeamento;

- Aumento da confiabilidade, pois a falha em algum componente deixará apenas parte do sistema fora de operação;

- Facilidade de expansão: o processo de expansão se resume à colocação de mais um elemento na rede e alteração apenas dos nós que sejam consumidores de informação do novo nó;

- Redução do custo de instalação e manutenção;

- Flexibilidade: a remoção, inserção e substituição dos dispositivos na rede têm impacto apenas nos nós afetados pela ação, deixando os outros nós operacionais; 
- Interoperabilidade de dispositivos: através da utilização de padrões abertos é possível a substituição de dispositivos fabricados por empresas diferentes.

Dentre as desvantagens pode-se citar:

- Necessidade de implementação de protocolo de comunicação entre os nós;

- Maior complexidade;

- Pouca disponibilidade de ferramentas genéricas e técnicas para a realização do princípio da distribuição (MAHALIK, 2002).

\subsection{Tendências atuais e futuras}

Os sistemas de controle passaram e estão passando por uma série de mudanças. Um primeiro paradigma foi quebrado na substituição dos relés pelos CLPs. Outro paradigma foi superado no momento em que houve a passagem de uma arquitetura centralizada para a cada vez mais utilizada rede de controle distribuído.

Para perceber qual a tendência dos sistemas de controle, considerou-se o raciocínio de Raji (2002), que faz uma comparação com os sistemas computacionais.

A evolução nos sistemas computacionais foi motivada por uma série de fatores, dentre os quais o custo e necessidades dos usuários. Passou-se de um sistema centralizado baseado em mainframes, para sistemas hierárquicos baseados em mainframe-microcomputadores e depois para sistemas em rede. A tendência atual é a interconexão de redes de diversos tamanhos (intranets corporativas, pequenas redes de pequenos negócios, redes governamentais, internet, etc). Aplicando-se um raciocínio análogo, os sistemas de controle passaram pelos mesmos estágios da 
evolução e, atualmente, encontra-se no estágio dos sistemas em rede. A tendência aponta para a interconexão de redes de sistemas de controle. (Figura 4).

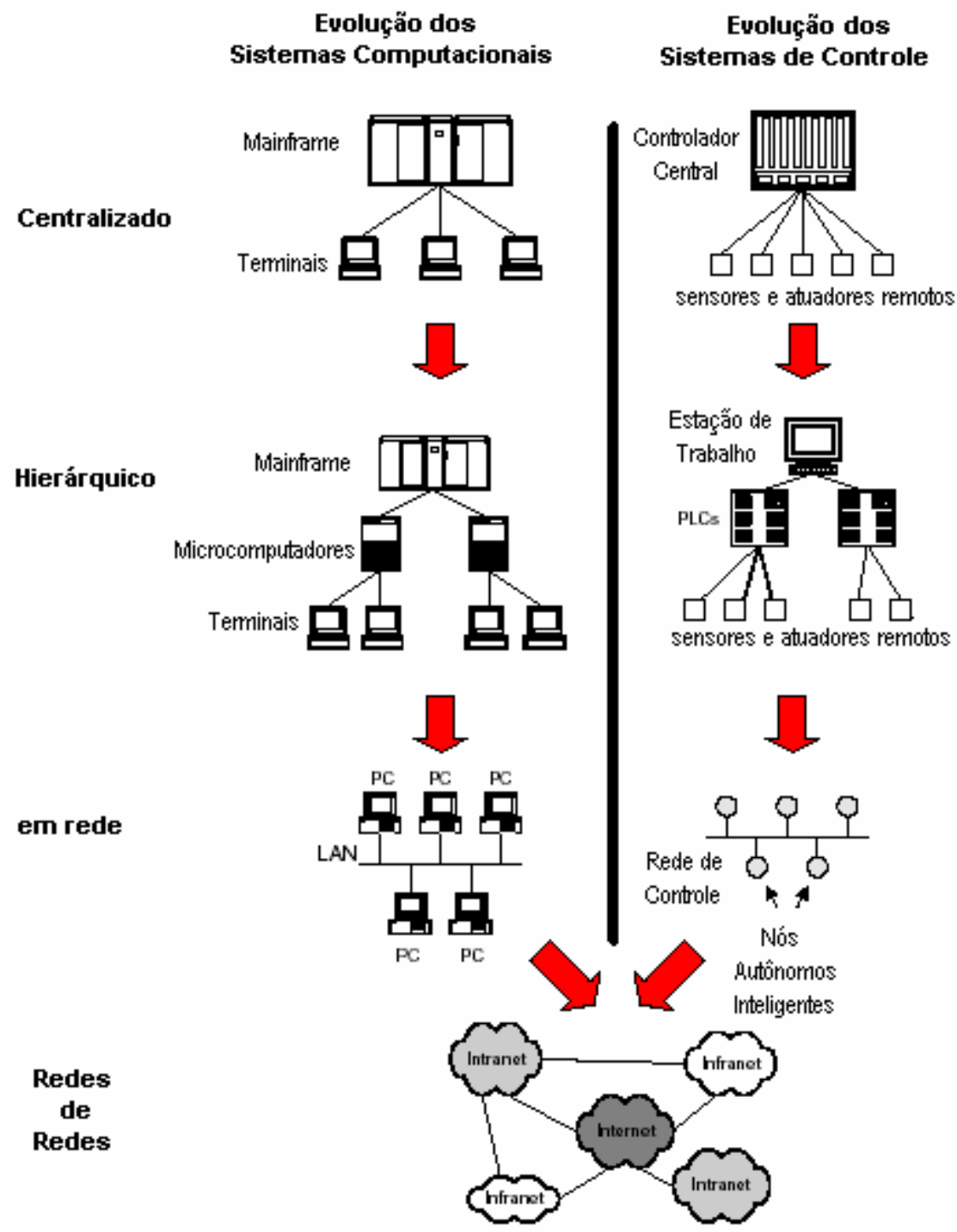

Figura 4 - Evolução dos sistemas computacionais e de controle. (Baseado em Raji, (2002)).

Assim como nos sistemas computacionais, ainda existem sistemas centralizados como o mainframe, o mesmo acontece nos sistemas de controle. No entanto, cada vez mais as soluções levam em consideração as vantagens da abordagem distribuída. 
Essa evolução esperada encontra algumas dificuldades como, por exemplo, a necessidade de redução dos custos através de ganhos de escala dos produtos. Além disso, um fator imprescindível e que está atrasando o progresso da indústria de controles é a padronização. A demora na adoção de padrões internacionais fêz com que inúmeras empresas criassem o seu próprio padrão. A adoção de um padrão internacional sofrerá inúmeras resistências devido ao grande número de soluções implantadas, podendo dificultar a criação do padrão único, e devem retardar também a sua adoção. No entanto, acredita-se que a definição e a adoção de uma padronização internacional é inevitável.

\subsection{Considerações finais}

Neste capítulo foi elaborada uma sistematização das informações relativas as redes de controle, enfatizando a comparação entre a abordagem centralizada e distribuída. Percebe-se uma tendência à adoção cada vez mais generalizada da abordagem distribuída, uma vez que proporciona flexibilidade, reduz o cabeamento e permite a interoperabilidade. Vale ressaltar que muitos dos conceitos e técnicas aplicáveis à automação industrial ou de outros setores podem ser utilizados na automação agrícola, tomando-se o cuidado de estudar as particularidades da aplicação. Existe uma certa semelhança entre a automação predial e o controle ambiental de uma casa de vegetação; porém, a casa de vegetação possui características particulares como maior hostilidade a equipamentos eletrônicos.

A proliferação de sistemas de controle distribuído é uma tendência, mas aspectos como a multiplicidade de soluções proprietárias e soluções abertas que já possuem muitos adeptos no mercado, são fatores que tendem a dificultar sua expansão. 


\section{A TECNOLOGIA LonWorks®}

Este capítulo se destina a apresentar características fundamentais da tecnologia LonWorks ${ }^{\circledR}$, seu funcionamento e principais componentes. Ela viabiliza a implementação de sistemas de automação baseados em redes de controle, considerados neste trabalho.

\subsection{Introdução}

A tecnologia LonWorks ${ }^{\circledR}$ surgiu no início da década de 90 com a proposta de implementar sistemas de controle de forma distribuída. Inicialmente voltada para sistemas de automação predial, tem sido aplicada também em outras áreas como transportes, medicina, indústrias e residências (GRAHAM, 2003). Possui a característica de distribuir a inteligência de controle entre os elementos que formam a rede de controle, chamados nós. Estes nós possuem a capacidade de se comunicarem uns com os outros e desempenhar suas tarefas individuais de modo integrado ao todo, recebendo e enviando informações de forma atemporal e organizada, através de um protocolo de comunicação chamado LonTalk ${ }^{5}$.

\subsection{Principais componentes}

A Figura 5 mostra um exemplo de uma rede implementada com a tecnologia LonWorks ${ }^{\circledR}$, e nela pode-se notar os seus principais componentes: nós, canais de comunicação, roteadores e gateways. Diversas topologias de redes baseadas no protocolo LonTalk são permitidas, bem como a sua interligação com outros tipos de redes.

\footnotetext{
${ }^{5}$ Protocolo aberto de rede de controle, desenvolvido pela Echelon Corporation. Também conhecido como ANSI/EIA 709.1 Norma de Rede de Controle, e protocolo LonTalk.
} 


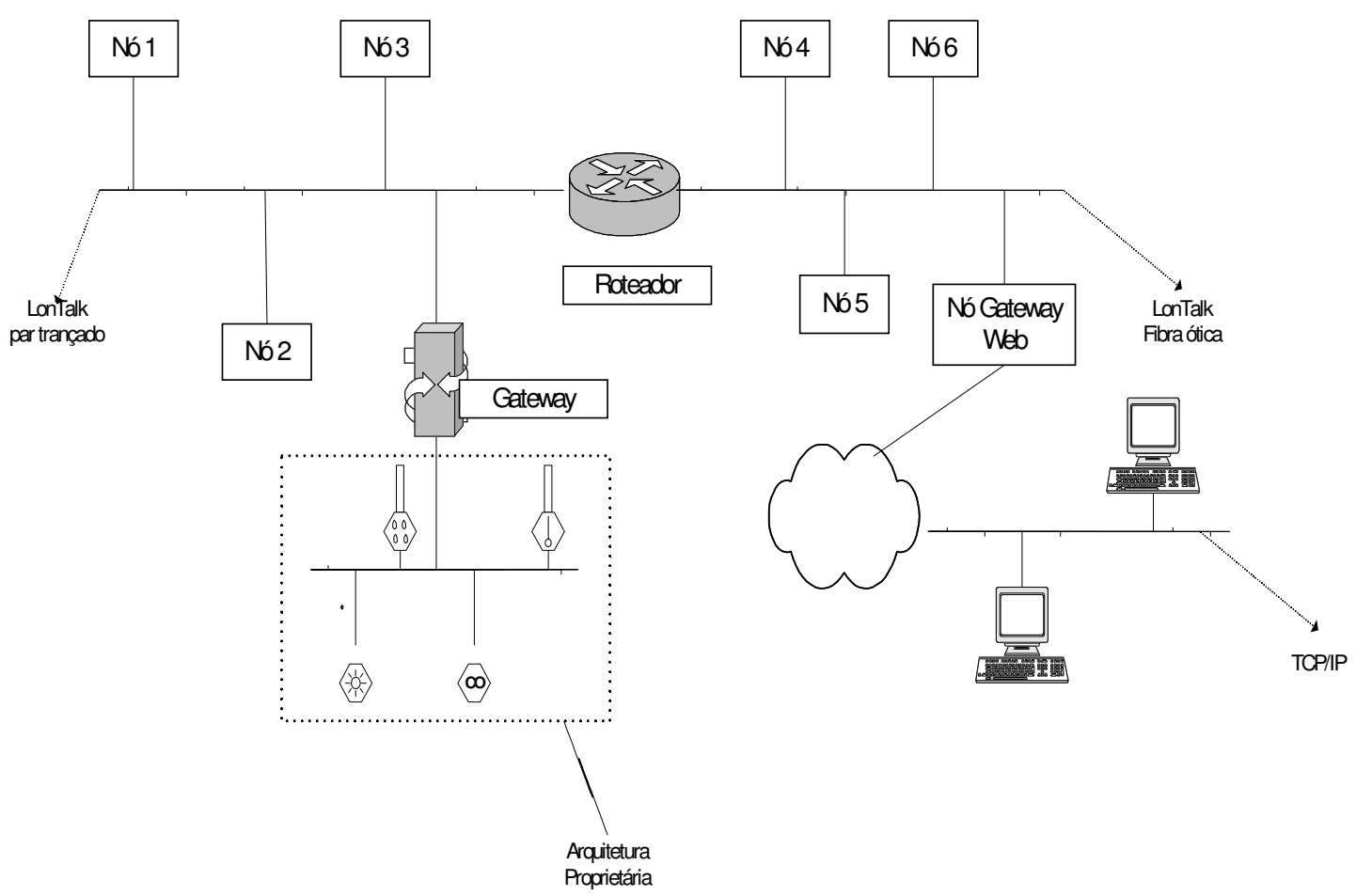

Figura 5 - Exemplo de uma rede utilizando a tecnologia LonWorks ${ }^{\circledR}$

\subsubsection{Nós}

Os nós ou dispositivos de rede são os elementos que possuem a inteligência na arquitetura dessa rede. Dispõem de processadores que são responsáveis por sua inteligência e pela implementação do protocolo de comunicação existente entre os nós (ECHELON, 1999). Normalmente são constituídos por sensores e atuadores. Tipicamente em um nó sensor, ocorre o tratamento do sinal lido (condicionamento, digitalização e linearização) e a comunicação da informação aos outros nós da rede. Um nó atuador, por sua vez, tipicamente utiliza as informações enviadas pelos outros nós para decidir quando deve acionar o seu atuador, por quanto tempo e com qual intensidade. Na Figura 6 pode-se ter uma idéia de uma configuração típica de um nó, sendo seus principais componentes apresentados a seguir: 


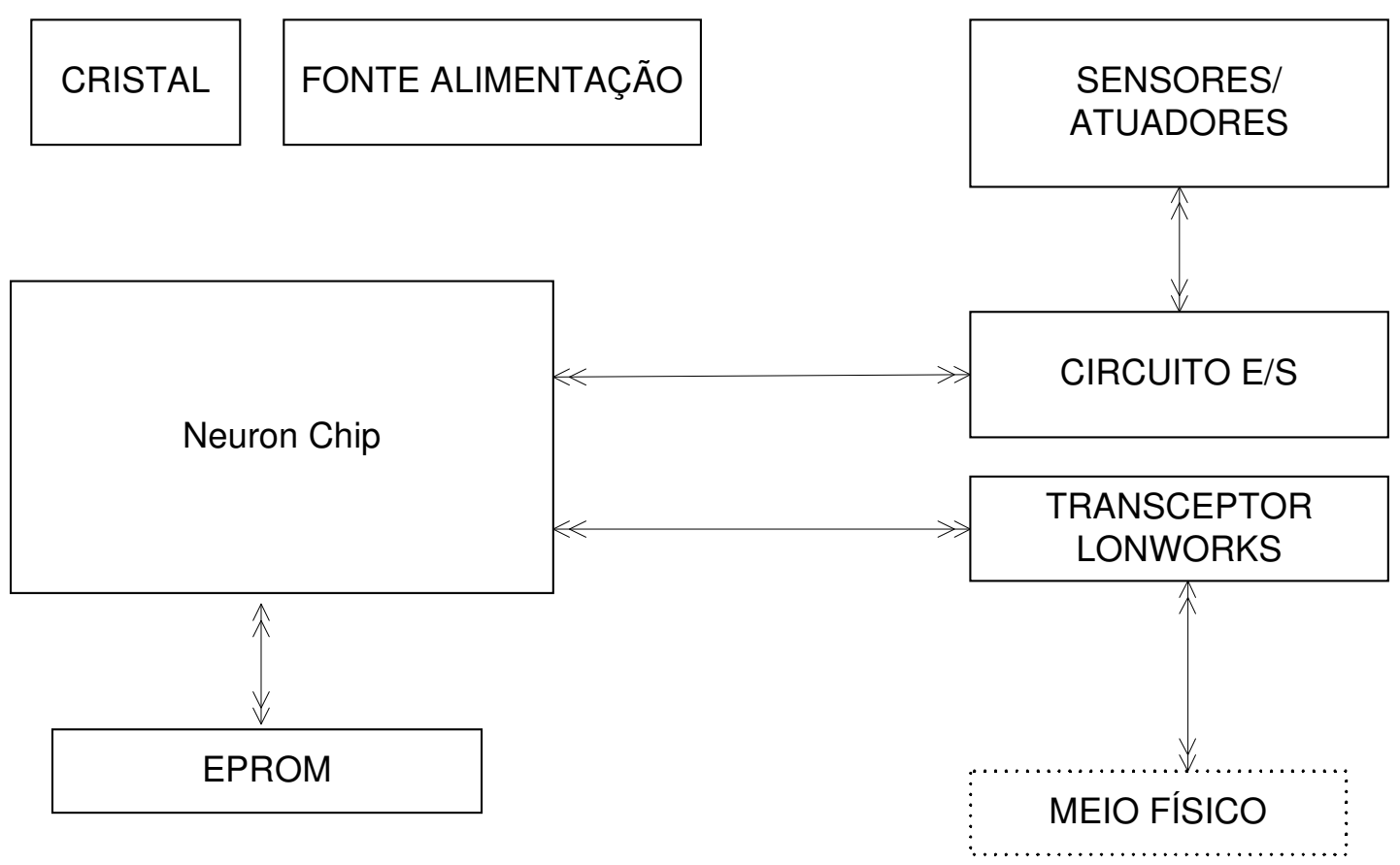

Figura 6 - Configuração típica de um nó LonWorks® (baseado em Echelon (1999) e Toshiba (1995)).

Transceptor - Cada dispositivo de rede possui um transceptor que promove a interface de comunicação física entre o dispositivo e a rede LonWorks®. Os transceptores facilitam o desenvolvimento de nós interoperáveis e estão disponíveis para uma variedade de meios físicos e topologias.

Circuitos de Entrada/Saídas e Sensores/Atuadores - Possibilitam que sensores, atuadores, displays, teclados, e outros dispositivos do gênero possam ser acoplados ao nó, permitindo sua interação com o meio em que se encontra.

Neuron Chip - É um circuito integrado com três processadores de 8 bits que se encarregam de implementar o protocolo de comunicação entre os nós e o programa aplicativo do nó (Figura 7).

O primeiro processador (P1) é o controlador de acesso ao meio (MAC) que controla os níveis 1 e 2 do padrão de protocolos OSI da ISO, contendo as configurações de hardware e subsistemas com algoritmos especializados na detecção de colisões. Esse processador P1 comunica-se com o P2 usando o buffer de rede e compartilhando memória. 


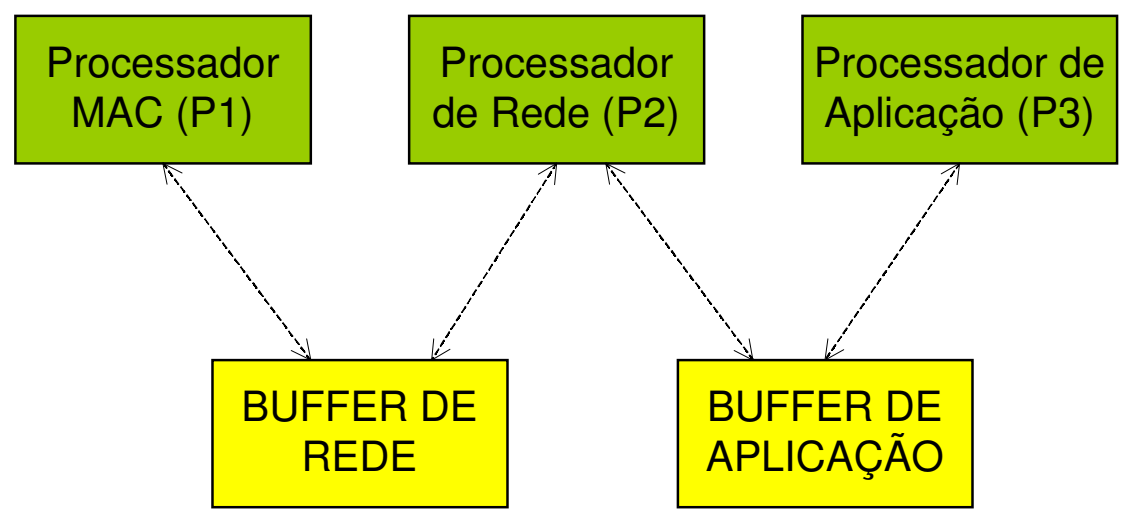

Figura 7 - Comunicação entre os processadores do Neuron Chip

O segundo processador (P2) é o processador de rede que é responsável pelos níveis de 3 a 6 do modelo OSI da ISO (TANENBAUM, 1996), contendo variáveis de processamento, endereçamento, processos de transação base de diagnósticos, tempos de instruções, controle geral da rede e definição de rotas das funções. Ele utiliza o buffer de rede de forma compartilhada para se comunicar com o processador P1, e com o buffer de aplicações para se comunicar com o processador P3. Qualquer acesso executado por um processador às memórias compartilhadas gera uma sinalização (semáforos) no barramento, possibilitando a outro processador fazer a leitura e a atualização das informações.

O terceiro processador (P3) é o que executa a aplicação, contendo todos os programas que controlam as entradas e saídas locais e tem a finalidade de controlar os dispositivos acoplados ao nó.

Opcionalmente, é possível atuar na detecção de colisão vinda do transceptor. Neste caso, o Neuron Chip é sinalizado da ocorrência de uma colisão e sabe que deve repetir a mensagem. O nó tentará reativar o acesso ao canal.

O fato de existirem dois processadores dedicados a tarefas de rede e um dedicado à aplicação assegura que a complexidade da aplicação não cause impacto negativo a resposta da rede e vice-versa (ECHELON, 1999). 
A utilização do Neuron Chip, embora não seja obrigatória, agiliza a implementação de um nó da rede uma vez que já possui o protocolo implementado. Atualmente existem dois fabricantes deste chip: a Toshiba e a Cypress. Devido à escala de produção seu custo é inferior a US\$10,00 por unidade. (GRAHAM, 2003; CANOVAS, 2006).

Cada Neuron Chip possui um identificador único de 6 bytes chamado NeuronId atribuído pelos fabricantes e que pode ser usado para o seu endereçamento em uma rede LonWorks®.

Os aplicativos executados nos Neuron Chips são gerados utilizando-se a linguagem Neuron C, que é baseada na linguagem C ANSI. O Neuron C utiliza o modelo de programação baseado em eventos, e dentre suas principais características pode-se citar (ECHELON, 2005a):

- A instrução "when", que introduz o conceito de eventos e define a ordem de execução das tarefas;

- 37 novos tipos de dados, 35 objetos de entrada/saída e 2 objetos de temporização, o que simplifica e padroniza o uso dos dispositivos de controle;

- Mecanismos de passagem de mensagem dos formatos explícitos (utilizando endereçamento físico e lógico) e implícitos (quando se utilizam as variáveis de rede).

\subsubsection{Canais de comunicação}

O protocolo de comunicação LonTalk é independente do meio físico, permitindo a comunicação dos dispositivos LonWorks® sobre uma variedade de meios. Esta característica possibilita mais flexibilidade aos projetos de redes de controle, como por exemplo, numa casa de vegetação podem-se utilizar um segmento de rede para os atuadores tendo como meio físico a fiação da rede elétrica (power line) e para os sensores um outro segmento, utilizando radiofreqüência, e os dois segmentos constituem a rede de controle. 
Essa independência do protocolo em relação ao meio físico é conseguida através dos transceptores, pois o acesso dos nós ao meio físico é efetuado a partir dos mesmos. O tipo de meio físico determina qual o transceptor mais adequado (ECHELON, 1999).

Um específico meio físico de comunicação (como por exemplo, par trançado ou fibra ótica) é chamado de canal no qual um grupo de dispositivos LonWorks® é conectado utilizando-se transceptores específicos para aquele canal. Existem vários tipos de transceptores disponíveis no mercado para diferentes meios físicos, tais como, rádio-frequiência (RF), infravermelho (IR), fibra ótica, cabo coaxial, cabo de alimentação (power line) e par trançado. Vale ressaltar que, dependo do meio físico, consegue-se velocidades de transmissão diferentes. Na Tabela 2 pode-se verificar os tipos transceptores mais comuns e suas velocidades:

Tabela 2 - Tipos de transceptores e taxas de velocidade

\begin{tabular}{ll}
\hline Tipo & Velocidade \\
\hline EIA-485 & $300 \mathrm{bps}$ por 1.25 Mbps \\
Par Trançado ou Barramento & $78 \mathrm{kbps}$ \\
Par Trançado ou Transformador & $78 \mathrm{kbps}$ \\
Cabos de Fonte & $2 \mathrm{kbps}, 5 \mathrm{kbps}, 10 \mathrm{kbps}$ \\
RF (300 Mhz) & $1200 \mathrm{bps}$ \\
RF (450 Mhz) & $4800 \mathrm{bps}$ \\
RF (900 Mhz) & $39 \mathrm{kbps}$ \\
Infravermelho & $78 \mathrm{kbps}$ \\
Fibra ótica & $1,25 \mathrm{Mbps}$ \\
Cabo Coaxial & $1,25 \mathrm{Mbps}$ \\
\hline
\end{tabular}

\subsubsection{Roteadores}

A finalidade dos roteadores é segmentar a rede, dividindo seu tráfego e eliminando gargalos. Um roteador também permite conectar redes que utilizam 
meios físicos diferentes ou meios de velocidades diferentes, como por exemplo, par trançado e fibra ótica. Os roteadores também executam a função de repetidores de sinal, permitindo a expansão dos nós de uma rede quando se chegou ao limite de nós especificado para aquele tipo de meio físico.

\subsubsection{Gateway}

Os gateways implementam uma interface de comunicação entre a rede LonWorks ${ }^{\circledR}$, dispositivos ou sistemas proprietários ou outras redes. Efetua a tradução das mensagens dos protocolos de maneira a haver a comunicação entre os sistemas, permitindo a integração entre uma rede LonWorks® e uma instalação proprietária ou pré-existente. Devido à sua forma de operação, um gateway pode gerar gargalos e não é considerado um nó padrão da rede. Um exemplo especial de gateway é um servidor Web que implementa uma interface padrão Web em uma rede LonWorks@. Esses dispositivos permitem a ligação entre uma rede LonWorks® e uma rede IP (ECHELON, 1999).

\subsubsection{Topologias de rede}

A topologia é uma forma de descrever os princípios de arquitetura de uma rede. Para aplicações LonWorks®, um segmento de rede é construído de acordo com um dos seguintes princípios topológicos:

- Topologia livre com terminador simples (Figura 8): neste tipo de topologia não existem restrições para a maneira como os dispositivos são conectados. No entanto, neste caso, o tamanho máximo do cabeamento deve ser de 500 metros;

- Topologia em bus com duplo terminador (Figura 9): neste caso, um segmento de rede pode ter até 2.700 metros, mas existe um limite no 
tamanho do ramal de conexão entre o dispositivo e a rede (stub). Para taxas de comunicação de $78 \mathrm{kbps}$ esse ramal não pode exceder 3 metros, e para taxas de 1,25 Mbps, não deve exceder 30 centímetros.

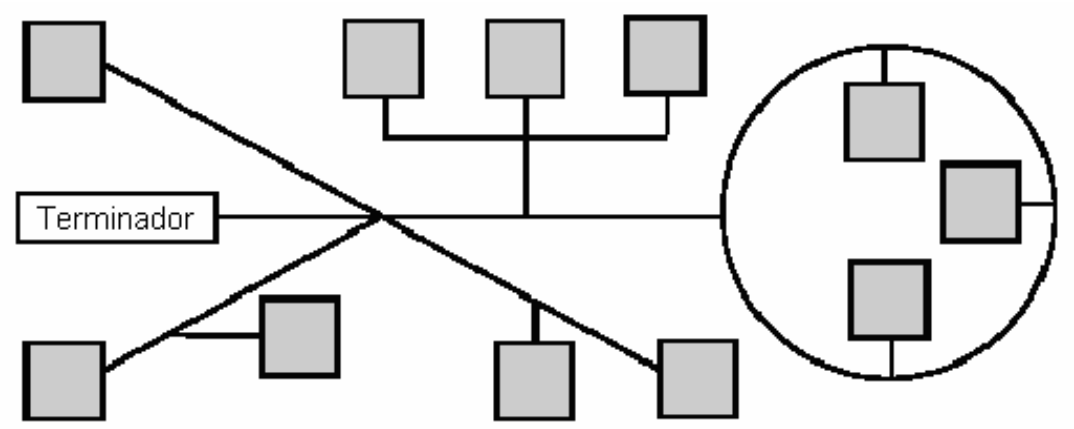

Figura 8 - Topologia livre com um terminador (Fonte: TAC (2001c))

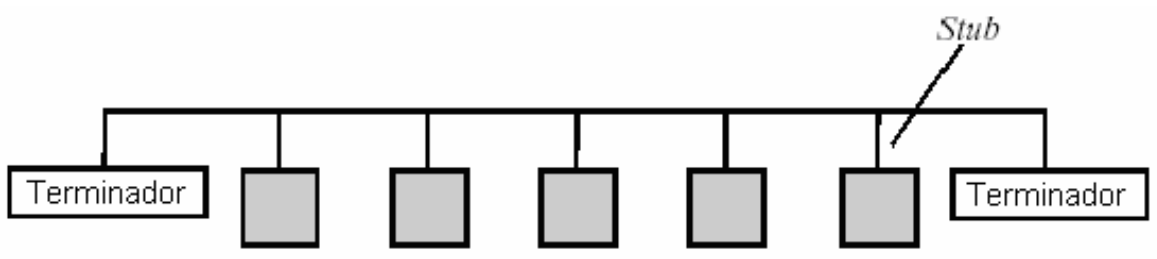

Figura 9 - Topologia Bus com dois terminadores (Fonte: TAC, 2001c)

Cada segmento de rede necessita de terminadores para que a performance da transmissão seja adequada. Os terminadores são conectados de maneiras diferentes, dependendo da topologia de rede utilizada. Podem ser embutidos em um nó ou conectados isoladamente na rede (TAC, 2001c).

Na topologia livre (free topology) somente um terminador é necessário e pode ser colocado em qualquer ponto da rede. Já na topologia em bus com dupla terminação, exatamente dois terminais devem ser colocados, um em cada ponta da rede.

\subsubsection{Protocolo Lontalk}

A tecnologia LonWorks ${ }^{\circledR}$ foi implementada com um protocolo completo para comunicação entre os nós de uma rede distribuída denominado LonTalk. Este 
protocolo segue o padrão de redes de controle ANSI/EIA 709.1, o que possibilita sua implementação por qualquer fabricante. Ele foi adotado como padrão europeu de automação predial em meados de 2005 (ECHELON, 2005b).

Este protocolo segue o modelo OSI da ISO (TANENBAUM, 1996) e implementa todas as camadas que esta norma preconiza. Através deste protocolo e do Neuron Chip combinado com um transceptor adequado a cada aplicação, é possível a implementação de uma rede de máxima integridade e velocidade.

Dentre as principais características desse protocolo pode-se citar:

- Suporte a diversos tipos de meios de comunicação e taxas de transmissão numa mesma rede;

- Comunicação segura e de confiança entre os nós de uma rede;

- Mensagens de tamanho pequeno;

- Comunicação ponto-a-ponto entre os nós da rede;

- Suporte para serviços de gerenciamento de redes, o que permite que ferramentas de gerenciamento remoto da rede acessem os nós e executem tarefas como reconfiguração dos endereços de rede, descarregamento de parâmetros de programas aplicativos, listagem de problemas de rede e gerenciamento da execução dos programas aplicativos dos nós.

Além das características citadas acima, um dos grandes diferenciais deste protocolo é a implementação do conceito de variáveis de rede. Uma variável de rede representa uma informação completa (como por exemplo, o valor de uma dada temperatura em graus Celsius) que um nó recebe ou envia (ou difunde) para a rede de controle. Quando o valor de uma variável de rede é alterado, ocorre a sua propagação para os nós da rede que estejam interessados em receber o novo valor. Sob o ponto de vista de um nó da rede, as variáveis de rede que possibilitam a entrada de informação para o nó são chamadas de variáveis de rede de entrada, enquanto as 
variáveis utilizadas pelo nó para fornecer informação para outros nós da rede são chamadas de variáveis de rede de saída. Canovas (2006) descreve em detalhes o funcionamento das variáveis de rede.

A simples criação das variáveis de rede não possibilita a comunicação entre os nós através dessas variáveis. É necessário que seja executado um processo de ligação entre essas variáveis denominado binding. Nesse processo, que é executado durante o projeto e instalação da rede através de ferramentas de gerenciamento da rede, as variáveis de saída de um nó são ligadas às variáveis de entrada de outros nós que tenham interesse por elas. Assim, quando um programa aplicativo altera o valor de uma variável de rede de saída, ela passa essa informação para o firmware do disposittivo. O firmware, através do processo de binding, foi configurado para saber o endereço lógico do nó ou grupo de nós que esperam receber a informação dessa variável de rede. Desta forma, estabelece-se uma ligação lógica entre os nós da rede (ECHELON, 1999).

Em função do número de nós de origem e destino e do número de variáveis de rede envolvidas no processo de ligação, existem vários tipos de binding possíveis. A Figura 10 demonstra esses tipos.

Vale observar que no processo de binding as informações da origem e destino devem ter o mesmo significado. Por exemplo, num nó sensor de temperatura pode-se ter como variável de rede de saída a temperatura e em nó ventilador como variável de rede de entrada a temperatura. Essa informação pode ser usada para decidir se o ventilador deve ou não ser acionado. No entanto, caso o sensor de temperatura envie informações de temperatura em graus Farenheit e o algoritmo do ventilador estiver preparado para utilizar a temperatura em graus Celsius, o sistema não funcionaria adequadamente caso o binding fosse realizado. Devido a isso, cada variável de rede possui um tipo padronizado e só são permitidos bindings entre variáveis de rede do mesmo tipo. 


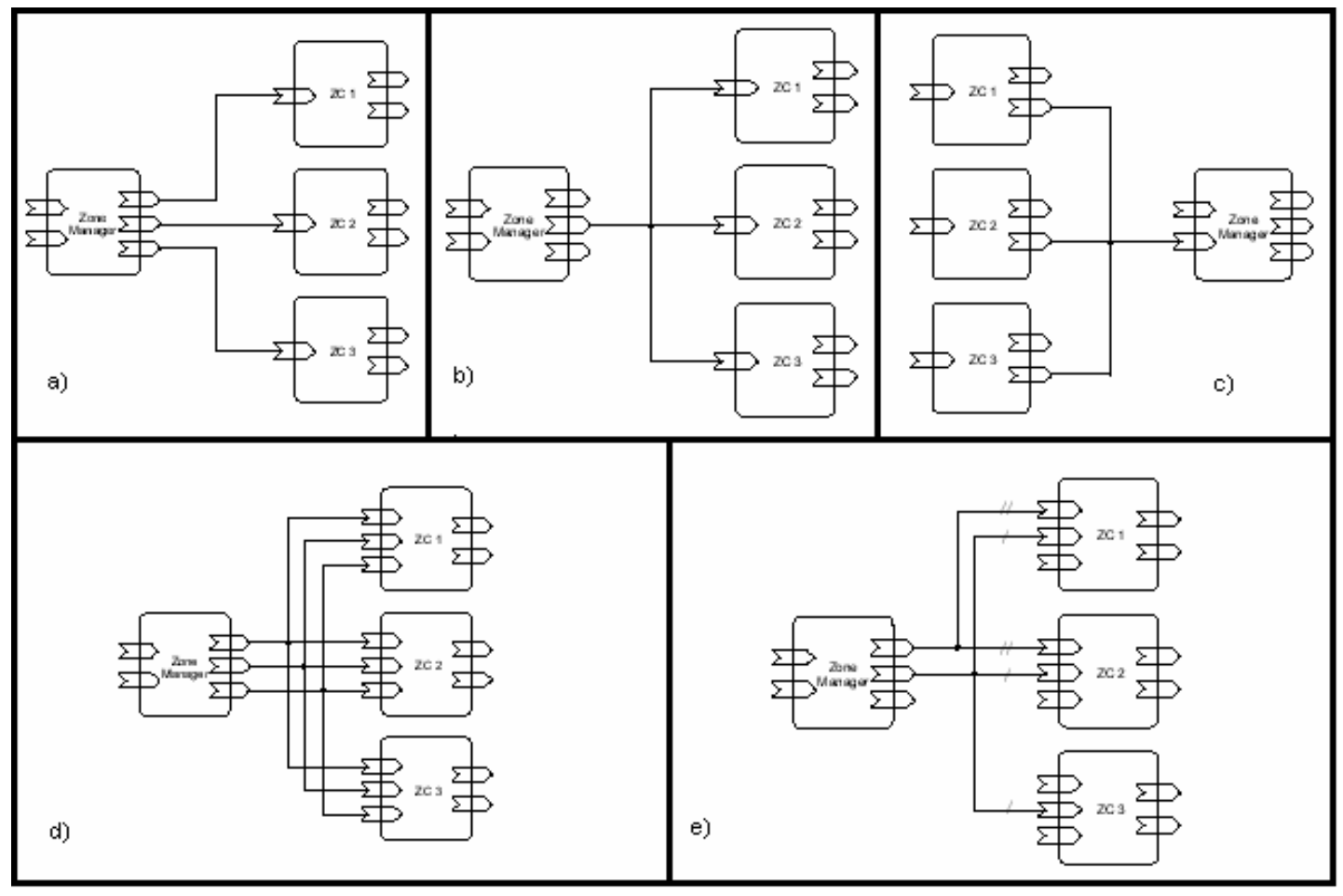

Figura 10 - Tipos de binding a) um para um b) um para muitos c) muitos para um d) muitos para muitos (mesmo grupo de nós) e e) muitos para muitos (grupos de nós diferentes)

Fonte: TAC (2001c).

Cada variável de rede possui um tipo que define a unidade, a escala e a estrutura do dado contido na variável de rede. Esses tipos são chamados Standard Network Variable Type (SNVT). Por exemplo, o tipo SNVT_temp é utilizado para temperaturas em graus Celsius. Os limites são de -274 a 6271 e a resolução é de 0,1 ${ }^{\circ} \mathrm{C}$. O conceito dessas variáveis de rede é semelhante ao de variável utilizado em linguagens de programação. A Tabela 3 mostra exemplos de algumas SNVTs. 
Tabela 3 - Exemplo de alguns tipos de variáveis de rede (SNVT) da tecnologia LonWorks ${ }^{\circledR}$

\begin{tabular}{lllll}
\hline Nome & Tipo & Unidade & Limites & Resolução \\
\hline SNVT_temp & Temperatura & Graus Celsius & $-274 . .6271$ & $0,1{ }^{\circ} \mathrm{C}$ \\
SNVT_angle & Fase/Rotação & Radianos & $0-65$ & $0,001 \mathrm{rad}$ \\
SNVT_speed & Velocidade & Metros/Segundo & $0-6553$ & $0,1 \mathrm{~m} / \mathrm{s}$ \\
SNVT_elapsed_tm & Tempo Transcorrido & HH:MM:SS & $0-65535$ dias & $1 \mathrm{~ms}$ \\
SNVT_lev_cont & Nível Contínuo & Percentual & $0-100 \%$ & $0,5 \%$ \\
SNVT_ascii & Cadeia ASCII & Caracteres & 30 Caracteres & N/A \\
SNVT_count & Eventos & Contagem & $0-65535$ & 1 Contagem \\
\hline
\end{tabular}

Fonte: TAC (2003)

Percebe-se que uma das principais formas de comunicação entre os nós é através das variáveis de rede. A padronização dos seus tipos através das SNVTs aliado ao protocolo LonTalk, possibilita a construção de uma rede com nós de fabricantes diferentes. Um nó sensor de temperatura que possui uma variável de rede do tipo SNVT_temp, descrito acima, pode ser substituído por um nó de um outro fabricante, desde que também tenha uma variável de saída do mesmo tipo SNVT_temp . Esta característica é chamada de interoperabilidade. Mahalik (2002) define interoperabilidade como sendo a habilidade de ligar instrumentos em um sistema de controle e conseguir que eles se comuniquem entre si. Echelon (1999) define como sendo a habilidade de sistemas de diferentes fabricantes e de diferentes tipos compartilhar informação um com o outro, sem que seja perdida nenhuma de suas capacidades funcionais independentes e sem ter a necessidade de implementar programações complexas pelo integrador. Nota-se por essas definições que, para que um sistema ou um componente de um sistema possa ter a capacidade de ser interoperável, a padronização é fundamental.

Dentre as vantagens da interoperabilidade pode-se citar:

- Possibilidade de utilização de dispositivos de diversos fabricantes integrados num único sistema, sem a necessidade de desenvolver ferramentas, hardware ou software específicos; 
- Eliminação de dependência do fabricante em relação à assistência e atualização, comuns nos sistemas proprietários;

- Possibilidade de utilização dos melhores dispositivos de cada fabricante, ao contrário de uma solução proprietária que restringe as opções à linha de produtos do fabricante;

- Redução de custo devido à concorrência.

Com esse objetivo, foi criada em 1994 a Associação LonMark® (LONMARK, 2006). Inicialmente formada pela empresa Echelon e 35 membros, hoje possui mais de 300 membros em 25 países. É uma associação aberta e qualquer empresa pode participar. Seus principais objetivos são desenvolver padrões que permitam a interoperabilidade e a certificação dos produtos nesses padrões. Uma vez certificado, o dispositivo pode usar o selo LonMark ${ }^{\circledR}$ que atesta a sua interoperabilidade. Entre outras coisas, a Associação LonMark ${ }^{\circledR}$ padroniza os tipos de variáveis de rede (SNVTs), os transceptores e os meios de comunicação.

\subsection{Considerações finais}

Neste capítulo mostrou-se em linhas gerais, as principais características e os principais componentes da tecnologia LonWorks®. É importante salientar que é uma solução completa, englobando meios de comunicação de rede, transceptores, circuitos integrados que implementam o protocolo LonTalk (Neuron Chip), nós com capacidade de processamento, protocolo padrão (LonTalk) seguindo a norma ANSI/EIA-709.1, assim como uma série de ferramentas de criação, desenvolvimento e testes de rede. Percebe-se o grande potencial que essa tecnologia tem principalmente porque o projetista de soluções de controle pode se dedicar mais às questões de solução do que de comunicação e infra-estrutura.

Existem portais na Internet que comercializam os produtos LonWorks ${ }^{\circledR}$ reunindo vários fornecedores como o Liberty Control Networks (LIBERTY, 2006) e o Engenuity (ENGENUITY, 2006). Nestes portais é possível encontrar produtos de 
todos os gêneros, desde módulos sensores de temperatura compatíveis com o padrão LonMark®, como aplicativos de gerenciamento de rede. Vale ressaltar que as grandes empresas têm a preocupação não só da comercialização, mas também do treinamento dos clientes, assegurando a forma correta de utilização de seus produtos. Em função disso, algumas linhas de produtos não são comercializadas nesses portais.

Embora a utilização dessa tecnologia no Brasil seja incipiente, no mundo existem cerca de 4.000 desenvolvedores de produtos envolvendo a tecnologia LonWorks® e mais de três milhões de dispositivos instalados (ECHELON, 2005a), o que mostra a abrangência e o alcance desta tecnologia. 


\section{PROPOSTA E IMPLEMENTAÇÃO DE UMA REDE DE CONTROLE DISTRIBUÍDO EM UMA CASA DE VEGETAÇÃO}

Neste capítulo apresenta-se uma proposta de uma rede de controle para uma casa de vegetação, baseada na tecnologia LonWorks®. Essa proposta dá origem a uma implementação experimental, destinada a pesquisas. A arquitetura proposta é discutida, bem como o processo de desenvolvimento e implementação, incluindo as ferramentas de desenvolvimento, funcionalidades implementadas, forma de operação, testes realizados e resultados obtidos.

\subsection{Introdução}

Conforme discutido nos capítulos anteriores, os sistemas com arquitetura distribuída, baseados em rede de controle vêm despertando cada vez mais interesse, tanto dos pesquisadores como dos usuários. Tecnologias como a LonWorks ${ }^{\circledR}$ envolvem conceitos modernos e avançados, viabilizando a mudança de paradigmas:

- Arquiteturas centralizadas dão lugar às arquiteturas distribuídas;

- Sensores e atuadores passam a dispor de inteligência, constituindo-se em um nó "inteligente" da rede de controle, cujas funções envolvem deste as etapas de condicionamento dos sinais até a sua disponibilização na forma digital para outros nós que necessitam da informação;

- Concepção de sistemas sem a presença de um computador central para comandá-lo;

- Interligação com a Internet, viabilizando a supervisão e o comando de qualquer lugar;

- Aproveitamento de soluções já existentes, implementadas com tecnologias convencionais, os chamados sistemas legados, que 
podem ser paulatinamente substituídos pela nova tecnologia, com investimentos graduais e proporcionais (ECHELON, 1999).

Entretanto, torna-se importante o real conhecimento dessas potenciais vantagens, bem como a avaliação de outros aspectos, como a facilidade de desenvolvimento de aplicações, flexibilidade para reconfigurações e mudanças, e a interoperabilidade, dentre outros. A pouca disponibilidade de casos reais para estudo estimula as pesquisas nessa área, e implementações experimentais ganham especial importância.

O sistema a seguir apresentado foi construído com esse objetivo. Ele foi implementado a partir de uma casa de vegetação experimental, incorporando diversos de seus recursos já existentes. Ela já possuía dois sistemas de automação: um sistema convencional, baseado em controles através de lógica de relés, e outro, fruto do trabalho de pesquisa de Cansado (2003), baseado em CLP.

A nova implementação procurou manter funcionando o sistema de controle original da casa de vegetação baseado em lógica de relés. Com relação ao controle por CLP foram utilizadas as conexões já existentes com os sensores e atuadores. Desta forma procurou-se executar a nova implementação possibilitando, caso seja necessário, que a antiga implementação com o CLP possa ser restabelecida.

\subsection{Arquitetura}

A arquitetura proposta neste trabalho tem o objetivo de atender às necessidades de pesquisa, não pretendendo ser um sistema abrangente e completo: trata-se de uma proposta exploratória, visando exercitar os principais conceitos, e dispor de recursos para levantamento de informações para as análises e discussões. Contudo, a sua flexibilidade intrínseca viabiliza que após a realização deste trabalho, a sua expansão possa ser realizada com relativa facilidade, caso seja de interesse de outros pesquisadores. 
Optou-se pela concepção de um sistema que possibilitasse a avaliação de inúmeros aspectos que poderiam estar presentes em um sistema real, que certamente deve atender a diversos aspectos, como a utilização de sensores e atuadores convencionais, nós comercialmente disponíveis e nós especialmente desenvolvidos para uma dada aplicação. Embora idealmente poder-se-ia considerar uma arquitetura com alto grau de homogeneidade, ou seja, cada dispositivo sensor ou atuador provido de inteligência e conectividade à rede, na prática é mais provável que a heterogeneidade prevaleça, pelo menos durante ainda algum tempo para a aplicação em questão, pois não se dispõe comercialmente de todos os sensores e atuadores adequados requeridos com inteligência e conectividade à rede de controle considerada, e o custo de desenvolver um nó para um único sensor ou atuador ainda é elevado (Figura 11).

A rede de controle proposta e implementada envolve quatro tipos de componentes LonWorks ${ }^{\circledR}$ :

- Um nó comercialmente disponível, responsável por um conjunto de sensores, o NOSE;

- Um nó responsável por dois sensores, desenvolvido no LAA, denominado PIC-LON;

- Dois nós programáveis e um módulo de entradas e saídas analógicas, comercialmente disponíveis, que foram utilizados tanto para a conexão de sensores como atuadores desprovidos de inteligência e condicionamento de sinais: procurou-se neles distribuir os atuadores e sensores disponíveis na casa de vegetação, para explorar a distribuição de inteligência na rede;

- Um nó com dupla função: gateway para a interconexão com uma rede TCP/IP, e servidor Web, onde fica residente um conjunto de páginas destinadas ao monitoramento, controle e atuação remota.

Assim, uma característica interessante para pesquisa é que a rede possui a presença de duas categorias de nós: nós comercialmente disponíveis, mas de 
fabricantes diferentes e um nó especialmente desenvolvido para a aplicação. Desta forma, tanto a interoperabilidade como o processo de desenvolvimento de novos nós e respectivo comissionamento na rede puderam ser avaliados.

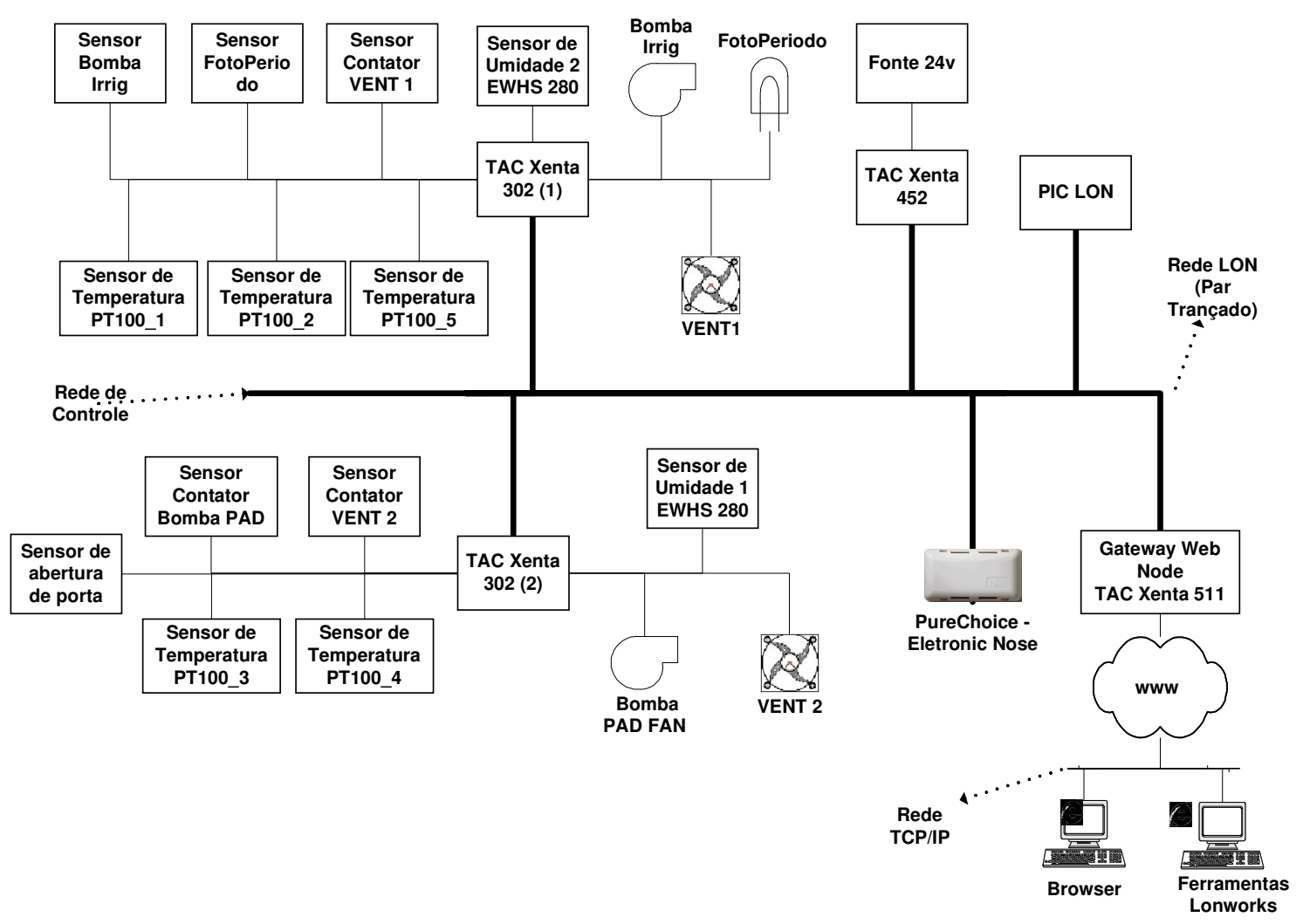

Figura 11 - Arquitetura do sistema implementado

Outro aspecto de relevância que se procurou avaliar nesse trabalho de pesquisa foi a interligação da rede de controle proposta com a Internet: trata-se de uma tendência verificada nos últimos anos, e que deve cada vez mais ser considerada nas novas implementações (CORDER, 2004; LEE; SCHNEEMAN, 1999; OVERSTREET; TZES, 1999). Em especial, na aplicação em questão, esse recurso ganha maior importância em face da localização de muitas casas de vegetação, nem sempre ser próxima dos especialistas, quer em cultivo protegido, quer em supervisão e controle de processos. O gerenciamento do sistema é feito através do módulo utilizado como gateway e servidor Web, que foi instalado na própria casa de 
vegetação, podendo ainda esse gerenciamento ser realizado remotamente, através da intranet ou Internet. Para o monitoramento e gerenciamento remoto, o acesso é feito através de um browser típico.

Um conjunto de ferramentas cliente-servidor de uso comercial, compatível com o padrão LonWorks ${ }^{\circledR}$ foi utilizado para a programação remota, criação e configuração da rede LonWorks®: software Vista 4.1, da empresa TAC (TAC, 2001d).

\subsubsection{Características da casa de vegetação}

A casa de vegetação utilizada neste trabalho pertence ao Instituto de Biociências da Universidade de São Paulo (IB-USP), e se encontra localizada na Cidade Universitária, São Paulo, SP. É um modelo de teto em arco, com área total de aproximadamente 116,5 metros quadrados, tendo 18,5 metros de comprimento e 6,2 metros de largura, 3 metros de altura com um arco de 1,5 metros, atingindo portanto a altura máxima de 4,5 metros na região central (Figura 12).

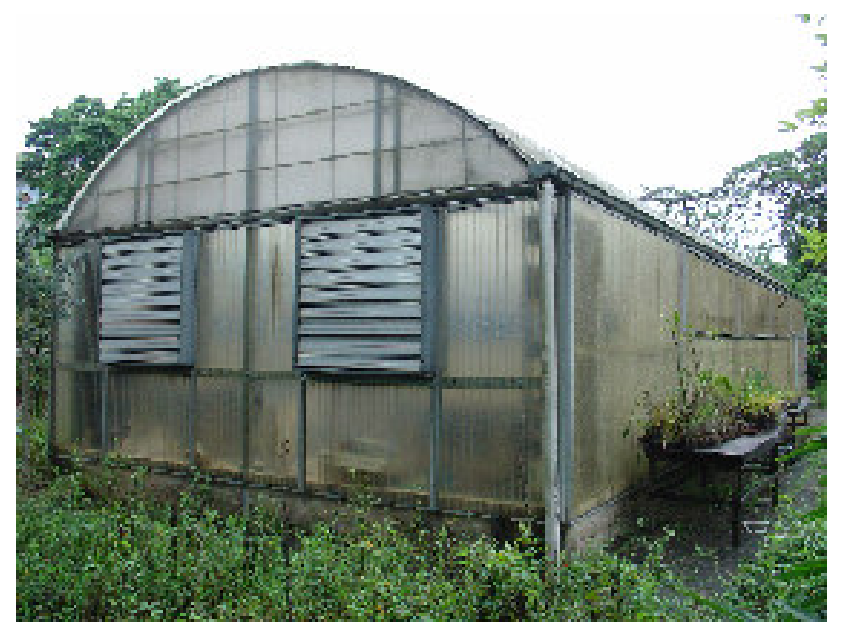

Figura 12 - Vista externa da casa de vegetação do IB-USP 


\subsubsection{Sensores}

\subsubsection{Sensor de temperatura - PT-100}

Um dos sensores utilizados para a medição de temperatura foi o PT-100 (Figura 13), que é conhecido como Resistance Temperature Detector (RTD). Ele é baseado no princípio do aumento da resistência elétrica de um condutor com o aumento da temperatura. O condutor utilizado é a platina $(\mathrm{Pt})$, que apresenta características especiais como precisão e estabilidade a uma grande faixa de temperaturas. É quimicamente inerte e pode ser utilizada em altas temperaturas. $\mathrm{O}$ PT-100 tem a característica de apresentar resistência de 100 ohms a $0{ }^{\circ} \mathrm{C}$. Suas especificações são:

- Faixa de operação: $-200{ }^{\circ} \mathrm{C}$ a $+850{ }^{\circ} \mathrm{C}$;

- Equação característica: $\mathrm{R}=0,385 \mathrm{~T}+100$ (onde $\mathrm{R}$ é a resistência em ohms do sensor e T é a temperatura em ${ }^{\circ} \mathrm{C}$ );

- Precisão: $\pm(0,15+0,002[\mathrm{~T}])$ para sensores classe A e $\pm(0,30+$ $0,005[\mathrm{~T}]$ ) para sensores classe $\mathrm{B}$ (onde $\mathrm{T}$ é a temperatura em graus Celsius);

- Tempo de resposta típico: $87 \mathrm{~s}$ no ar a $1 \mathrm{~m} / \mathrm{s}$.

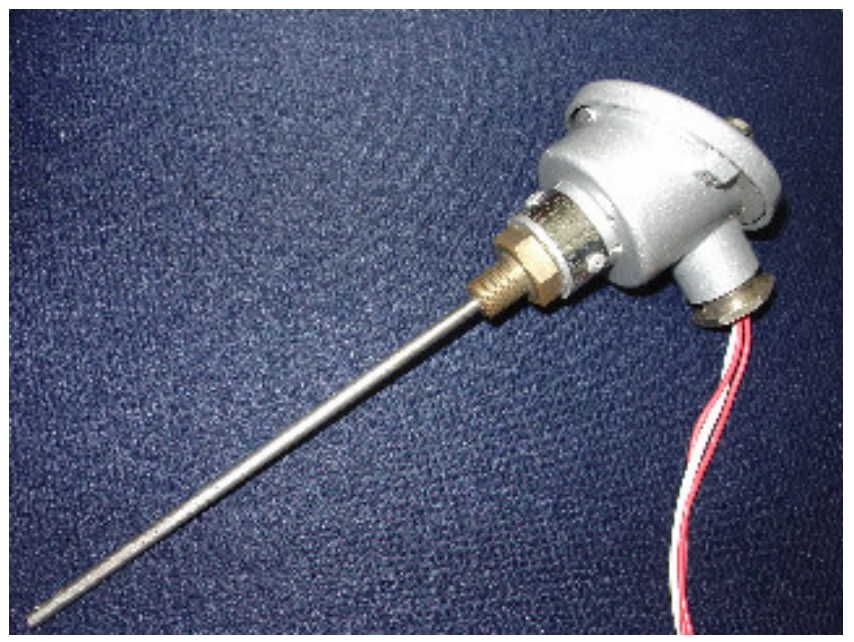

Figura 13 - Sensor de temperatura PT-100 
A casa de vegetação possui cinco sensores como o descrito, sendo que um deles foi posicionado externamente com o objetivo de medir a temperatura externa da casa de vegetação, posicionado em uma das extremidades, a cerca de 1 metro do solo. Os demais foram acoplados a um suporte a cerca de 2,3 metros do solo, e cuja disposição é representada na Figura 14.

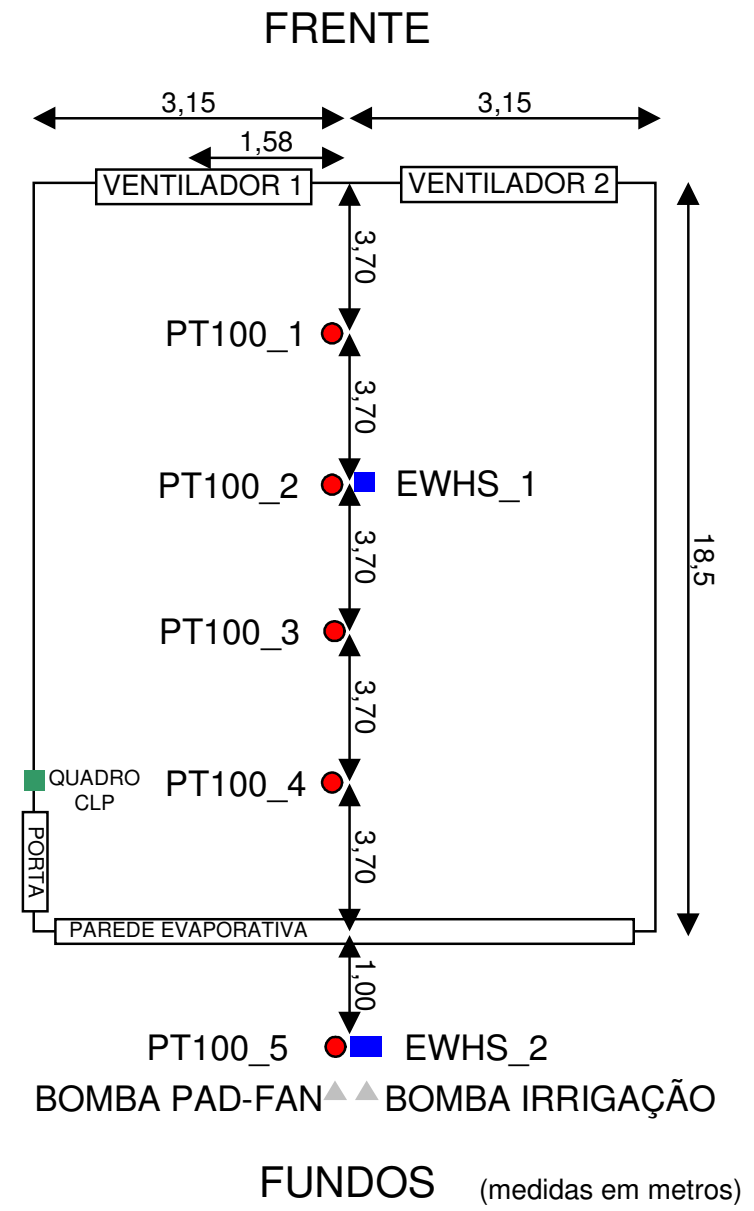

Figura 14 - Vista superior da casa de vegetação com o posicionamento dos sensores e atuadores

\subsubsection{Sensor de umidade relativa EWHS 280}

Foram utilizados sensores de umidade do tipo capacitivo, fabricado pela empresa Invensys Control (INVENSYS, 2006). Esse sensor fornece a informação de saída em corrente elétrica, na faixa de 3 a $18 \mathrm{~mA}$, correspondendo respectivamente de $15 \%$ a $90 \%$ de umidade relativa, com precisão de $\pm 5 \%$. Requer para a sua 
alimentação uma fonte de tensão contínua, de 9 a $20 \mathrm{~V}$. Seu tempo de resposta é de 60s (Figura 15).

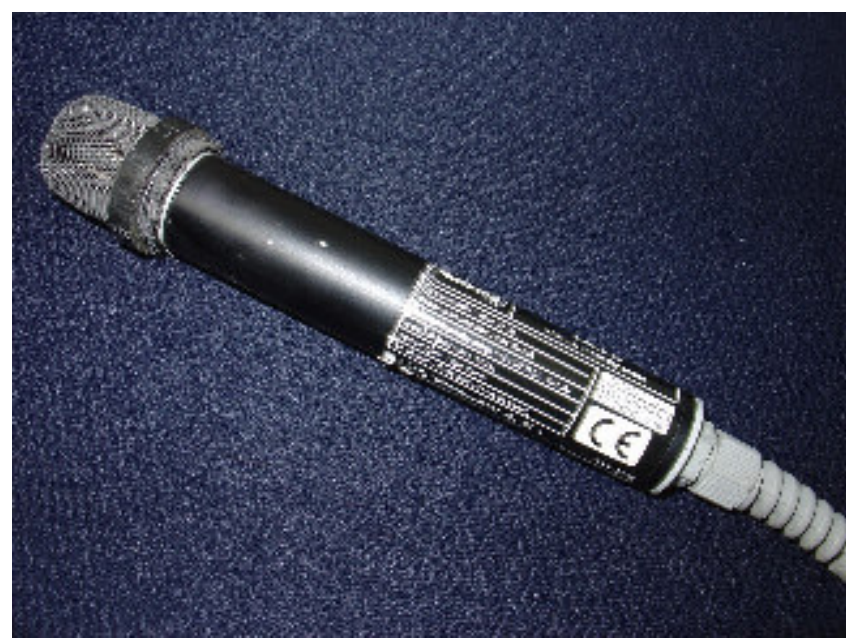

Figura 15 - Sensor de umidade EWHS 280

A casa de vegetação possui dois sensores deste tipo, sendo que um deles foi posicionado externamente nos fundos da casa de vegetação a cerca de 1 metro do solo, e o outro internamente, acoplado em um suporte a cerca de 2,7 metros do solo, cuja disposição é representada na Figura 14.

\subsubsection{Sensor PIC-LON}

Este sensor foi desenvolvido em um trabalho de iniciação científica por um pesquisador do LAA (BURDELIS, 2005). O objetivo foi o desenvolvimento de um nó baseado na tecnologia LonWorks ${ }^{\circledR}$, que pudesse ser utilizado na casa de vegetação para a medição de temperatura e umidade. Ele é composto pelo sensor de temperatura e umidade SHT11 fabricado pela empresa Sensirion (SENSIRION, 2003), placa de circuito impresso baseada no microprocessador PIC16F873 da empresa Microchip (MICROCHIP, 2006), display de cristal líquido e módulo LTM10 para o desenvolvimento de nós para redes LonWorks ${ }^{\circledR}$, fabricado pela empresa Echelon (ECHELON, 2006) (Figura 16). 


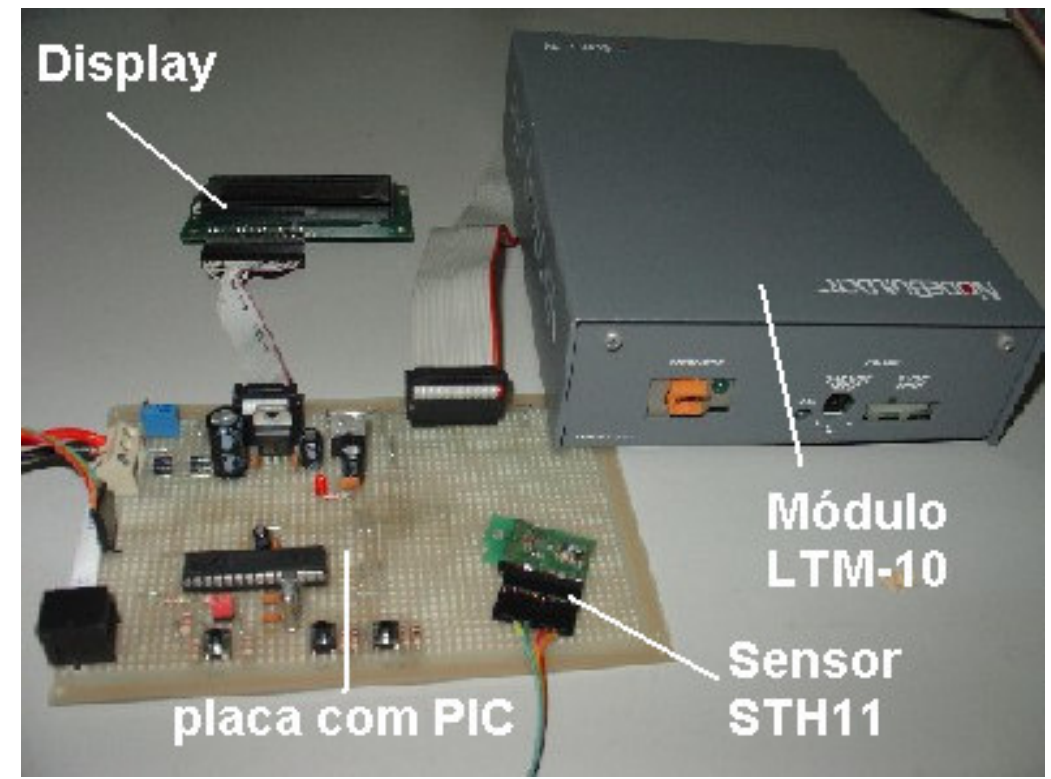

Figura 16 - Protótipo do nó PIC-LON

O sensor SHT11 (Figura 17) opera numa faixa adequada para ser utilizado em casas de vegetação: $-20{ }^{\circ} \mathrm{C}$ a $60{ }^{\circ} \mathrm{C}$. Suas especificações são:

- Faixa de medição:

- umidade relativa: $0-100 \%$;

- temperatura: $-20{ }^{\circ} \mathrm{C}$ a $80{ }^{\circ} \mathrm{C}\left(40 \%\right.$ de umidade relativa) ou $-20{ }^{\circ} \mathrm{C}$ a 60 ${ }^{\circ} \mathrm{C}(100 \%$ de umidade relativa)

- Precisão:

- umidade relativa: $+/-3 \%$;

- temperatura: $+/-0.4^{\circ} \mathrm{C}$ a $25^{\circ} \mathrm{C}$;

- Tempo de resposta: inferior a 4 segundos

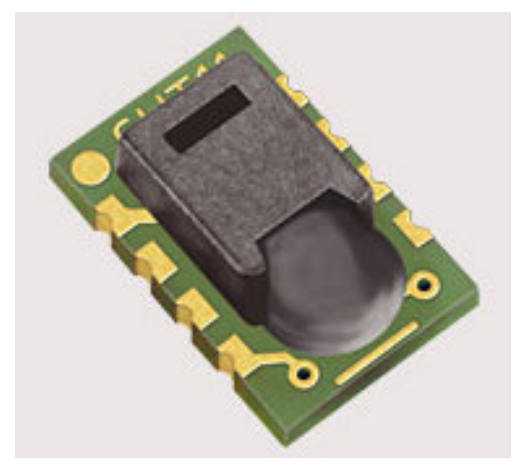

Figura 17 - Sensor STH11 da SENSIRION (Fonte: Sensirion , 2003) 
O Módulo LTM-10 (Figura 18) permite implementar nós LonWorks®, sendo utilizado para a criação de protótipos. Ele inclui um Neuron Chip, um transceptor, memória para armazenar aplicação, alguns botões de controle, LED’s de diagnóstico e entradas e saídas de vários tipos para a ligação de componentes eletrônicos de uso diverso.

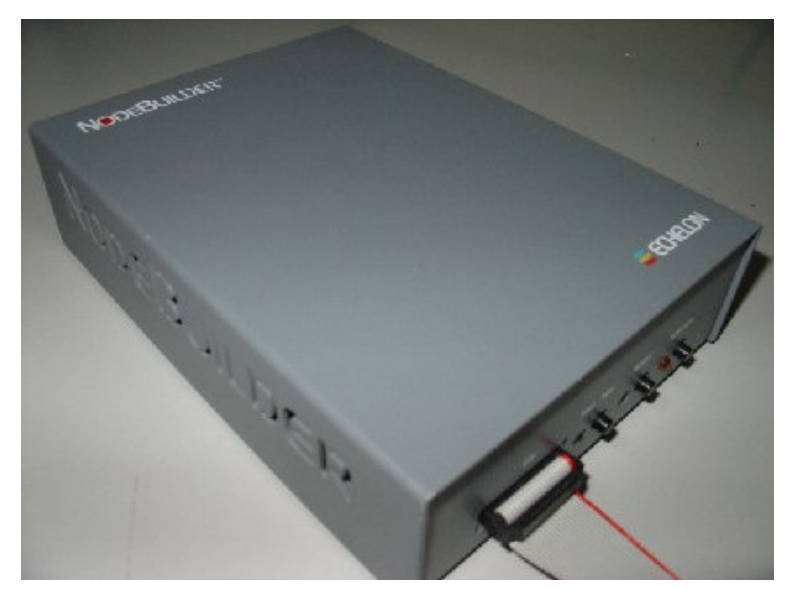

Figura 18 - Módulo LTM-10 utilizado no experimento

O STH11 possui uma interface de comunicação que utiliza um protocolo proprietário. Já o módulo LTM-10 dispõe de uma interface de comunicação que segue o padrão SPI. Utilizou-se, assim, o microcontrolador PIC16F873 para a implementação da comunicação entre esses dois módulos, além da realização dos cálculos necessários para transformar os dados coletados no sensor de temperatura, adequando-os a um formato mais conveniente para a manipulação pelo Neuron Chip do módulo LTM-10, e também para o envio ao display de cristal líquido.

Esse nó sensor foi instalado em um bastidor vedado dentro da casa de vegetação, visando a sua proteção ao ambiente da estufa, especialmente no que tange aos altos valores de umidade relativa. 


\subsubsection{Sensor múltiplo NOSE da PureChoice}

Foi utilizado um dispositivo comercialmente disponível, da empresa PureChoice, denominado NOSE (NOSE, 2003) Figura 19. Este nó na verdade se constitui em um dispositivo que engloba cinco diferentes sensores: de temperatura, de umidade relativa, de concentração de $\mathrm{CO}$, de concentração de $\mathrm{CO}_{2}$ e de odores e gases. É compatível com o padrão LonMark®, constituindo-se em um nó que pode ser conectado diretamente em uma rede que segue o padrão LonWorks@. Neste trabalho ele foi utilizado apenas para mensurar a temperatura interna da casa de vegetação.

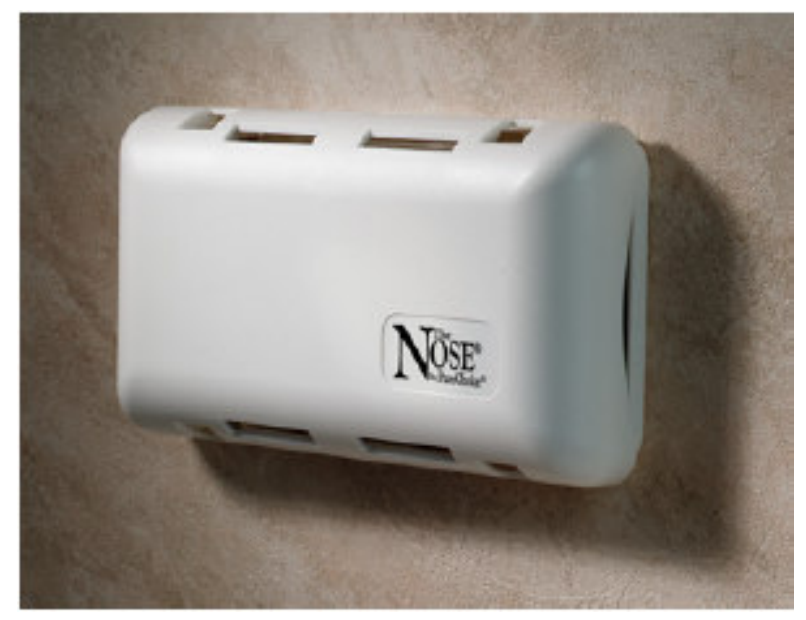

Figura 19 - Sensor múltiplo NOSE (Fonte: NOSE ( 2003))

Suas especificações são:

- Faixa de medição nominal: $0^{\circ}$ a $32^{\circ} \mathrm{C}$ (pode chegar na prática a valores mais elevados (próximo de $40^{\circ} \mathrm{C}$ ), englobando a faixa de operação de estufas);

- Precisão: $+/-0,5^{\circ} \mathrm{C}$;

- Resolução: $0,1^{\circ} \mathrm{C}$. 


\subsubsection{Sensor de abertura de porta}

Para indicar abertura da porta da casa de vegetação foi utilizado um sensor do tipo chave magnética (Figura 20). Sua função é servir para a supervisão da presença de pessoas e também para a detecção do esquecimento da porta na posição aberta, o que interfere no desempenho do sistema de controle.

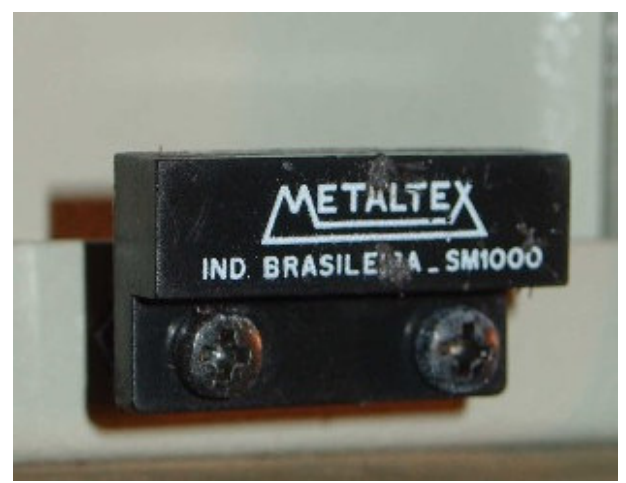

Figura 20 - Sensor de abertura utilizado na porta da casa de vegetação

\subsubsection{Atuadores}

\subsubsection{Ventiladores}

A casa de vegetação possui dois ventiladores colocados na sua parte frontal, com potência de 1,5 HP. O diâmetro de sua hélice é de 1,25 m e sua velocidade de rotação de 455 RPM. Possui venezianas horizontais externas que se abrem quando o ventilador é acionado, que são utilizadas para impedir a entrada de insetos (Figura 21).

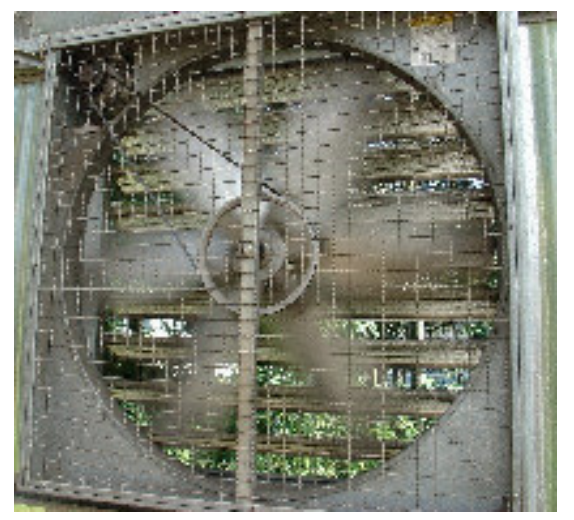

Figura 21 - Ventilador utilizado na casa de vegetação 


\subsubsection{Bomba de irrigação}

A casa de vegetação possui uma bomba de recalque que tem a finalidade de suprir o sistema de irrigação por meio de bicos aspersores (Figura 22) distribuídos em 3 canos de $30 \mathrm{~mm}$ de diâmetro, posicionados longitudinalmente a 2,1 $\mathrm{m}$ do solo. Sua potência é de $1 \mathrm{HP}$.

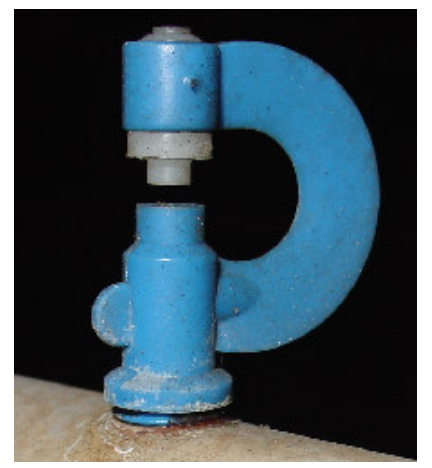

Figura 22 - Bico aspersor utilizado no sistema de irrigação

\subsubsection{Sistema de Pad-Fan}

O sistema de Pad-Fan é composto por uma bomba de recalque de potência de $1 \mathrm{HP}$, e uma parede evaporativa de $2,1 \mathrm{~m}$ x 6,2 $\mathrm{m}$, posicionada, em uma das extremidades da casa de vegetação (Figura 23).

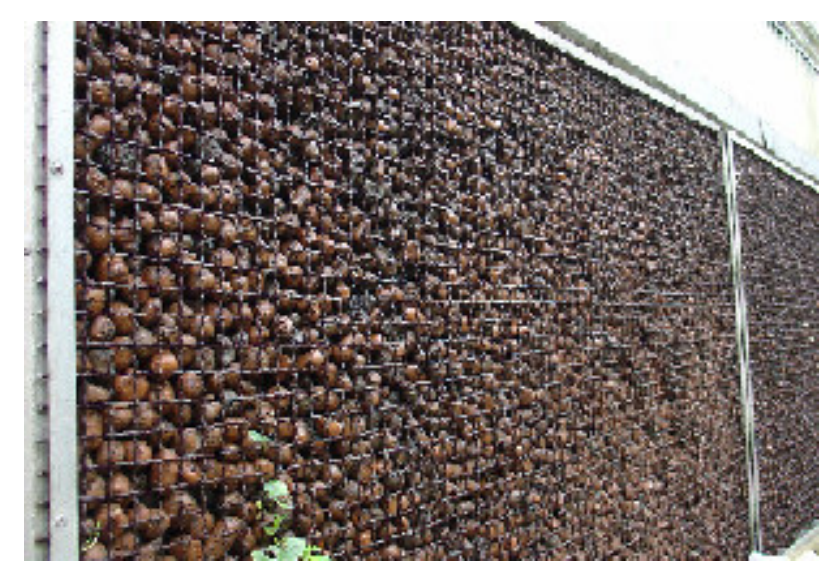

Figura 23 - Parede evaporativa do sistema Pad-Fan 


\subsubsection{Micromotor}

A cobertura da casa de vegetação é formada por uma camada dupla de plástico que é inflada através de um micromotor de potência de 1/30 HP. Esta camada de ar funciona como isolante térmico. Normalmente esse micromotor permanece permanentemente ligado durante todo dia. (Figura 24). $\mathrm{O}$ micromotor não foi utilizado neste experimento.

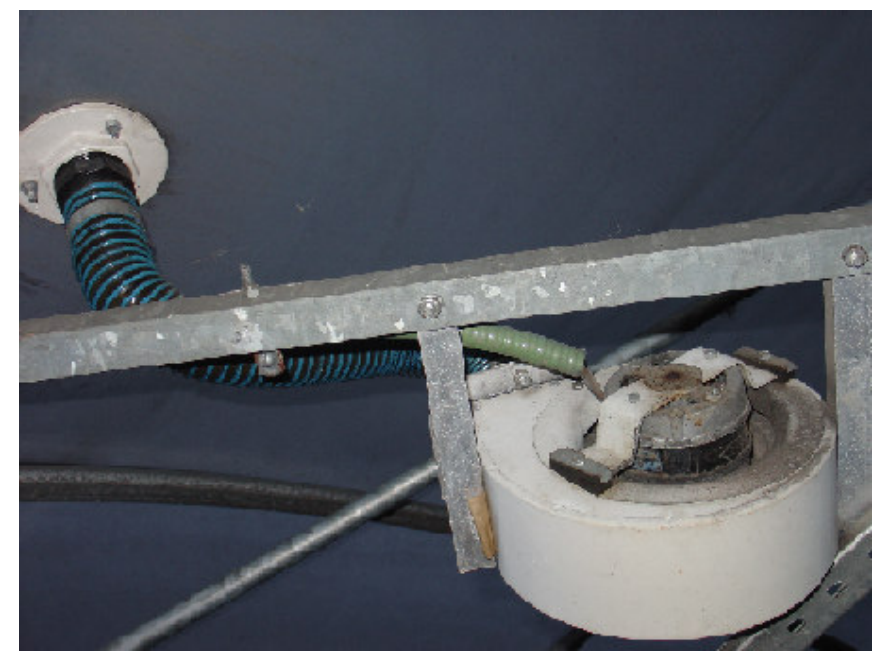

Figura 24 - Micromotor

\subsubsection{Iluminação}

A casa de vegetação possui 36 lâmpadas incandescentes, dispostas em quatro linhas longitudinais (Figura 25). Elas são utilizadas para o controle de fotoperíodo.

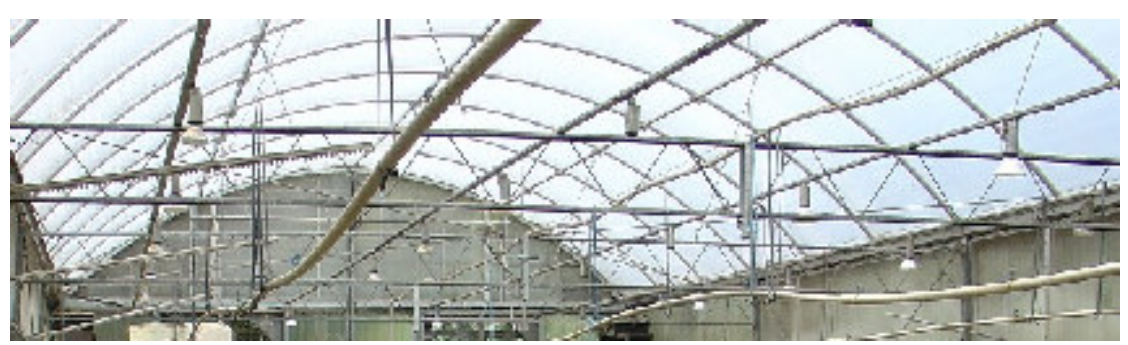

Figura 25 - Disposição das lâmpadas da casa de vegetação 


\subsection{Nós programáveis}

Os nós programáveis utilizados são fabricados pela empresa TAC, do grupo Schneider Electric, que dispõe de uma grande variedade de dispositivos para a constituição de redes de controle baseadas na tecnologia LonWorks®, aplicados à supervisão e controle de ambientes.

Foram escolhidos os seguintes módulos:

- nós programáveis e de entrada e saída para a conexão de sensores e atuadores diversos;

- nó servidor Web e gateway de comunicação para redes TCP/IP.

A Figura 26 apresenta a montagem experimental com tais módulos.

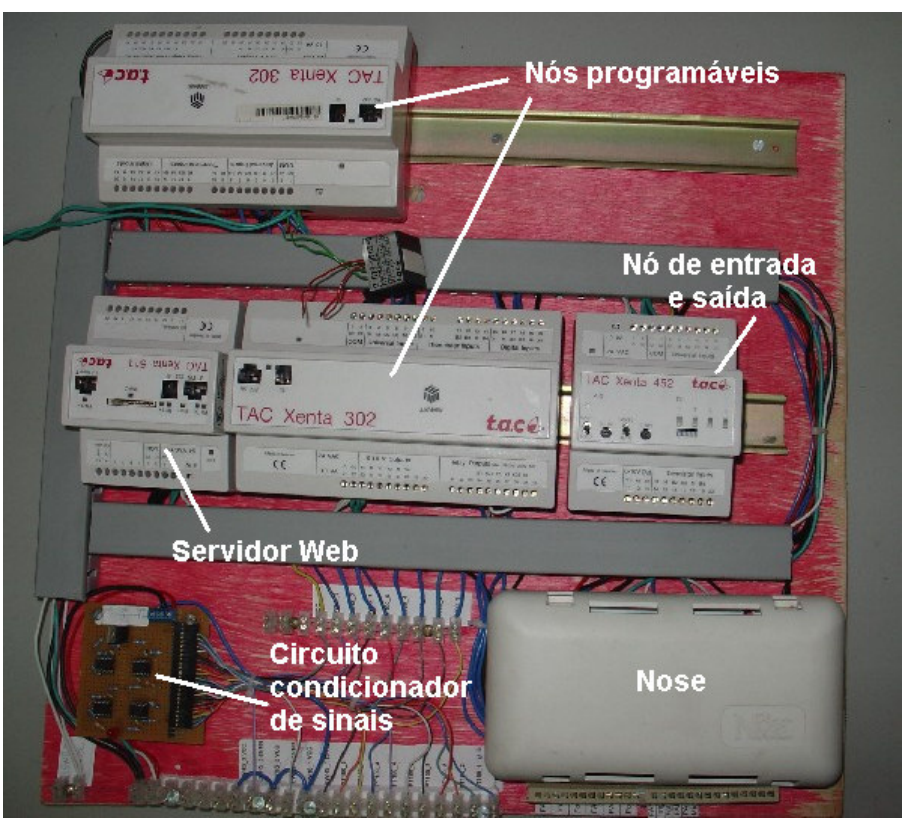

Figura 26 - Conjunto de componentes utilizados na rede experimental 


\subsubsection{Módulo Xenta 302}

É um módulo programável com capacidade de operar isoladamente ou como parte de um sistema. É compatível com o padrão LonMark®, podendo operar como um nó de uma rede LonWorks®. Possui 56Kb disponível para aplicações e dados e $64 \mathrm{~Kb}$ disponível para parâmetros. Pode ser alimentado com $24 \mathrm{~V} \mathrm{AC} \pm 20 \%$, $50 / 60 \mathrm{~Hz}$ ou 19-40 VDC. Sua temperatura de operação fica entre $0-50{ }^{\circ} \mathrm{C}$ e a umidade relativa máxima para operação é 90\% (TAC, 2001a). Ele pode ter a sua capacidade de entradas e saídas expandida, através de até 2 módulos de expansão da família Xenta 400 (TAC, 2001a). Possui ainda os seguintes recursos:

- LED verde indicador de programa em execução;

- Pino de serviço: quando pressionado envia uma mensagem para a rede com a identificação da unidade;

- 2 terminais para a conexão à rede LonWorks® através de par trançado sem polaridade;

- 4 entradas digitais: devem ser ligadas em chaves liga/desliga. A tensão quando o contato estiver aberto é de 33 VDC. A corrente com o contato fechado é de $4 \mathrm{~mA}$. Foram utilizadas como indicador de abertura para a porta da casa de vegetação, indicador de funcionamento para os ventiladores, bomba de irrigação e bomba Pad-Fan (através do estado dos contatores) e de funcionamento da iluminação (através do estado do relé de acionamento).

- 4 entradas universais: podem ser usadas como entradas digitais ou analógicas. A configuração é individual e feita via programação. Os valores máximos e mínimos podem ser configurados para cada entrada: entradas analógicas: 0 a 10V. Essas entradas foram utilizadas para os sensores de temperatura PT-100 e de umidade EWHS 280. Foi montado um circuito condicionar os sinais de 
entrada ao padrão dos módulos TAC, que não possuem entradas específicas para a medição de corrente (Figura 27). Foram adequadas as variações de resistência dos sensores PT-100 e de corrente dos sensores de umidade EWHS-280 (4/20mA) para valores correspondentes em tensões de 0 a $10 \mathrm{~V}$. O circuito foi calibrado considerando-se $-259,7{ }^{\circ} \mathrm{C}$ correspondendo a $0 \mathrm{~V}$, e 82,0 ${ }^{\circ} \mathrm{C}$ correspondendo a $10 \mathrm{~V}$. Para a medida de umidade relativa, a calibração foi: umidade relativa $=0 \%$, a tensão de saída $=0 \mathrm{~V}, \mathrm{e}$ para umidade relativa $=100 \%$, tensão de saída $=9,4 \mathrm{~V}$.

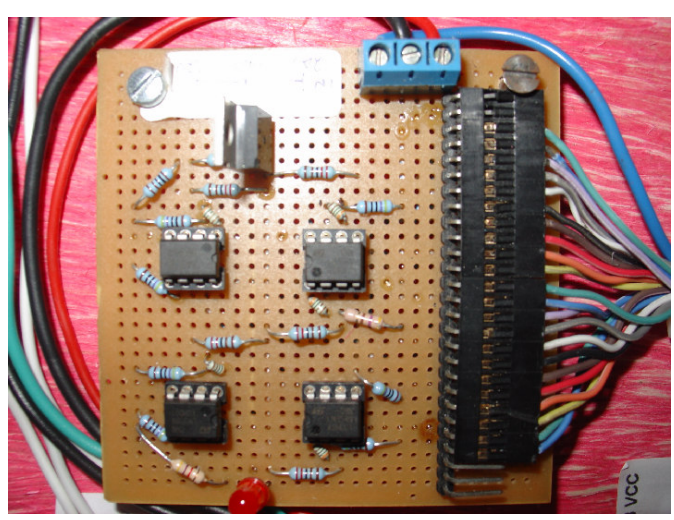

Figura 27 - Placa condicionadora de sinais dos sensores PT-100 e EWHS 280

- 4 saídas digitais a relés: suportam até 230 VAC. Foram utilizadas para o acionamento dos ventiladores, bomba de irrigação, bomba Pad-Fan e iluminação. Devido à potência envolvida nos atuadores o acionamento dos atuadores é feito através de cinco circuitos baseados em transistor e relés comandados que já estavam disponíveis (Figura 28) (CANSADO, 2003). Essas saídas foram configuradas de forma que quando ativadas transferem para a saída 24 V (nível lógico 1); 


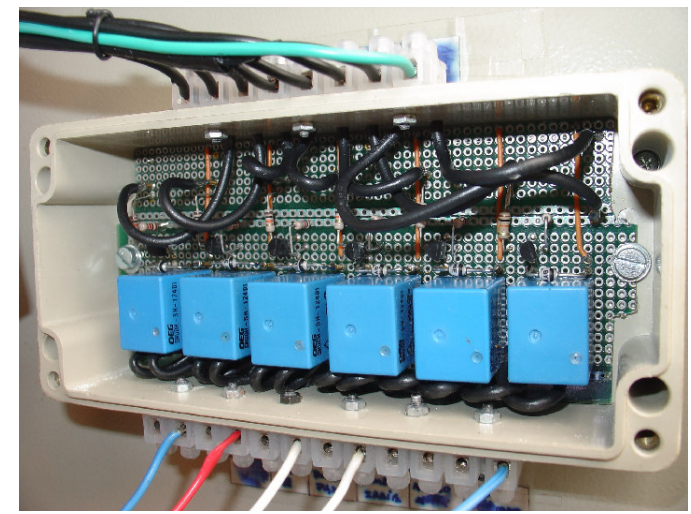

Figura 28 - Caixa de relés acionadores dos atuadores

- 4 saídas analógicas: de 0-10 V, mas não foram usadas no corrente trabalho.

A Figura 29 apresenta uma foto do módulo Xenta 302. Foram utilizados dois desses módulos, indicados como 302_1 e 302_2. A Tabela 4 apresenta a relação de entradas e saídas dos dois módulos e os dispositivos a elas associados.

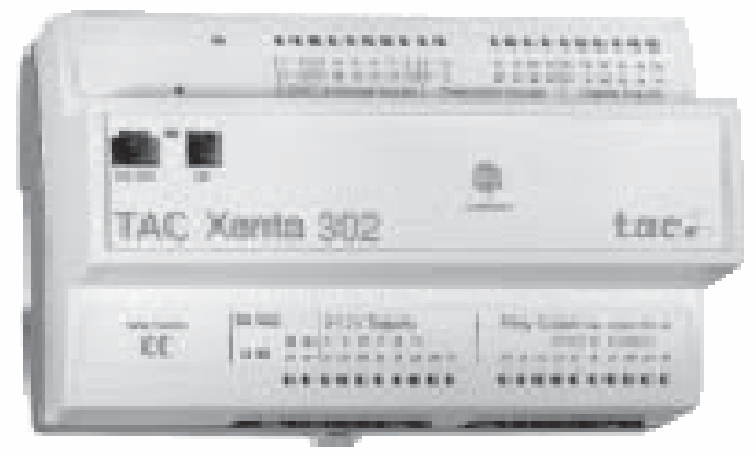

Figura 29 - Módulo Xenta 302 (Fonte: TAC (2003)) 
Tabela 4 - Ligações dos módulos Xenta 302 aos atuadores e sensores

\begin{tabular}{|c|c|c|}
\hline TIPO & $\begin{array}{c}\text { Módulo } \\
\text { Xenta }\end{array}$ & DESCRIÇÃOO \\
\hline Entrada Digital & 302_1 FAN1 & $\begin{array}{l}\text { Ligação feita no contator do ventilador } \\
0 \text { ligado/1 desligado }\end{array}$ \\
\hline Entrada Digital & 302_1 IRRIG & 0 ligada/1 desligada \\
\hline Entrada Digital & FOTOPERIODO & 0 acesa/1 apagada \\
\hline Entrada Digital & $302 \_2$ FAN2 & $\begin{array}{l}\text { Ligação feita no contator do ventilador } \\
0 \text { ligado/1 desligado }\end{array}$ \\
\hline Entrada Digital & $302 \_2$ PAD & 0 ligada/1 desligada \\
\hline Entrada Digital & 302_2 PORTA & 0 fechada/1 aberta \\
\hline Saída Relé & 302_1 FAN1 & $\begin{array}{l}\text { Relé de acionamento do ventilador } 1 \\
0 \text { desativado/1 ativado }\end{array}$ \\
\hline Saída Relé & 302_1 IRRIG & $\begin{array}{l}\text { Relé acionamento da bomba de irrigação } \\
0 \text { desativado/1 ativado }\end{array}$ \\
\hline Saída Relé & 302_1 FOTOPERIODO & $\begin{array}{l}\text { Relé de acionamento do fotoperiodo } \\
0 \text { desativado/1 ativado }\end{array}$ \\
\hline Saída Relé & 302_2 FAN2 & $\begin{array}{l}\text { Relé de acionamento do ventilador } 2 \\
0 \text { desativado/1 ativado }\end{array}$ \\
\hline Saída Relé & 302_2 PAD & $\begin{array}{l}\text { Relé de acionamento da bomba Pad-Fan } \\
0 \text { desativado/1 ativado }\end{array}$ \\
\hline $\begin{array}{l}\text { Entrada Analógica } \\
\text { (Tensão) }\end{array}$ & 302_1 PT100_1 & $\begin{array}{l}\text { Ligada à saída do circuito condicionador de sinais } \\
0 \mathrm{~V}=-259,7^{\circ} \mathrm{C} / 10 \mathrm{~V}=82,0^{\circ} \mathrm{C}\end{array}$ \\
\hline $\begin{array}{l}\text { Entrada Analógica } \\
\text { (Tensão) }\end{array}$ & 302_1 PT100_2 & $\begin{array}{l}\text { Ligada à saída do circuito condicionador de sinais } \\
0 \mathrm{~V}=-259,7^{\circ} \mathrm{C} / 10 \mathrm{~V}=82,0^{\circ} \mathrm{C}\end{array}$ \\
\hline $\begin{array}{l}\text { Entrada Analógica } \\
\text { (Tensão) }\end{array}$ & 302_1 PT100_5 & $\begin{array}{l}\text { Ligada à saída do circuito condicionador de sinais } \\
0 \mathrm{~V}=-259,7^{\circ} \mathrm{C} / 10 \mathrm{~V}=82,0^{\circ} \mathrm{C}\end{array}$ \\
\hline $\begin{array}{l}\text { Entrada Analógica } \\
\text { (Tensão) }\end{array}$ & 302_1 EWHS_2 & $\begin{array}{l}\text { Ligada à saída do circuito condicionador de sinais } \\
0 \mathrm{~V}=0 \% \text { Umidade Relativa } \\
9,4 \mathrm{~V}=100 \% \text { Umidade Relativa }\end{array}$ \\
\hline $\begin{array}{l}\text { Entrada Analógica } \\
\text { (Tensão) }\end{array}$ & 302_2 PT100_3 & $\begin{array}{l}\text { Ligada à saída do circuito condicionador de sinais } \\
0 \mathrm{~V}=-259,7^{\circ} \mathrm{C} / 10 \mathrm{~V}=82,0^{\circ} \mathrm{C}\end{array}$ \\
\hline $\begin{array}{l}\text { Entrada Analógica } \\
\text { (Tensão) }\end{array}$ & 302_2 PT100_4 & $\begin{array}{l}\text { Ligada à saída do circuito condicionador de sinais } \\
0 \mathrm{~V}=-259,7^{\circ} \mathrm{C} / 10 \mathrm{~V}=82,0^{\circ} \mathrm{C}\end{array}$ \\
\hline $\begin{array}{l}\text { Entrada Analógica } \\
\text { (Tensão) }\end{array}$ & 302_2 EWHS_1 & $\begin{array}{l}\text { Ligada à saída do circuito condicionador de sinais } \\
\text { OV = } 0 \% \text { Umidade Relativa } \\
9,4 \mathrm{~V}=100 \% \text { Umidade Relativa }\end{array}$ \\
\hline $\begin{array}{l}\text { Entrada Analógica } \\
\text { (Tensão) }\end{array}$ & $\mathrm{VCC}$ & $\begin{array}{l}\text { Mede a tensão da fonte de alimentação do sistema. } \\
\text { Foi usado um circuito divisor de tensão com resistores de } \\
1 \mathrm{k} \text { e } 3 \mathrm{k}\end{array}$ \\
\hline
\end{tabular}

\subsubsection{Módulo Xenta 452}

É um módulo destinado a tratar entradas e saídas analógicas (Figura 30), utilizado como módulo de expansão para controladores da família Xenta conectados numa rede comum. Esse módulo deve ser associado com um único controlador através da ferramenta TAC Menta. (TAC, 2004). Ele se comunica com o controlador através da rede LonWorks ${ }^{\circledR}$, mas através de um padrão fechado. Pode ser alimentado com $24 \mathrm{~V} \mathrm{AC} \pm 20 \%, 50 / 60 \mathrm{~Hz}$ ou 19-40 VDC. Sua temperatura de operação fica 
entre $0-50{ }^{\circ} \mathrm{C}$ e a umidade relativa máxima para operação é 90\% (TAC, 2001a). Possui os seguintes recursos:

- Pino de serviço: quando pressionado envia uma mensagem para a rede com a identificação da unidade;

- 2 terminais para a conexão à rede LonWorks® através de par trançado sem polaridade;

- 4 entradas universais: possui as mesmas especificações do módulo Xenta 302;

- 4 entradas para termistor: para sensores de temperatura do tipo termistor, operando na faixa de $1800 \mathrm{ohms} \mathrm{a} 25^{\circ} \mathrm{C}$, sendo a sua faixa de operação de $-50{ }^{\circ} \mathrm{C}$ a $150{ }^{\circ} \mathrm{C}$. Não foram usadas neste trabalho;

- 2 saídas analógicas: de 0-10 V. Não foram usadas neste trabalho;

- 2 chaves para acionamento manual das saídas analógicas e um potenciômetro para regulagem da tensão de saída (0-10V). Não foram usadas neste trabalho;

- 2 LEDs indicativos de funcionamento; o vermelho indica falha de hardware, e o verde indica execução de programa.

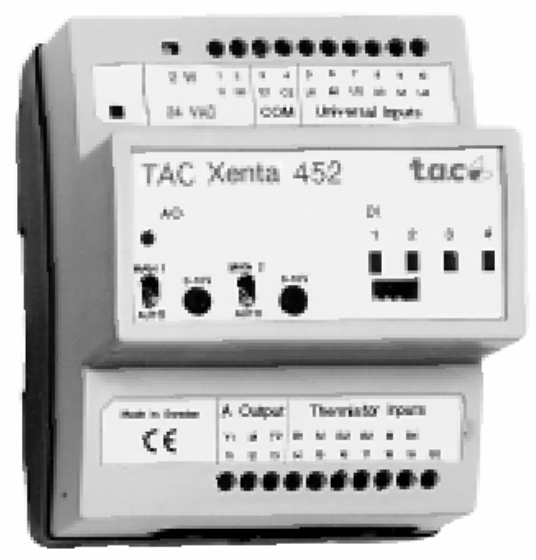

Figura 30 - Módulo Xenta 452 (Fonte: TAC (2003)) 
Foi utilizado um desses módulos. A Tabela 4 apresenta a relação de entradas deste módulo utilizada com o correspondente dispositivo.

\subsubsection{Módulo Xenta 511}

Este módulo é um servidor Web (Web server) que permite a criação de um site destinado à operação e monitoramento da rede de controle, através de páginas HTML e applets ${ }^{6}$. Possui 8 Mbytes de memória não volátil para armazenamento de software de sistema, aplicações ou arquivos. É possível a expansão dessa memória até 128Mbytes através, de um cartão do tipo MultiMedia Card (MMC). Além disso, este módulo permite que seja feita a comunicação de uma rede Ethernet (que utiliza o TCP/IP) com a rede de controle LonWorks ${ }^{\circledR}$ servindo como um LonTalk Adapter (LTA). Assim, através de um PC pode-se programar os módulos da rede LonWorks® ${ }^{\circledR}$ utilizando o software TAC Vista.

O módulo Xenta 511 (Figura 31) permite que até 100.000 valores de dados históricos sejam armazenados. Pode-se programar para que esses valores sejam enviados por correio eletrônico, através da configuração de um servidor SMTP. É possível a programação de envio de mensagens de alarmes para grupos usuários. Para o acesso às páginas através de um navegador é necessária a instalação do Java Plug- $I n^{7}$ para execução dos applets disponibilizados pela sua funcionalidade Web Server. O módulo implementa uma camada de autenticação para que as páginas possam ser visualizadas. Assim, através de um gerenciador de usuários intrínseco ao Web Server, podem-se criar usuários, mudar sua senha e limitar a visualização das páginas residentes por usuário. A conexão é criptografada utilizando Secure Sockets Layer (SSL). Os seguintes recursos também estão disponíveis no módulo:

\footnotetext{
${ }^{6}$ Pequenos aplicativos escritos em linguagem Java que utilizam-se da Java Virtual Machine (JVM) existente na máquina cliente ou embutida no seu navegador, para interpretar a forma intermediária de código denominada bytecode. Dessa forma, estes aplicativos tornam-se independentes de plataforma, podendo ser executandos em qualquer sistema que possua uma JVM.

7 Programa de computador que serve normalmente para adicionar funções a outros programas para prover alguma função particular ou muito específica.
} 
- Pino de serviço: quando pressionado envia uma mensagem para a rede com a identificação da unidade;

- 2 terminais para a conexão à rede LonWorks® através de par trançado sem polaridade;

- 2 conectores EIA RS232C: um destinado à conexão de um modem e outro para conexão em PCs. Foi usado para a configuração do endereço IP do módulo;

- 1 conector 10 BaseT para conexão em rede LAN. Através desta conexão foi feito o acesso a todas as funcionalidades do módulo;

- 1 soquete para placa de expansão de memória MMC. Este recurso não foi utilizado.

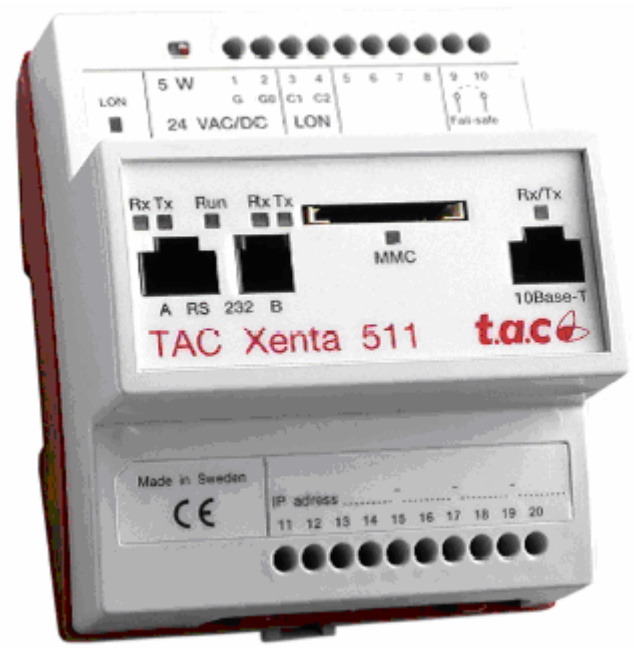

Figura 31 - Módulo Xenta 511 (Fonte: TAC (2003))

\subsubsection{Terminador TP/FT - 10}

A exemplo de outros tipos de redes baseada em par trançado, a rede LonWorks ${ }^{\circledR}$ requer um dispositivo resistivo-capacitivo denominado terminador que deve ser colocado em pontos convenientes dos cabos para evitar reflexões e 
interferências, possibilitando um meio de comunicação de boa qualidade (Figura 32). Ele pode ser usado tanto para redes baseadas na topologia livre (free topology) quanto na topologia em barramento (bus topology), citadas no Capítulo 4, e deve ser colocado em posições específicas dependendo da topologia utilizada. Neste trabalho utilizou-se a topologia livre, que permite a colocação do terminador em qualquer ponto do cabo. O local escolhido foi uma das extremidades da rede.

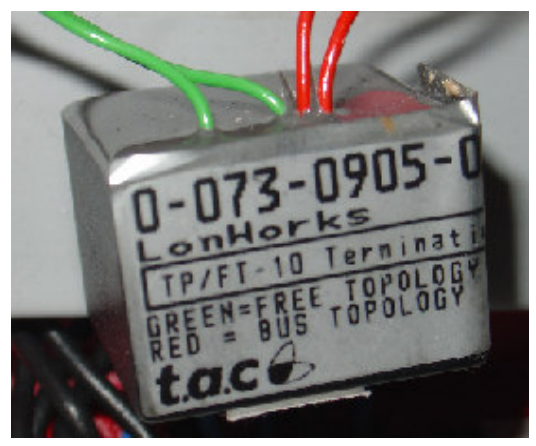

Figura 32 - Terminador TP/FT -10 utilizado na montagem da rede LonWorks $®$

\subsection{Programação}

\subsubsection{Programas de desenvolvimento e configurações básicas}

A programação dos módulos de fabricação TAC utilizados e configuração da rede LonWorks ${ }^{\circledR}$ foram feitas utilizando-se as ferramentas de desenvolvimento fornecidas pela TAC:

- Menta, versão 4.10 - 77: é uma ferramenta gráfica baseada em blocos funcionais utilizada para a programação dos módulos. Nela escolhe-se o módulo a ser programado e os dispositivos de expansão de entrada e saída, se existirem. Deve ser feito um projeto para cada módulo a ser programado (TAC, 2001b; TAC, 2004);

- Vista Explorer, versão 4.10 - 77: é uma ferramenta de criação e mautenção de redes Lonworks®. Através desta ferramenta é 
possível se fazer a criação, inclusão de novos nós, (tanto nós de fabricação TAC como de outros fabricantes) e gerenciamento e monitoração de uma rede LonWoks ${ }^{\circledR}$ (TAC, 2001d).

- Vista Server, versão 4.10 - 77: módulo servidor do pacote Vista. Gerencia a base de informações da rede LonWorks ${ }^{\circledR}$. Esta base possui as informações da rede, nós, endereços e programas (TAC, 2001d).

- Xbuilder, versão 1.1: ferramenta de programação para o módulo Xenta 511. Utilizada para a criação de aplicações constituídas de páginas HTML a serem disponibilizadas no módulo Xenta 511 . Permite também o envio da aplicação para o módulo e configuração de logs de arquivos. As funcionalidades desta ferramenta são descritas em maiores detalhes no item 5.4.4.1 (TAC, 2003a, 2003b).

Para a utilização do Menta, do Vista Explorer e do Xbuilder deve-se primeiramente executar o aplicativo TAC Vista Server. O microcomputador utilizado para o desenvolvimento deste trabalho foi um microcomputador pessoal PC (Personal Computer) com processador Atlhon da AMD, com freqüência de clock de 1,1 GHz, memória RAM (Random Access Memory) principal de 256 Mbytes, disco rígido com capacidade de 40 Gbytes, unidade de floppy disk de 3 1/2”, unidade de CD-ROM (Compact Disc - Read Only Memory), placa de rede 10 Mbps. Nessa plataforma foi instalado o sistema operacional Windows 2000 Professional Service Pack 5.

Inicialmente, montou-se fisicamente a rede LonWorks ${ }^{\circledR}$, conectando-se os módulos programáveis Xenta 302, o módulo Xenta 452 e o módulo servidor Web/LTA Xenta 511, alimentando-os com uma fonte 24 VDC. Através do canal de comunicação EIA RS232C do módulo Xenta 511 e do programa emulador de terminal Hyperterminal do Windows 2000, configuraram-se os parâmetros de rede para que esse módulo pudesse ser acessado pela rede do laboratório. 


\subsubsection{Criação da rede LonWorks ${ }^{\circledR}$}

Através do software Vista Explorer criou-se a rede LonWorks®. Este software requer a criação de um projeto do software de aplicação, que envolve a programação de todos os módulos da TAC presentes na rede: Xenta 302, Xenta 452 e Xenta 511. Informa-se que o componente Xenta 511 será usado como porta de comunicação para a rede LonWorks®. Para cada módulo incluído na rede aciona-se seu pino de serviço, que difunde uma mensagem na rede com o seu código de identificação (Neuron ID, exclusivo de cada nó). No Vista Explorer existem opções pré-configuradas para a utilização dos módulos TAC; porém é possível utilizar esse aplicativo para incluir componentes de outros fabricantes.

O Vista Explorer possibilita que seja realizada a etapa de comissionamento e carga dos programas nos módulos, que consiste na verificação do funcionamento do módulo e armazenamento do programa na memória do módulo. Para isso, indica-se para cada módulo programável qual o seu projeto, desenvolvido através do Menta, envolvendo a programação a ser feita.

A programação é feita através de uma linguagem gráfica, baseada em blocos funcionais, Function Block Diagram (FBD). Esse tipo de linguagem facilita a visualização e identificação do fluxo do procedimento de controle. Isso facilita o desenvolvimento do projeto, programação, depuração e manutenção, além de auxiliar na redução de erros (MIYAGI, 1996). Neste tipo de programação, os blocos funcionais processam os sinais de entrada para gerar um único sinal de saída. O sinal de saída é transportado para outros blocos, seguindo o caminho definido pelas conexões, que representam o fluxo de dados, da esquerda para direita, durante a execução do programa (Figura 33) (TAC, 2004). Os blocos podem possuir entradas e saídas (digitais ou analógicas) ou variáveis de rede. Assim, cada entrada do bloco pode ser associada a entradas físicas dos módulos ou a variáveis de rede. Essa informação pode ser processada ou submetida a transformações (por exemplo, 
através da realização de cálculos com o seu valor) ou caso seja uma informação booleana, pode ser utilizada em algum bloco que utilize informação dessa natureza (por exemplo, blocos de saída que também podem ser associados a saídas físicas dos módulos ou a variáveis de rede).

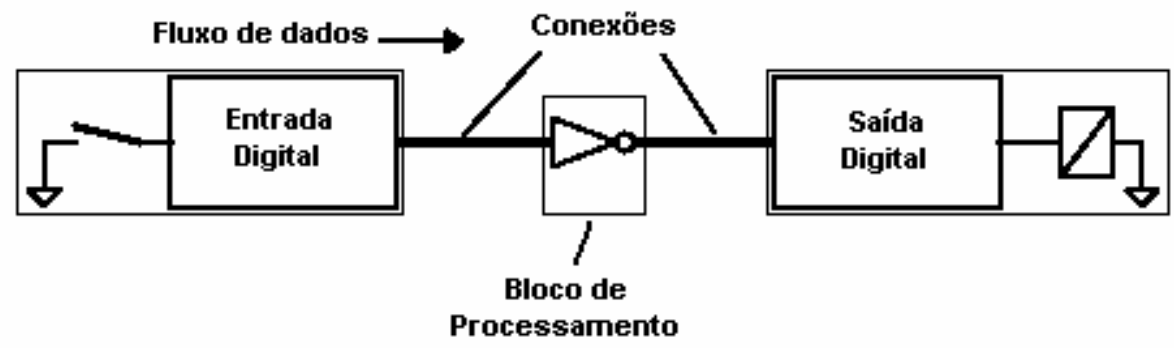

Figura 33 - Fluxo de processamento utilizado na ferramenta Menta. (Baseado em TAC, (2004))

Vale destacar que existe uma grande gama de blocos funcionais complexos como controles PID, gerador de pulsos e construtor de expressões. Uma vez finalizada a programação do módulo, é gerado um arquivo com extensão .mta, que é usado no Vista Explorer para gerar e transferir o código para respectivo módulo.

\subsubsection{Inclusão dos nós Nose e PIC-LON na rede LonWorks ${ }^{\circledR}$}

Para a inclusão de nós de vários fabricantes deve-se utilizar o aplicativo Vista Explorer, definindo-se um grupo para dispositivos de fabricação TAC, o TAC Xenta Group, e outro para os demais, denominado LonWorks® Group. A seguir deve-se criar cada novo dispositivo da rede. Para isso é necessário se obter a identificação do dispositivo (Neuron ID) e o arquivo XIF (External Interface Files). O Neuron ID geralmente está identificado no dispositivo ou pode ser utilizado o pino de serviço para a sua obtenção (conforme já mencionado anteriormente). O Neuron ID é sempre fornecido quando se adquire um Neuron Chip ou um dispositivo que o contenha. $\mathrm{O}$ arquivo XIF contém descrições padronizadas de todas as variáveis de rede e objetos do programa aplicativo, que permitem a ligação e comunicação com nós de outros fornecedores. Ele deve ser fornecido juntamente com o produto. Tanto no caso do dispositivo NOSE quanto do PIC-LON, por comodidade foi utilizado o 
pino de serviço para a obtenção dos respectivos Neuron IDs . Com relação aos arquivos XIF, para o NOSE ele pode ser encontrado no site do fabricante (NOSE, 2003). No caso do módulo PIC-LON, desenvolvido no LAA, o respectivo arquivo XIF foi gerado pelo software de desenvolvimento de nós chamado NodeBuilder (ECHELON, 1995b) durante o processo de elaboração desse nó.

Uma vez executado este procedimento, os dois novos nós, NOSE e PICLON, passam a estar configurados para operar na rede LonWorks ${ }^{\circledR}$ e suas informações (variáveis de rede e objetos) podem ser utilizadas para monitoramento ou como entradas de outros módulos.

\subsubsection{Tratamentos de sinais e cálculos implementados}

Apresentam-se, a seguir, os módulos de programa desenvolvidos para o sistema experimental.

\subsubsection{Tratamento das medidas de temperatura e umidade}

Com o objetivo de transformar os dados analógicos dos sensores de temperatura e umidade em valores de temperatura em graus celsius e percentual de umidade relativa, foram feitos dois tratamentos: a) adequação da grandeza a ser medida em tensões de 0 a $10 \mathrm{~V}$ b) transformação dessas tensões nas grandezas temperatura e umidade relativa através das equações características dos sensores. (Isso pode ser visto com mais detalhes no Apêndice A). Para isso, essas equações foram introduzidas em um bloco funcional do projeto do módulo 302 desenvolvido com o software Menta, gerando em sua saída os valores adequados para as grandezas medidas. A Figura 34 mostra os blocos funcionais utilizados para tratamento do valor de temperatura lido pelo sensor PT100_3. 


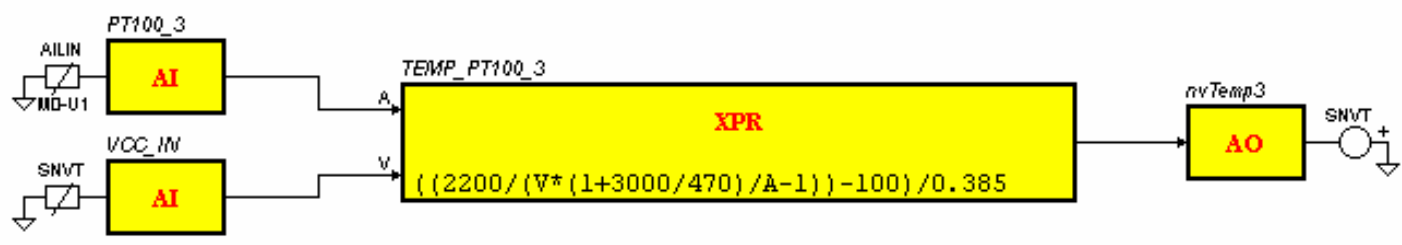

Figura 34 - Blocos funcionais usados para tratamento dos valores de temperatura do sensor PT100_3

O cálculo é feito levando-se em consideração os valores de tensão da fonte de alimentação (VCC) e da saída do circuito condicionador de sinais para o PT100_3. Neste caso, o valor de VCC é obtido através da variável de rede de entrada chamada nviVCC. Como saída é gerada uma variável de rede chamada nvoTemp3. A Figura 35 mostra os blocos funcionais utilizados no aplicativo Menta para tratamento do valor de umidade lido pelo sensor EWHS_1. Neste caso, como saída é gerada uma variável de rede chamada nvoUmid1.

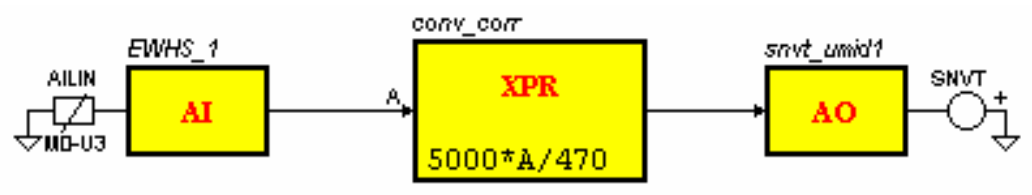

Figura 35 - Blocos funcionais usados para tratamento dos valores de umidade do sensor EWHS_1

\subsubsection{Média das temperaturas}

Com o objetivo de distribuir carga de processamento entre os dois nós programáveis e verificar o funcionamento das variáveis de rede, foi implementado em cada módulo o cálculo da média de temperaturas. Para o módulo 302_1 é gerada uma média entre as temperaturas dos sensores PT100_3, PT100_4 e PIC_LON (Figura 36). As três temperaturas são obtidas através das seguintes variáveis de rede: nviTemp3, nviTemp4 e nviTempPICLON. Como saída é gerada uma outra variável de rede chamada nvoAVGTemp302_1, que contém a média aritmética das temperaturas de entrada. Para o módulo 302_2 é gerada uma média entre as temperaturas dos sensores PT100_1, PT100_2 e NOSE (Figura 37). As três temperaturas são obtidas através das seguintes variáveis de rede: nviTemp1, nviTemp2 e nviHAVCTemp. Como saída é gerada uma outra variável de rede 
chamada nvoAVGTemp302_2 que contém a média aritmética das temperaturas de entrada.

Dessa forma, os módulos programáveis calculam médias de temperatura de valores que não são tratados no respectivo módulo, utilizando para isso a comunicação por meio das variáveis de rede.

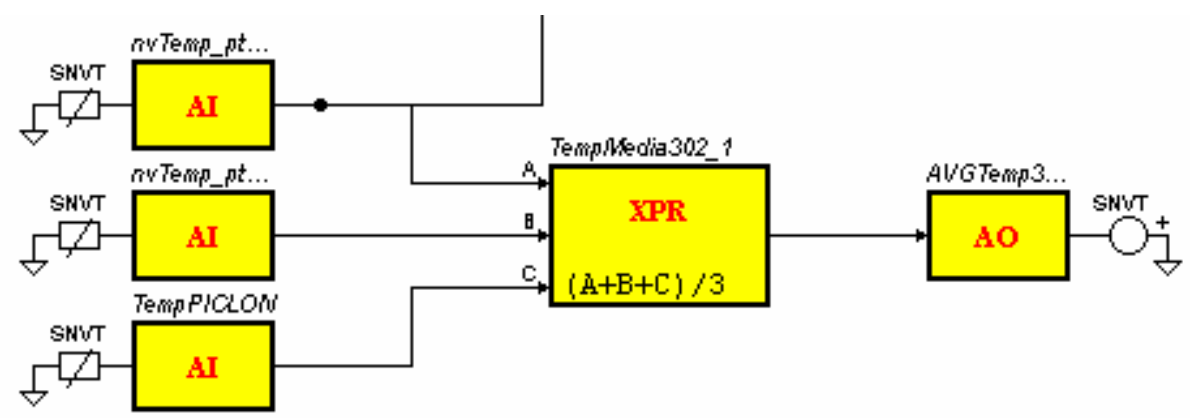

Figura 36 - Blocos funcionais usados para cálculo da média de temperatura dos sensores PT100_3, PT100_4, e PIC-LON utilizadas no módulo programável 302_1

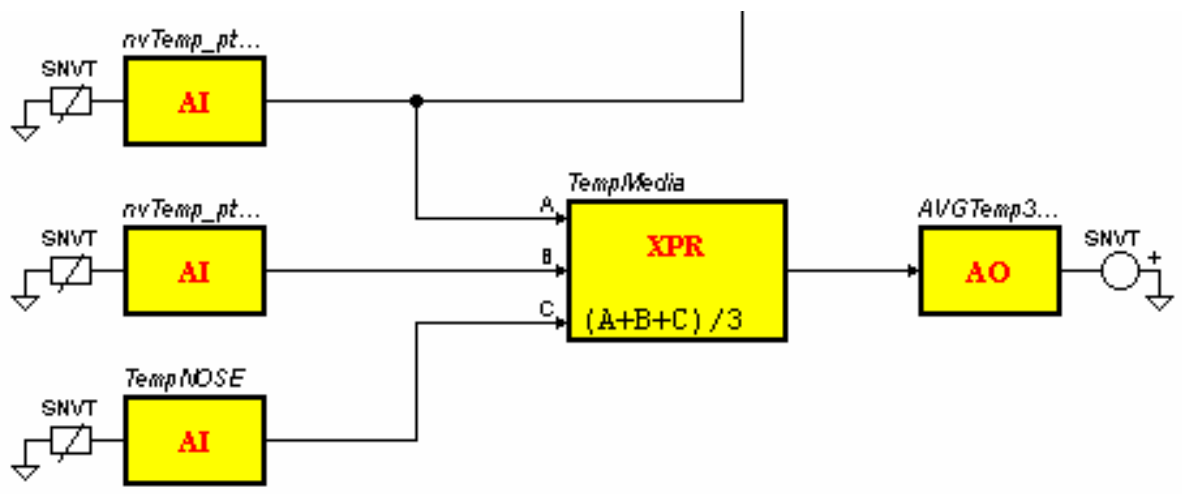

Figura 37 - Blocos funcionais usados para cálculo da média de temperatura dos sensores PT100_1, PT100_2, e NOSE utilizadas no módulo programável 302_2

\subsubsection{Controle dos ventiladores}

Com o intuito de utilizar o conceito de inteligência distribuída, o controle dos dois ventiladores foi dividido da seguinte forma: cada ventilador foi comandado por um nó Xenta 302. O ventilador 1 é comandado pelo módulo 302_1 e pela 
temperatura PT100_3 que está sendo gerada pelo módulo 302_2 e o ventilador 2 está sendo comandado pelo módulo 302_2 e pela temperatura PT100_1 que está sendo gerada pelo módulo 302_1. Desta forma pode-se verificar o funcionamento da distribuição de inteligência entre os atuadores e os sensores e aspectos de comunicação entre os módulos através de variáveis de rede (network variables).

Neste trabalho foi implementado o algoritmo de controle de temperatura baseado em dois limites de temperatura (two-step). O funcionamento do algoritmo é o seguinte: quando a temperatura atinge o valor do limite máximo (setpoint superior), o ventilador é acionado. O ventilador é então desligado apenas quando o valor da temperatura atingir o limite mínimo de temperatura (setpoint inferior). O ventilador só voltará a ser ligado caso a temperatura atingir novamente o setpoint superior. $\mathrm{Na}$ Figura 38 pode-se observar o comportamento deste algoritmo (o setpoint inferior foi fixado em $22{ }^{\circ} \mathrm{C}$ e o superior em $28^{\circ} \mathrm{C}$ ).

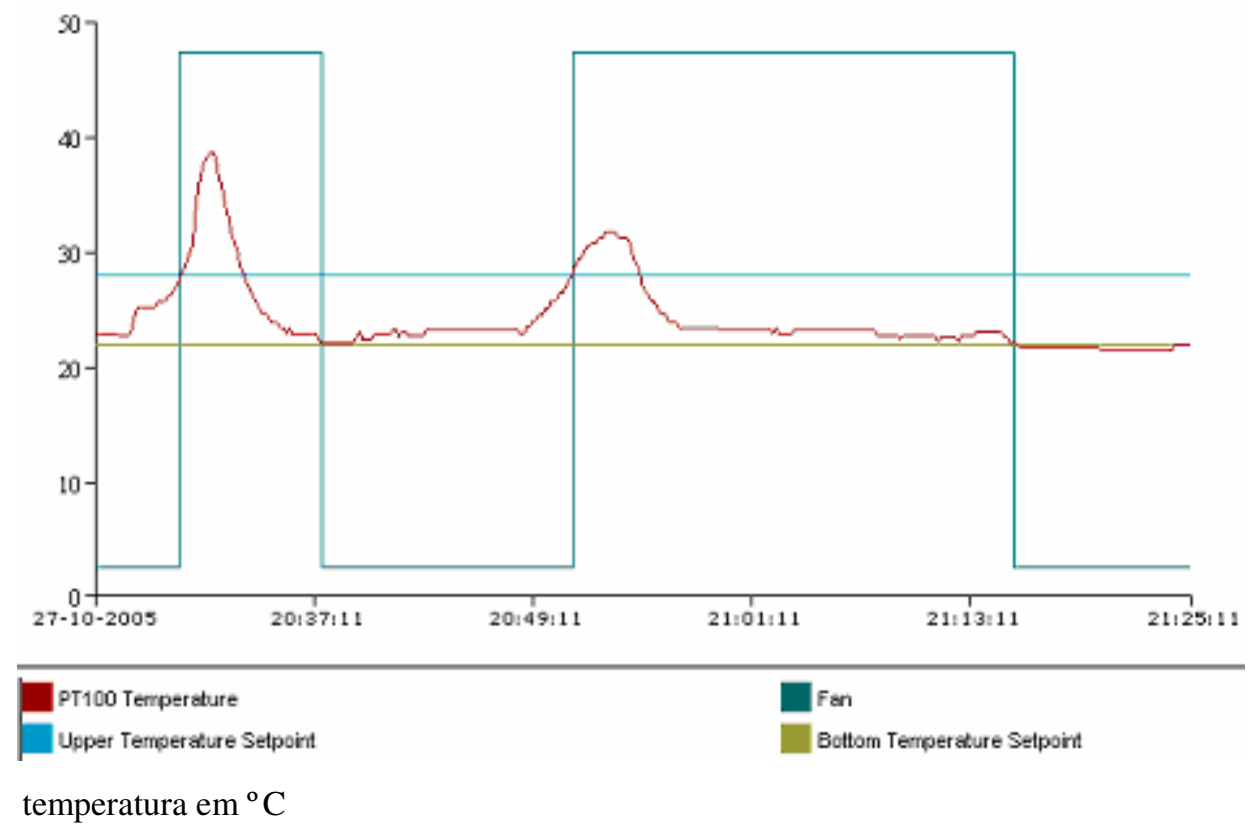

Figura 38 - Gráfico exemplificando o funcionamento do algoritmo two-step

Para a implementação deste algoritmo utilizou-se o bloco funcional da ferramenta Menta chamado Hyst. Na Figura 39 é possível visualizar o comportamento da saída em função da entrada do bloco. Existem dois atributos do 
bloco (Activate e Deactivate) que controlam quando a saída deve valer 1 ou 0 . Percebe-se que esse comportamento implementa o algoritmo exposto acima se for estipulado o valor do atributo Activate como sendo o ponto de controle superior (setpoint superior) e Deactivate como sendo o ponto de controle inferior (setpoint inferior). Foi utilizado o valor do sensor de temperatura PT100_3 para acionar o ventilador 1 e o valor do sensor de temperatura PT100_1 para acionar o ventilador 2.

A Figura 40 mostra os blocos funcionais utilizados para o controle do ventilador 1.

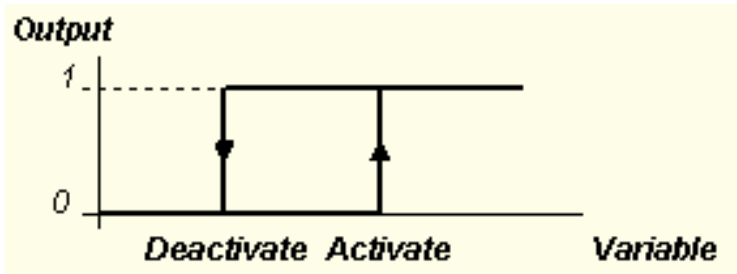

Figura 39 - Gráfico da saída em função dos valores de referência para o bloco HYST. Fonte: arquivo de ajuda da ferramenta Menta

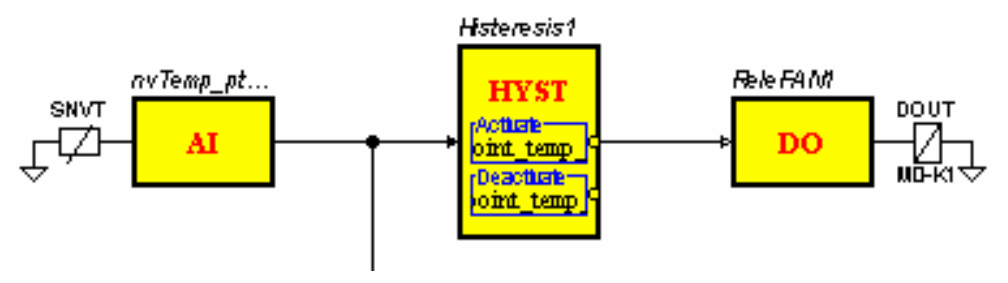

Figura 40 - Blocos funcionais usados para acionamento do ventilador 1 utilizando o algoritmo two-step

\subsubsection{Binding}

Para que possa haver a troca de informações entre os nós através de variáveis de rede deve-se executar o processo de binding. Neste processo, liga-se a variável de rede de saída de um nó às variáveis de rede de entrada dos nós que a utilizam, conforme descrito no Capítulo 4. Por exemplo, no presente caso, deve-se ligar a variável de rede de saída nvoTemp3 do módulo 302_2 à variável de rede de entrada nviTemp3 do módulo 302_1. Para se executar esse processo, utiliza-se a ferramenta de gerenciamento de redes LonMaker Integration Tool. (ECHELON, 2001). Por praticidade, utilizou-se um objeto conexão disponível na ferramenta TAC Xbuilder 1.1. Esse objeto faz com o módulo Xenta 511 se encarregue de obter a 
informação do nó origem e enviá-la ao nó destino. A diferença dessa forma de implementação e do binding utilizando a ferramenta LonMaker reside no fato de que no primeiro caso, a obtenção de informação da origem e envio para todos os destinos fica a cargo do Xenta 511, enquanto que no segundo caso, cada nó se encarrega de enviar a informação aos nós destinos. Como se trata de uma rede pequena com poucas variáveis de rede, a implementação através do binding tem efeito semelhante da realizada através do LonMaker. A

Figura 41 mostra os nós da rede implementada com as ligações entre as variáveis de rede.

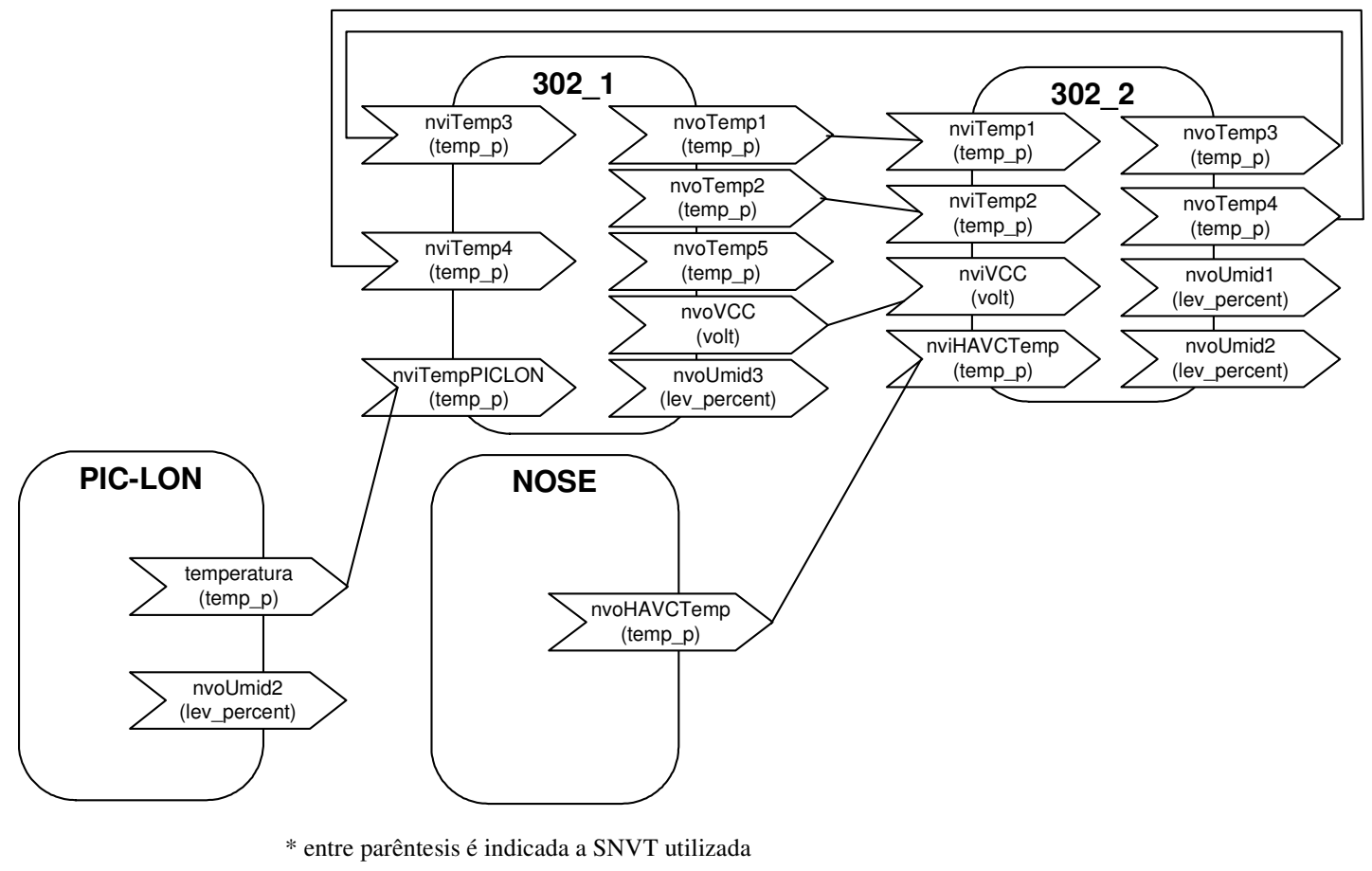

Figura 41 - Nós LonWorks® ${ }^{\circledR}$ com as ligações entre as suas variáveis de rede

\subsubsection{Páginas desenvolvidas}

\subsubsection{Site Web para monitoramento e controle}

A construção das páginas para o Web site residente no módulo Xenta 511 foi feita utilizando-se a ferramenta Xbuilder. Este aplicativo permite a confecção e o 
envio das páginas de controle e monitoração da rede LonWorks® para o módulo Xenta 511. Para o acesso às páginas do módulo através de aplicativos de navegação é necessária a instalação do Plug-in Java 1.4.2.

O Xbuilder disponibiliza para a utilização quatro tipos de páginas:

- Página Gráfica: criada através da ferramenta TAC Graphics Editor e importadas para o projeto feito com o Xbuilder. Ela permite a exibição de dados através de gráficos dinâmicos, como por exemplo, termômetros. Através deste tipo de página é possível alterar parâmetros e executar acionamentos remotamente.

- Páginas de Valores: mostram na forma de tabela dinâmica os valores das medidas. Permitem a alteração de dados e acionamentos remotos. Pode-se, por exemplo, através deste tipo de página alterar o estado de um relé que aciona um ventilador.

- Páginas de Históricos: possuem três partes, incluindo: uma poderosa ferramenta gráfica que permite explorar com bastante facilidade os dados mostrados, tabelas com os dados históricos e tela para alteração das configurações do gráfico. Os dados históricos mostrados neste tipo de página são armazenados no módulo Xenta 511. Existe uma limitação de no máximo 100.000 valores armazenados no total. No armazenamento dos dados históricos existem três informações que devem ser configuradas para cada medida armazenada: o tempo de retenção da informação, o tempo mínimo entre coletas e a variação mínima que deve ter a medida em relação ao último dado coletado para que haja uma nova coleta (delta). Foi utilizado para todas as medidas armazenadas, o valor de 30 segundos como tempo mínimo entre as coletas. O valor de delta utilizado variou de 0,3 para as medidas de temperatura, e 1 para umidade e entradas e saídas digitais. O período de retenção utilizado foi de uma semana.

- Páginas geradas pelo usuário: não foi usado esse tipo de página. 
As páginas são acessadas mediante um sistema de autenticação. É possível criar perfis de usuários e limitar seu acesso às informações do site.

\subsubsection{Páginas criadas}

Foram criadas páginas que permitem o monitoramento, alteração de setpoint e operação manual dos atuadores. Podem-se também exportar os dados coletados para outros programas, como o Microsoft Excel, para que eles possam ser manipulados e analisados de acordo com a necessidade.

\section{- Página inicial}

A página inicial apresenta os valores das temperaturas dos sensores PT100_1, PT100_2 e NOSE. Mostra a umidade do sensor EWHS_1 (umidade interna) e a indicação de abertura da porta e funcionamento dos dois ventiladores, além dos valores de setpoint utilizados (Figura 42).

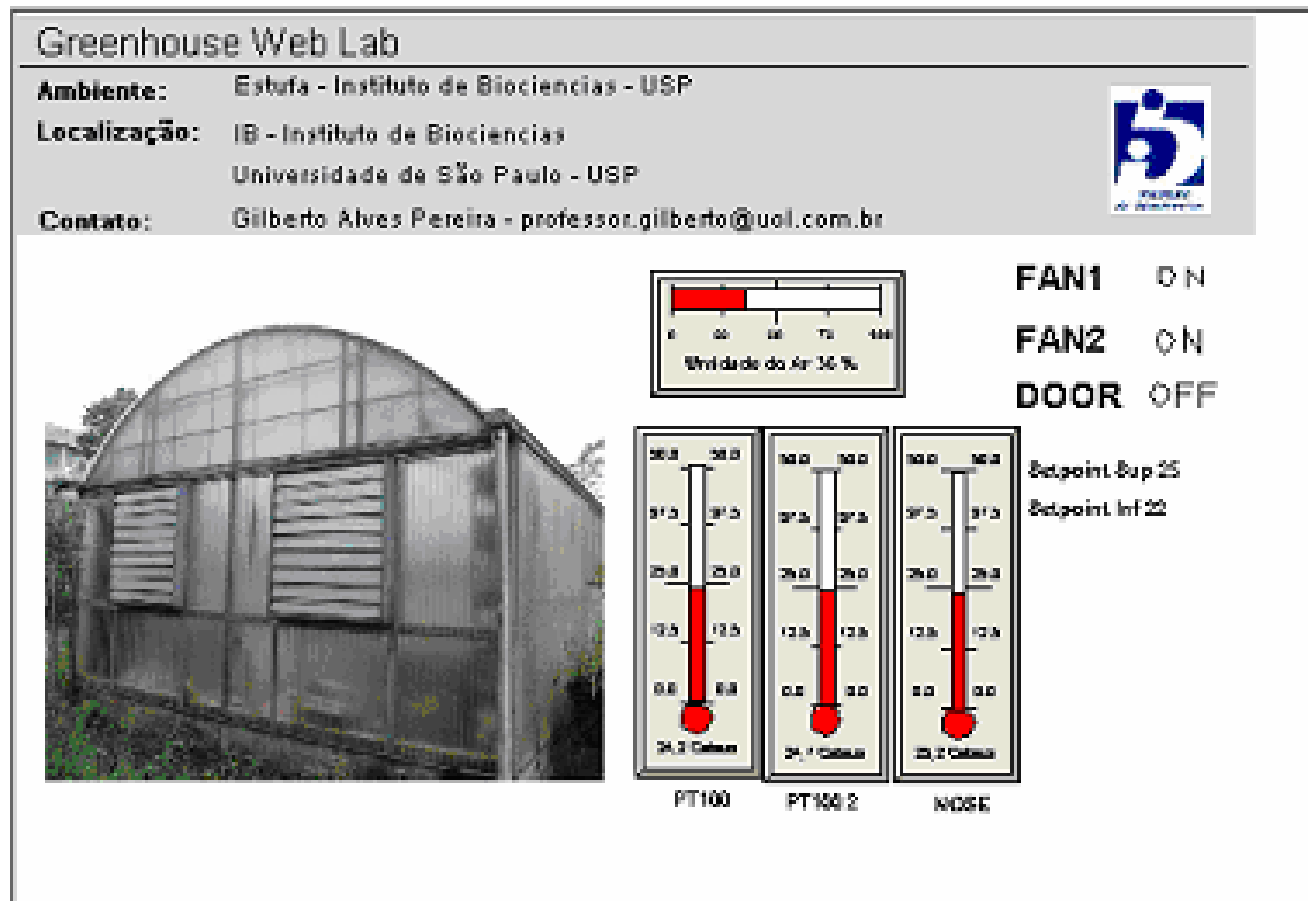

Figura 42 - Sistema de monitoramento e controle - página inicial 
- Página de Monitoramento das Temperaturas

Através dessa página é possível verificar o comportamento histórico de todas as temperaturas do sistema PT100_1, PT100_2, PT100_3, PT100_4, PT100_5 (temperatura externa), Temperatura NOSE e Temperatura PIC-LON. (Figura 43).

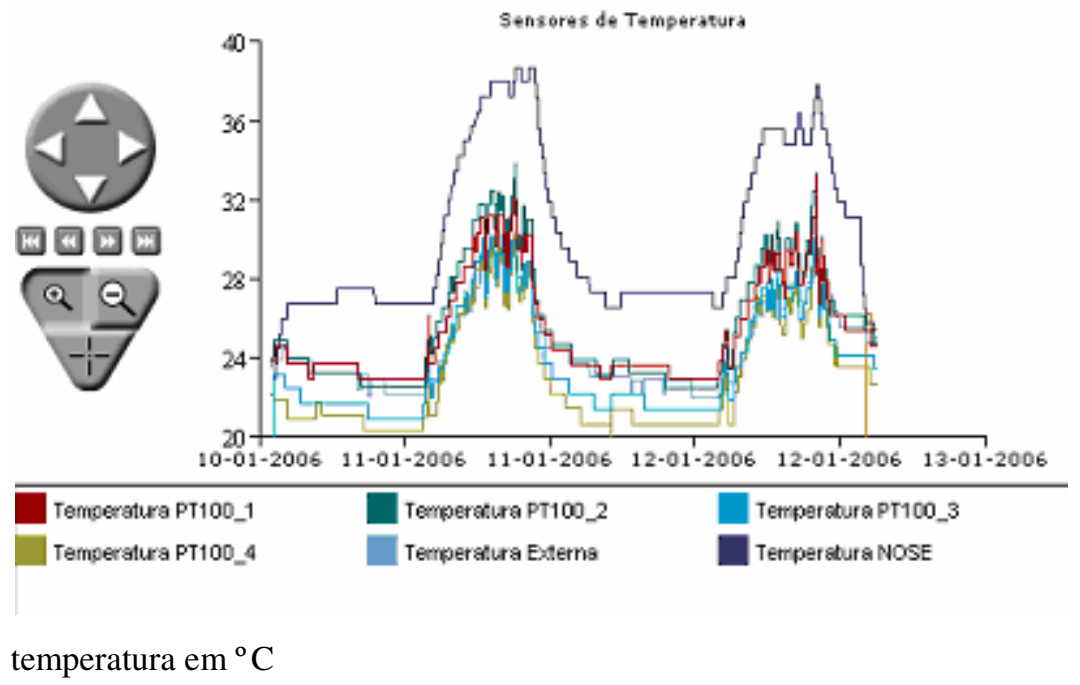

Figura 43 - Página de monitoramento das temperaturas

- Página de Monitoramento das Umidades

Através dessa página é possível verificar o comportamento histórico de todas as medidas de umidade relativa do sistema EHWS_1 (umidade interna) e EHWS_2 (umidade externa). (Figura 44). 


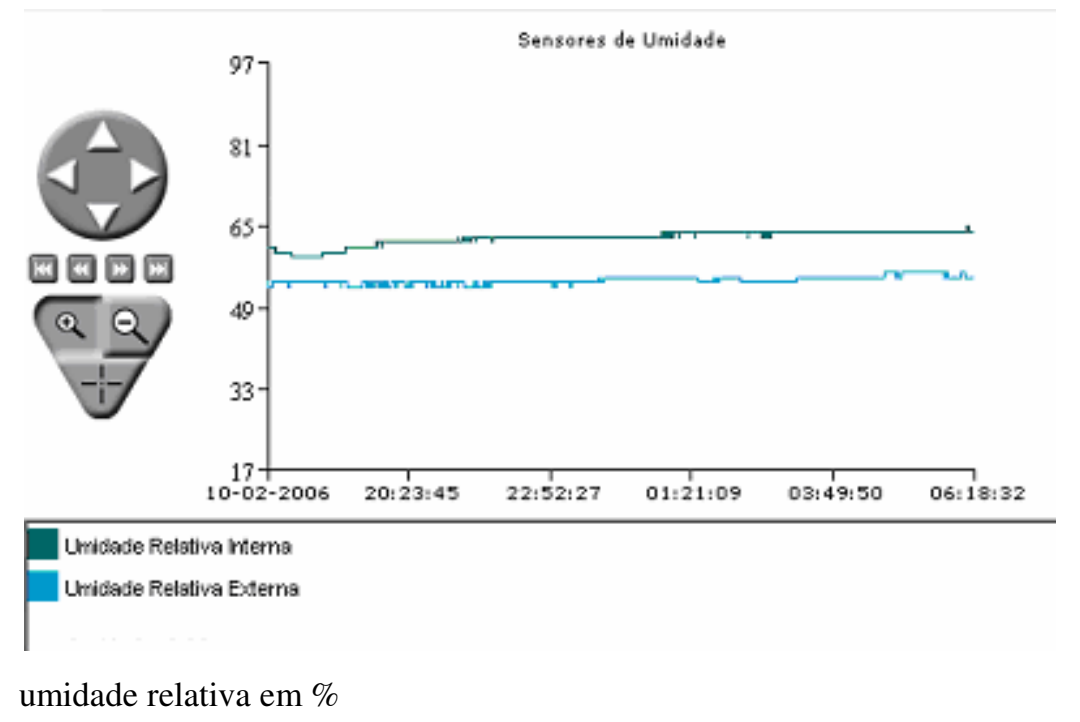

Figura 44 - Página de monitoramento da umidade relativa

\section{- Página de Monitoramento do Controle do Ventilador 1}

Esta página permite observar o correto funcionamento da ativação e desativação do Ventilador 1. Nela são mostrados os setpoints máximo e mínimo, a temperatura do sensor PT100_3, o estado do relé de acionamento do ventilador e o estado do contator do Ventilador 1. Os valores dos estados do relé e do contator são representados como ondas quadradas, sendo que para o estado do relé o nível 0 representa desligado e o nível 1 representa ligado. Já para o contator, o nível lógico 0 representa ligado e 1 representa desligado. Através desta página pode-se verificar facilmente o comportamento esperado para o controle: quando a temperatura atinge o setpoint superior o relé deve ser acionado (nível 1) e, caso o ventilador esteja funcionando o estado do contator deve ficar em zero. Quando a temperatura atinge o valor do setpoint inferior, o relé de acionamento do ventilador deve ser desativado (nível 0) e o estado do contator deve ficar em nível 1 (Figura 45). 


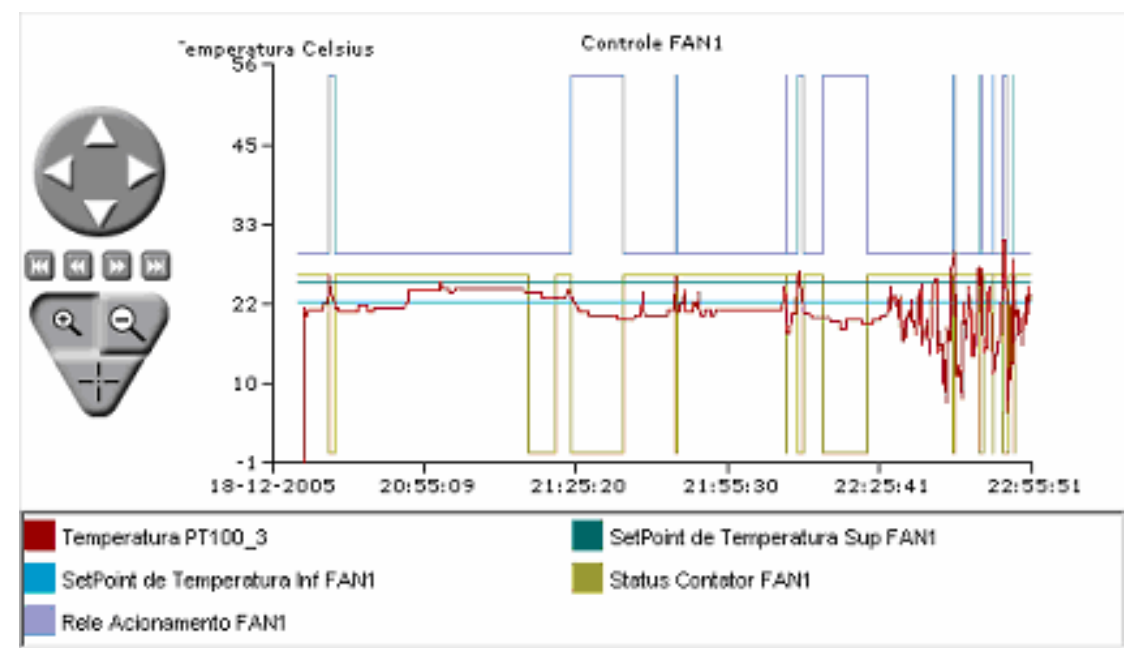

Figura 45 - Página de monitoramento do controle do ventilador 1

- Página de Monitoramento do Controle do Ventilador 2

Esta página permite observar o correto funcionamento da ativação e desativação do Ventilador 2. Nela são mostrados os setpoints máximo e mínimo, a temperatura do sensor PT100_1, o status do relé de acionamento do ventilador e o status do contator do ventilador 2. Seu comportamento segue o mesmo descrito para o Ventilador 1 (Figura 46).

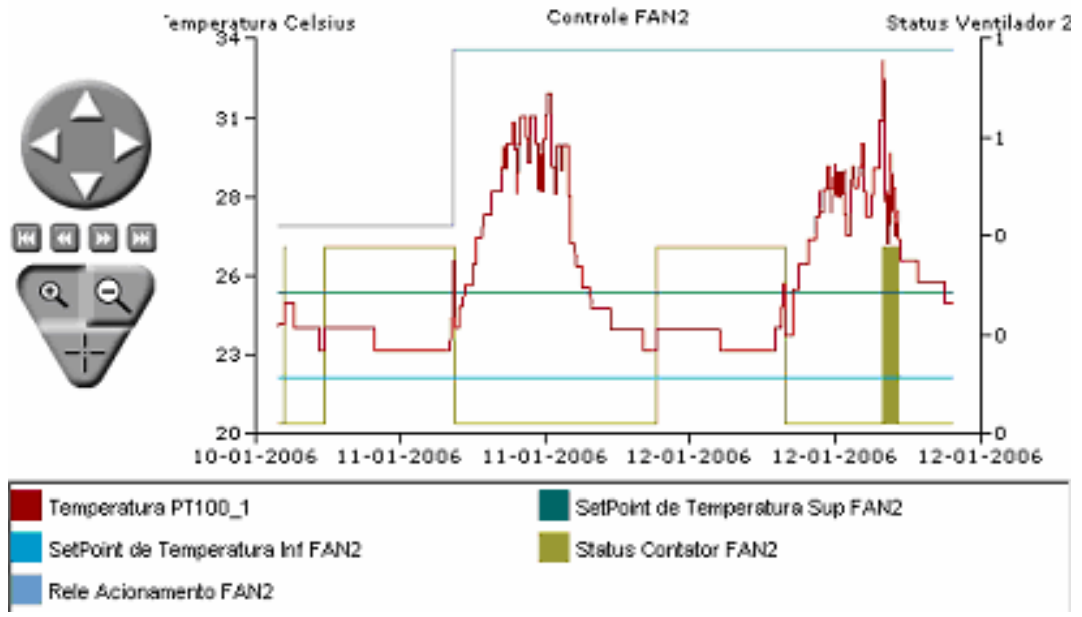

Figura 46 - Página de monitoramento do controle do ventilador 2 


\section{- Página de Monitoramento da Temperatura Média}

Foram criadas duas páginas, uma mostrando a temperatura média calculada pelo módulo 302_1 e outra página mostrando a temperatura média calculada pelo módulo 302_2 Elas permitem verificar o comportamento da temperatura média calculada pelos módulos 302_1 e 302_2, e seu objetivo é validar a aplicação das variáveis de rede (Figura 47).

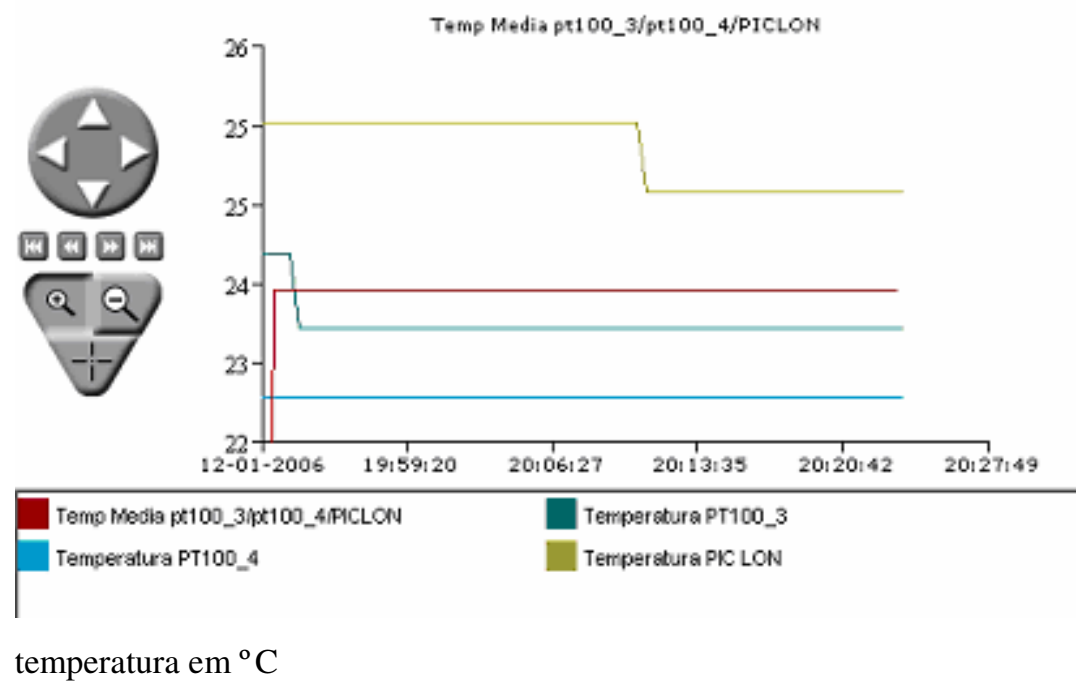

Figura 47 - Página de monitoramento de temperatura média

\section{- Página de Monitoramento do Estado dos Atuadores e Porta}

Esta tela mostra o estado dos seguintes elementos: Contator do Ventilador 1, Contator do Ventilador 2, Lâmpadas de Controle do Fotoperíodo, Bomba de Irrigação, Bomba PAD e Porta. O nível zero indica que a porta está aberta e os atuadores estão ligados. É possível, por exemplo, verificar quando a porta da casa de vegetação foi aberta, indicando a presença de pessoas nesses horários (Figura 48). 


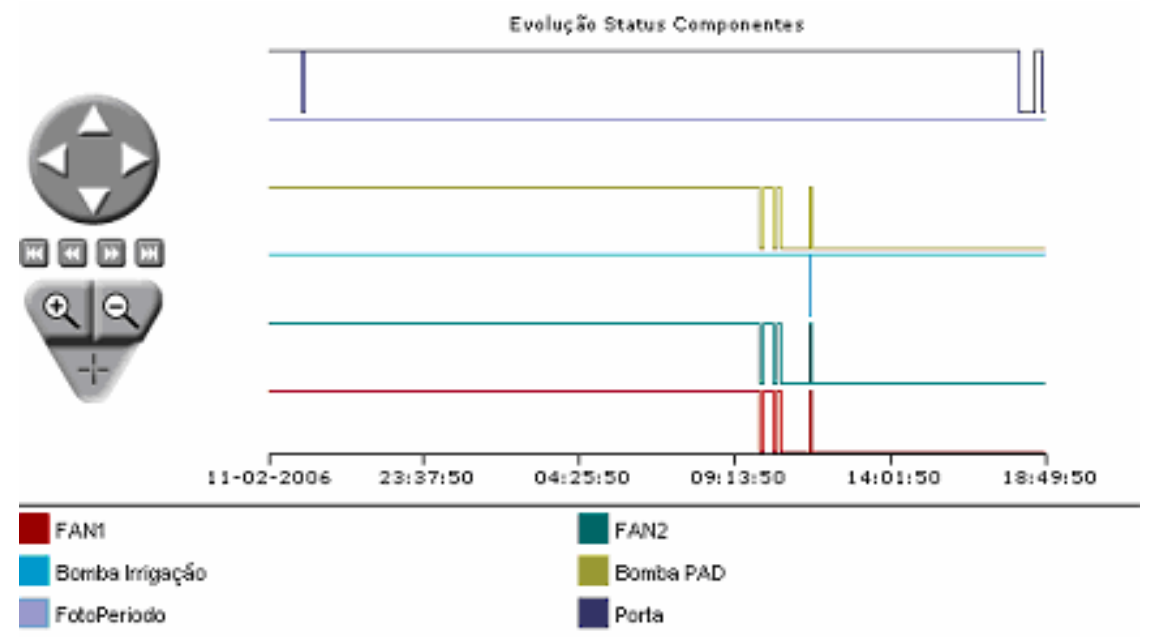

Figura 48 - Página de monitoramento do estado dos atuadores e porta

- Página de Monitoramento das Medidas

Esta página mostra uma tabela os valores das temperaturas (inclusive das médias), umidades, valores de setpoints e da voltagem da fonte de alimentação (Figura 49).

\begin{tabular}{|c|c|c|}
\hline Name & Value & Unit \\
\hline Temp PT100_1 & 23,52 & c \\
\hline Temp PT100_2 & 23,83 & c \\
\hline Temp PT100_3 & 21,56 & $\mathrm{C}$ \\
\hline Temp PT100_4 & 20,55 & C \\
\hline Temp PT100_5 (Externa) & 22,11 & c \\
\hline Temperatura NOSE & 27,04 & c \\
\hline Temperstura PIC & 28,00 & $\mathrm{c}$ \\
\hline Temp Macia pt100_3knt100_... & 23,20 & C \\
\hline Temp Mbcia pt100_1 kt100_.. & 24,90 & c \\
\hline Unidade Irterna & 54 & $\%$ \\
\hline Urridade Externa & 55 & $\%$ \\
\hline Uridade PIC LON & 71,10 & $\%$ \\
\hline vec & 23,90 & $v$ \\
\hline Setpoint Superior & 25,00 & C \\
\hline Setpoint Inferior & 2200 & C \\
\hline
\end{tabular}

Figura 49 - Página de monitoramento das medidas

\section{- Página de Acionamento Manual dos Atuadores}

Este página permite o acionamento dos relés dos atuadores. Para tanto devem-se clicar na linha do atuador que se deseja alterar o estado e utilizar a opção "Force by operator". O valor 1 indica que o relé foi acionado. O valor zero indica sua desativação (Figura 50). 


\begin{tabular}{|c|c|c|}
\hline Name & Value & Unit \\
\hline FAN1 & & \\
\hline FAN2 & & \\
\hline Bomba lmigaç⿻ & & \\
\hline Bombs PAD & & \\
\hline FotoPeriodo & & \\
\hline
\end{tabular}

Figura 50 - Página de acionamento manual dos atuadores

\section{- Página de Alteração dos Setpoints}

Esta página permite a alteração dos valores dos setpoints máximo e mínimo. Os valores default são $22{ }^{\circ} \mathrm{C}$ e $25{ }^{\circ} \mathrm{C}$ para o inferior e superior respectivamente. Para alterá-los basta clicar no valor que se quer alterar e digitar o novo valor (Figura 51).

\begin{tabular}{|c|c|c|}
\hline Name & Value & Unt \\
\hline Setpoint Superior & 25,00 & C \\
\hline Setpoint Inferior & 22,00 & C \\
\hline
\end{tabular}

Figura 51 - Página de alteração dos setpoints

\subsection{Testes}

O objetivo dos testes realizados foi, além de verificar o correto funcionamento do sistema proposto e implementado, o levantamento de informações para a validação e comportamento dos cálculos envolvendo as variáveis de rede e a avaliação do mérito da solução proposta, comparativamente com soluções convencionais.

Os itens seguintes apresentam e comentam os principais testes realizados.

\subsubsection{Monitoramento}

O monitoramento da temperatura e umidade limitou-se à observação do comportamento dos valores no tempo. Para a temperatura percebe-se comportamento inverso, ou seja, aumento durante o dia e diminuição à noite (Figura 52). No caso da 
umidade, ocorreu diminuição nos períodos mais quentes do dia e aumento no período noturno (Figura 53). Atarassi (2000) relata comportamento semelhante em seu trabalho.

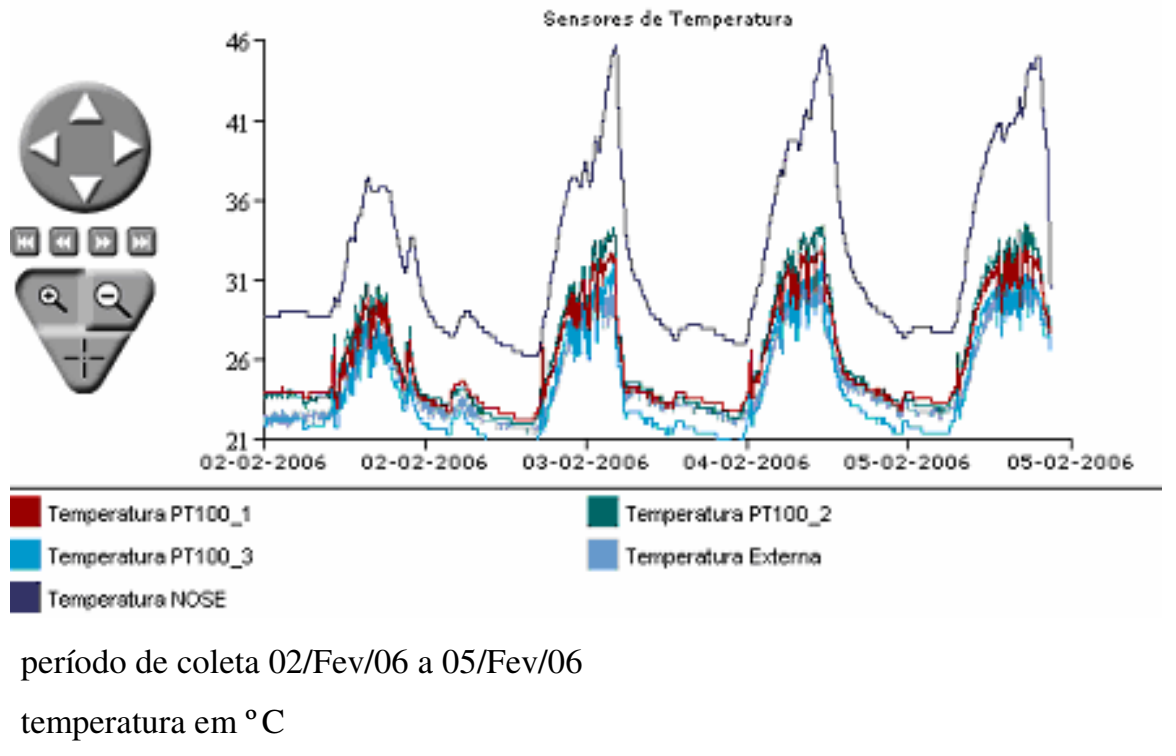

Figura 52 - Gráfico do comportamento da leitura das temperaturas

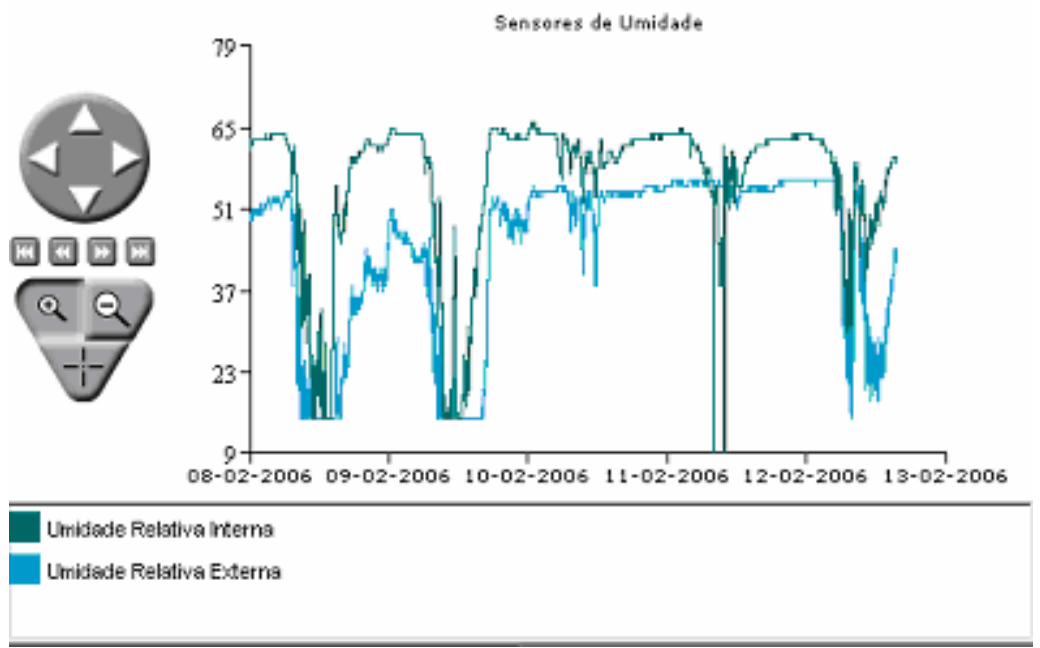

período de coleta $08 / \mathrm{Fev} / 06$ a 12/Fev/06

umidade relativa em \%

Figura 53 - Gráfico do comportamento da leitura da umidade 


\subsubsection{Controle manual dos atuadores}

O teste de controle manual dos acionadores foi feito utilizando-se a página desenvolvida para tal. Acionaram-se um a um os atuadores e verificou-se seu funcionamento. Não foi possível verificar o funcionamento da bomba Pad-Fan, uma vez que ela encontrava-se inoperante. No entanto verificou-se o acionamento correto do seu relé acionador. Foram acionados manualmente os relés de acionamento dos ventiladores, da bomba de irrigação, das lâmpadas, da bomba de Pad-Fan (Figura 54). Na Figura 55 pode-se verificar também o estado dos contatores durante o teste.

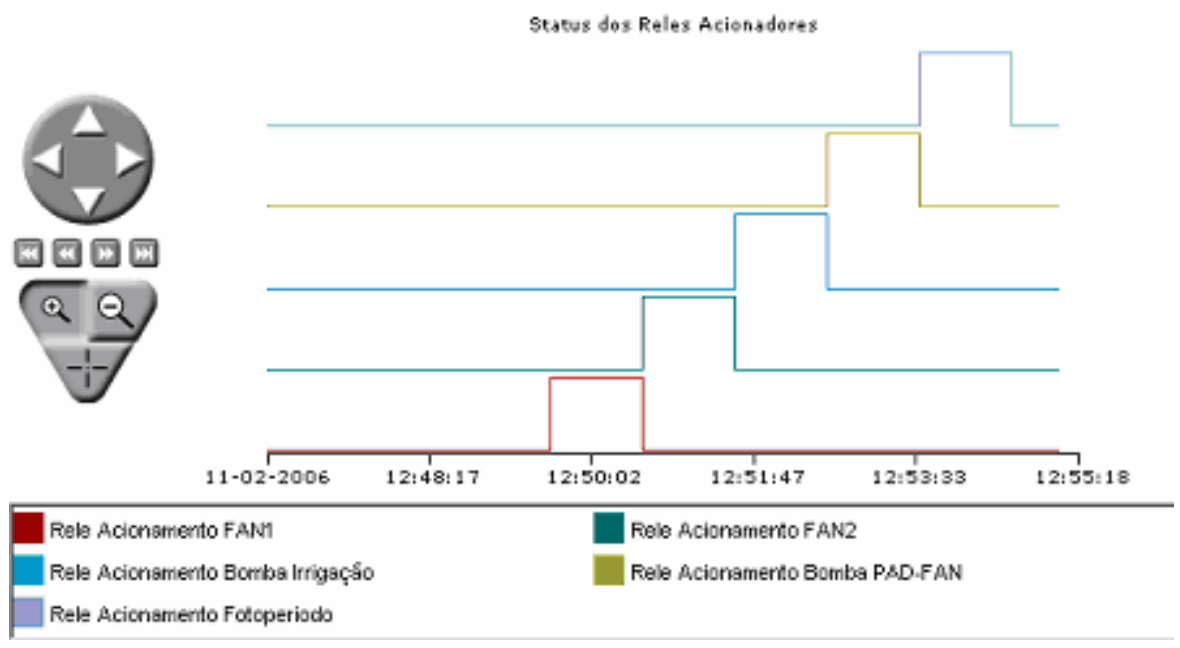

Figura 54 - Resultado do teste de acionamento dos relés

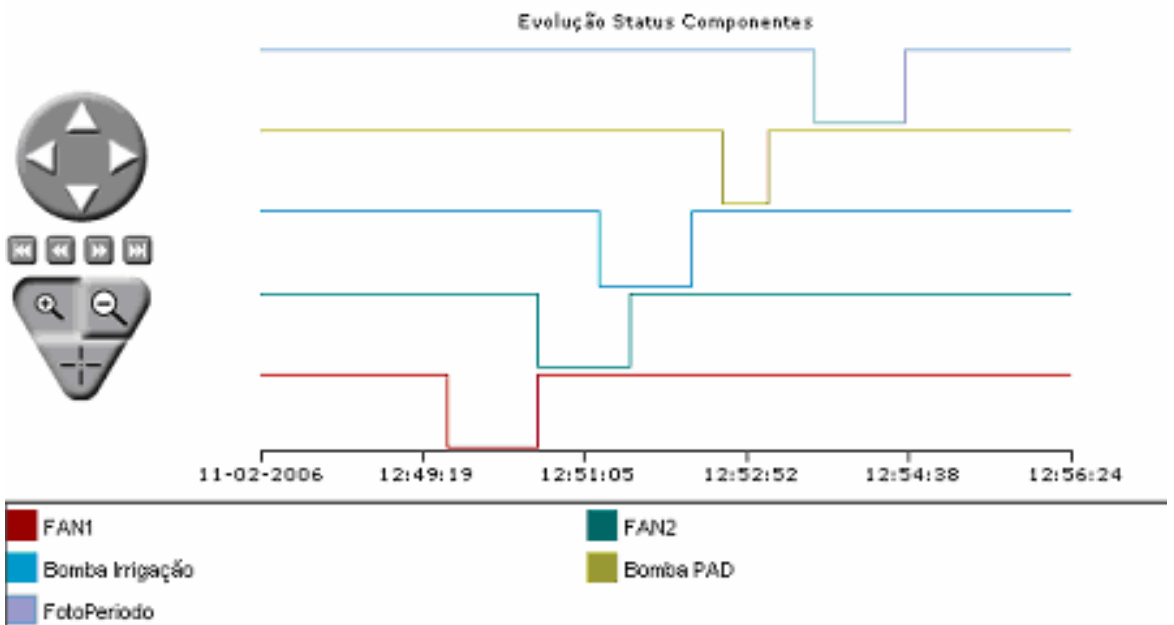

Figura 55 - Estado dos contatores dos atuadores e relé da iluminação durante acionamento dos relés 


\subsubsection{Controle automático}

Para a verificação do comportamento do algoritmo de controle implementado foi feita uma simulação na qual, através do aumento da temperatura dos sensores PT100_1 e PT100_3 pôde-se verificar que quando a temperatura atinge o valor do setpoint superior o ventilador é acionado e quando atinge o valor do setpoint inferior ocorre o seu desligamento, mostrando comportamento compatível com o algoritmo de controle utilizado (Figura 56 e Figura 57).

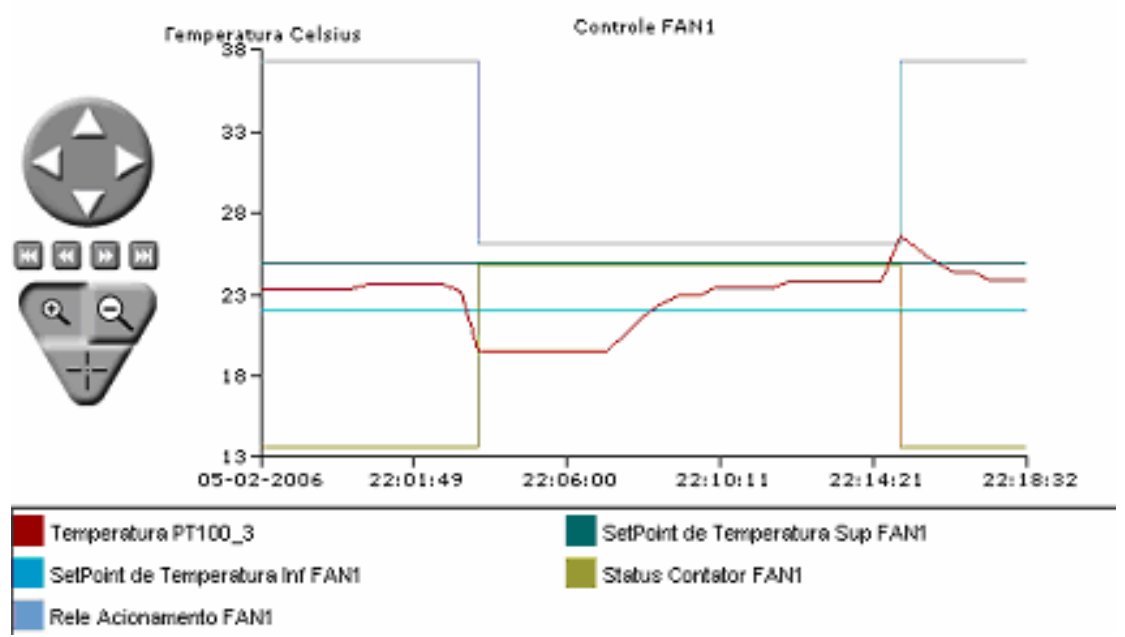

Figura 56 - Resultado do teste de acionamento do ventilador 1 


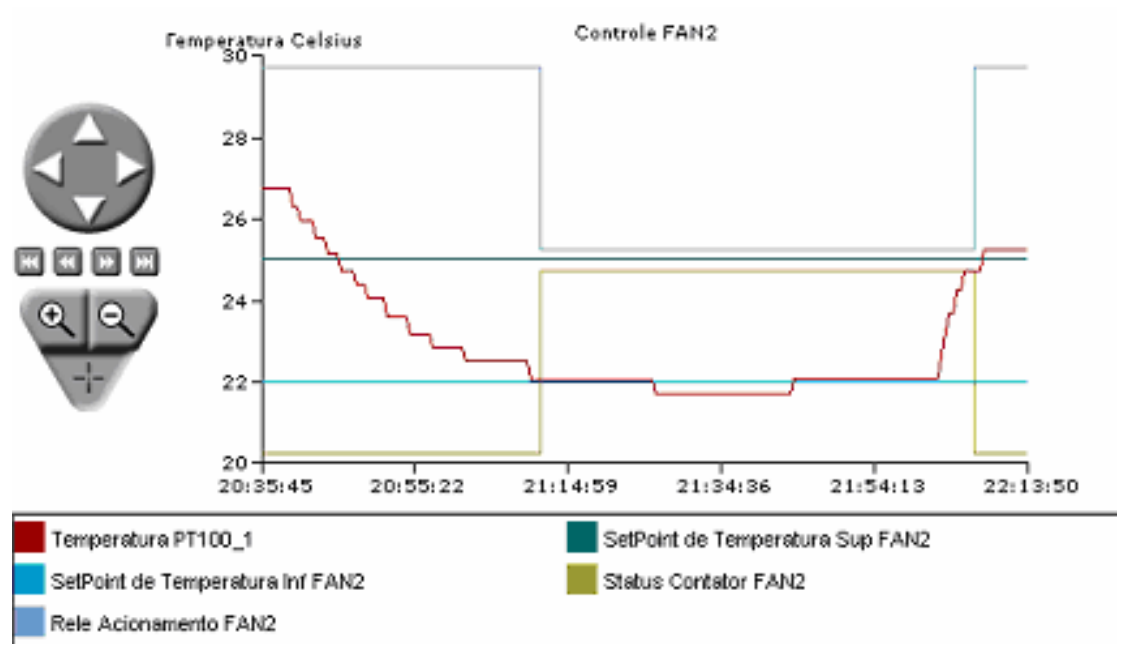

Figura 57 - Resultado do teste de acionamento do ventilador 2

\subsubsection{Temperaturas médias}

Foi verificado o cálculo das temperaturas médias envolvendo variáveis de rede dos dois módulos. A Figura 58 mostra o gráfico de tendências com a temperatura média e as temperaturas envolvidas no cálculo para o módulo 302_1 e a Figura 59 mostra o gráfico com a temperatura média e as temperaturas envolvidas no cálculo para o módulo 302_2. Na Figura 60 pode-se verificar os valores das medidas. A partir dos dados desta tela foram coletadas 12 amostras de valores das temperaturas utilizadas no cálculo das médias. Esses valores estão dispostos na Tabela 5 e na Tabela 6. Percebe-se que existem, em alguns casos, pequenas diferenças entre o valor da média mostrada na tela e a calculada. Essa diferença ocorre devido ao ciclo de programação do módulo, que causa um atraso entre as informações de entrada para o cálculo da média e da divulgação da média calculada. O efeito deste processo é que a informação dos sensores pode ter mudado antes da informação ter sido calculada e divulgada causando um erro aparente de cálculo. De qualquer forma, o objetivo deste teste é verificar que um módulo está processando informações advindas das variáveis de rede provindas de outros módulos e isso o teste conseguiu verificar, pois, caso não estivesse sendo feito, o valor da média mostrada na tela seria significativamente diferente da média calculada. 


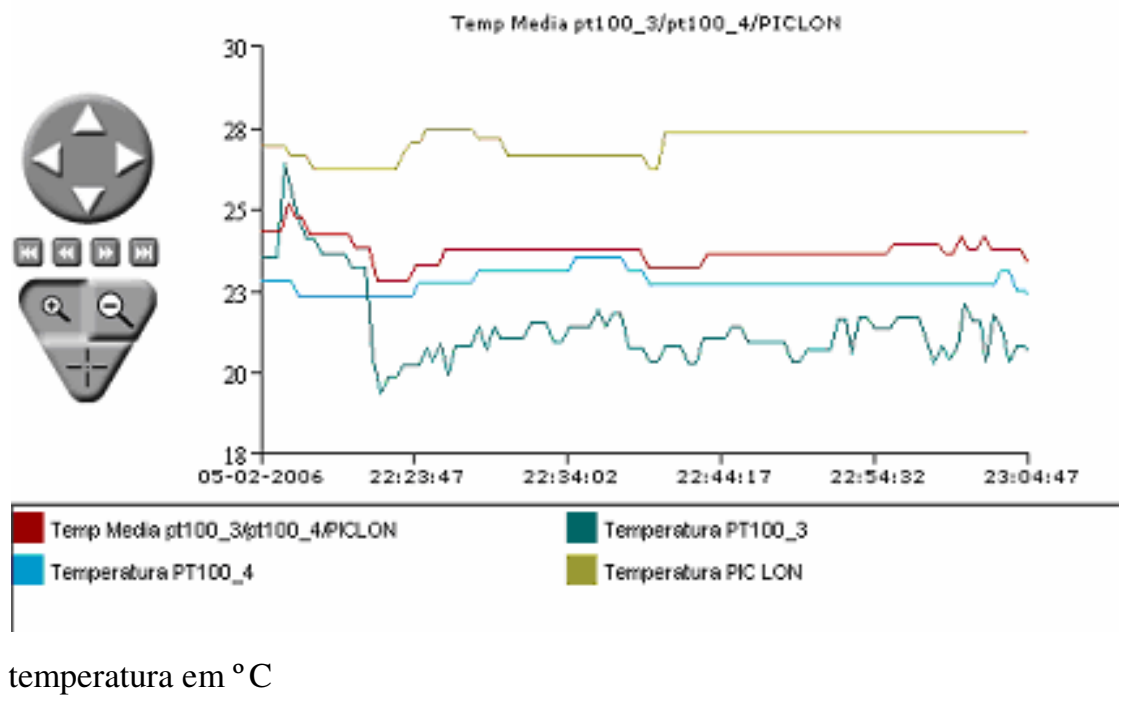

Figura 58 - Temperatura média calculada pelo módulo 302_1

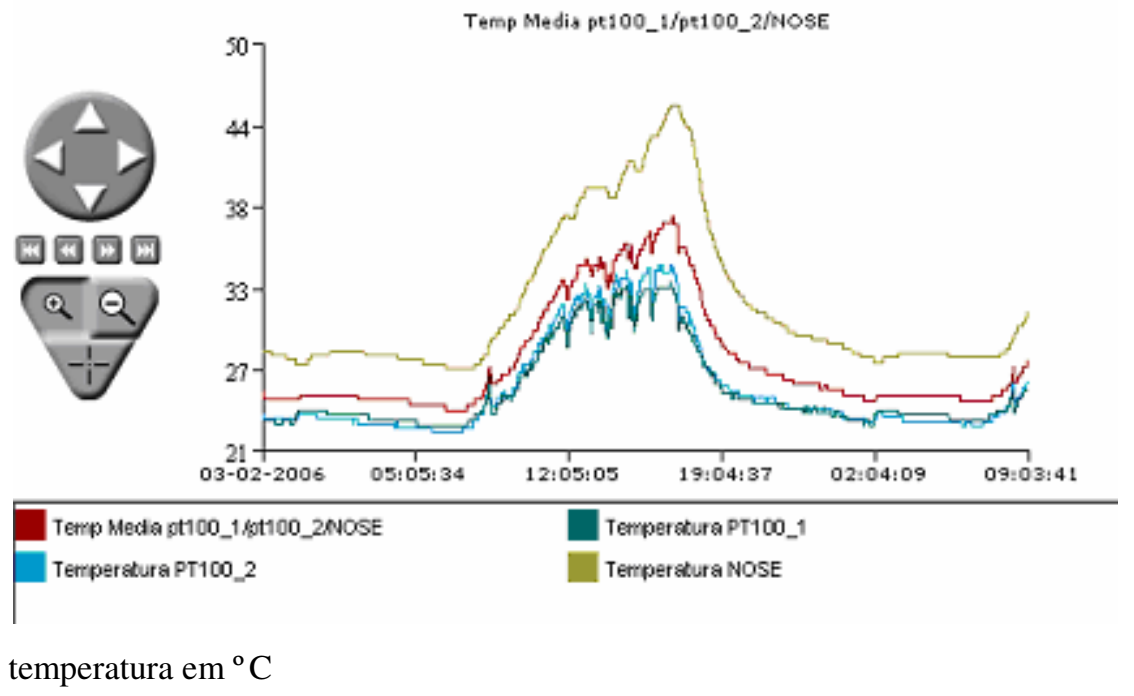

Figura 59 - Temperatura média calculada pelo módulo 302_2 


\begin{tabular}{|c|c|c|}
\hline Name & Value & Unit \\
\hline Temp PT100_i & 23,52 & c \\
\hline Temp PT100_2 & 23,83 & C \\
\hline Temp PT100_3 & 21,56 & C \\
\hline Temp PT100_4 & 20,55 & C \\
\hline Temp PT100_5 (Externa) & 22,11 & c \\
\hline Temperatura NOSE & 27,04 & c \\
\hline Temperstura PKC & 28,00 & C \\
\hline Temp Mecia pt100_3:kn100_.. & 23,20 & C \\
\hline Temp Mecia pt100_1 knt100_. & 24,90 & c \\
\hline Unidade Irterna & 54 & $\%$ \\
\hline Urridade Externa & 55 & $\%$ \\
\hline Umidade PC LON & 71,10 & $\%$ \\
\hline Voc & 23,90 & 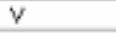 \\
\hline Setpoint Superior & 25,00 & c \\
\hline Setpoint Inferior & 22,00 & c \\
\hline
\end{tabular}

Figura 60 - Tela das medidas dos sensores e as médias

Tabela 5 - Verificação da média de temperaturas calculada pelo módulo 302_1

\begin{tabular}{ccccccc}
\hline Amostra & PT-100_3 & PT-100_4 & PIC & Média & $\begin{array}{c}\text { Media } \\
\text { (Tela) }\end{array}$ & DIF \\
\hline 1 & 22,7 & 22,2 & 28,7 & 24,5 & 24,5 & 0,0 \\
2 & 22,6 & 22,1 & 28,4 & 24,4 & 24,3 & 0,1 \\
3 & 22,6 & 22,0 & 28,4 & 24,3 & 24,3 & 0,0 \\
4 & 22,6 & 21,9 & 27,1 & 23,8 & 23,8 & 0,0 \\
5 & 22,6 & 22,0 & 27,0 & 23,8 & 23,7 & 0,1 \\
6 & 22,6 & 22,0 & 26,8 & 23,8 & 23,7 & 0,1 \\
7 & 22,4 & 22,0 & 26,7 & 23,7 & 23,7 & 0,0 \\
8 & 22,5 & 22,1 & 26,9 & 23,8 & 23,8 & 0,0 \\
9 & 22,5 & 22,0 & 27,0 & 23,8 & 23,8 & 0,0 \\
10 & 22,5 & 21,9 & 27,3 & 23,9 & 23,9 & 0,0 \\
11 & 22,6 & 22,0 & 27,7 & 24,1 & 24,1 & $(0,0)$ \\
12 & 22,7 & 21,9 & 28,0 & 24,2 & 24,2 & - \\
\hline
\end{tabular}

Temperatura em graus celsius

Tabela 6 - Verificação da média de temperaturas calculada pelo módulo 302_2

\begin{tabular}{ccccccc}
\hline Amostra & PT-100_1 & PT-100_2 & NOSE & Média & $\begin{array}{c}\text { Media } \\
\text { (Tela) }\end{array}$ & DIF \\
\hline 1 & 24,0 & 24,0 & 27,7 & 25,2 & 25,3 & $(0,1)$ \\
2 & 24,1 & 23,9 & 27,3 & 25,1 & 25,0 & 0,1 \\
3 & 24,1 & 23,9 & 27,3 & 25,1 & 25,0 & 0,1 \\
4 & 24,0 & 23,9 & 27,9 & 25,3 & 25,3 & $(0,0)$ \\
5 & 24,1 & 23,8 & 28,0 & 25,3 & 25,3 & 0,0 \\
6 & 24,0 & 24,0 & 28,1 & 25,4 & 25,5 & $(0,1)$ \\
7 & 24,1 & 23,9 & 28,2 & 25,4 & 25,5 & $(0,1)$ \\
8 & 24,0 & 24,0 & 28,2 & 25,4 & 25,3 & 0,1 \\
9 & 24,0 & 23,7 & 28,2 & 25,3 & 25,3 & 0,0 \\
10 & 24,1 & 23,7 & 28,2 & 25,3 & 25,3 & 0,0 \\
11 & 24,1 & 23,9 & 28,2 & 25,4 & 25,3 & 0,1 \\
12 & 24,0 & 23,7 & 28,1 & 25,3 & 25,3 & $(0,0)$ \\
\hline
\end{tabular}

Temperatura em graus celsius 


\subsubsection{Acionamento das lâmpadas}

Adicionalmente foi feito um teste para a verificação do acionamento de um atuador através da alteração de uma variável de rede. O acionamento das lâmpadas utilizadas para o controle do fotoperíodo foi configurado para ocorrer ao ser fechada a porta. Para isso associou-se a variável de rede de saída, que indica o estado da porta, com a variável de rede de entrada, que comanda o acionamento das lâmpadas. Ao se fechar a porta (nível zero do gráfico), a luz é acesa (nível um) e, ao se abrir a porta (nível um) a luz é apagada (nível zero), conforme Figura 61.

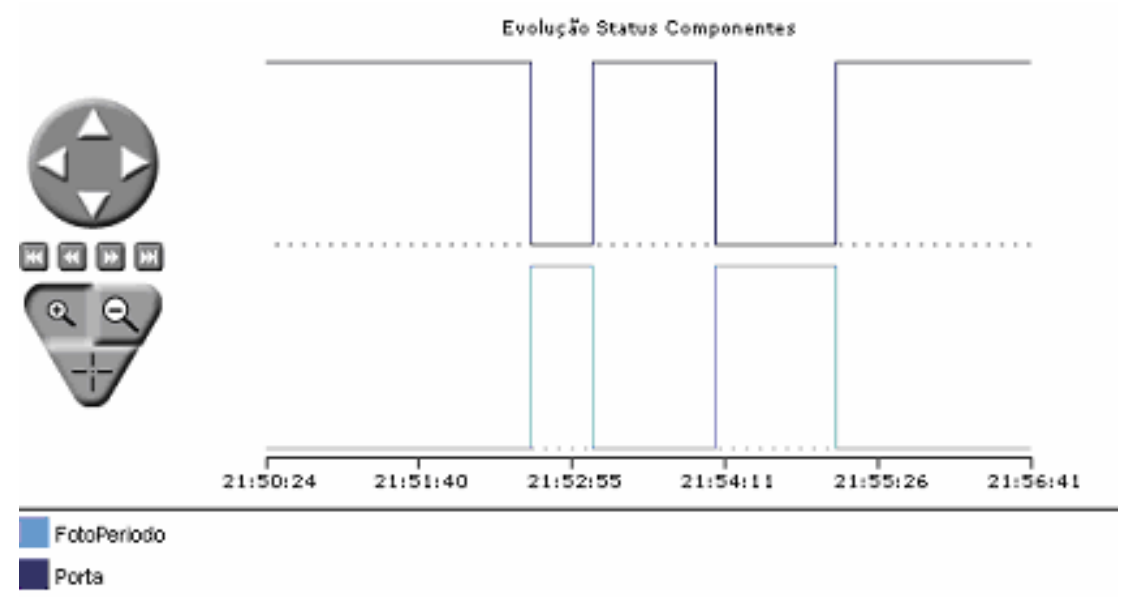

Figura 61 - Resultado do teste de acionamento do fotoperíodo através do fechamento da
porta Este teste demonstra o acionamento dos atuadores através de variáveis de rede.

\subsubsection{Acesso via $W e b$}

O teste de acesso ao sistema via Internet foi feito em laboratório, pois a casa de vegetação ainda não possui cabeamento para acesso à Internet e intranet. Os módulos que foram instalados na casa de vegetação foram montados no LAA, e um endereço IP externo (endereço que pode ser acessado externamente à rede da USP) foi configurado no módulo Xenta 511:

Endereço IP : 143.107.164.110 
Subrede: 255.255 .255 .0

Gateway default: 143.107 .164 .1

DHCP: Desabilitado

Nome do Servidor: ESTUFA

Nome do Domínio: USP

Após essa configuração pode-se acessar as páginas do módulo Web Server através do endereço eletrônico: http://143.107.164.110. O teste de acesso foi feito no LAA e também de outros locais, utilizando conexão com a Internet via acesso discado e acesso com banda larga.

Um teste adicional foi realizado, por ocasião do evento II Workshop TIDIA (TIDIA, 2006), quando foi disponibilizado um link para o acesso ao sistema desenvolvido no endereço http://www.ib.usp.br/vinces (neste site existem informações a respeito deste e de outros projetos). Este acesso faz parte do contexto do projeto TIDIA/Kyatera, que pretende disponibilizar toda a infra-estrutura desenvolvida para a casa de vegetação para a comunidade científica, através de uma rede de alta velocidade: são os chamados Web Labs.

\subsubsection{Interoperabilidade}

Com o objetivo de verificar o grau de dificuldade em se colocar novos nós aderentes ao padrão LonMark ${ }^{\circledR}$ na rede, foram adicionados os sensores NOSE e PIC-LON, como descrito no item 5.4.3. A execução dos procedimentos descritos nesse item fez com que os dispositivos fossem incluídos na rede. Verificou-se, através da ferramenta Vista Explorer e das páginas residentes no módulo Web Server, o funcionamento correto dos módulos: as suas informações puderam ser difundidas na rede e utilizadas pelos nós. Cabe destacar a facilidade e rapidez com que esses módulos podem ser incorporados na rede, estimulando a proposição de soluções que 
podem ser desenvolvidas gradualmente, em função das necessidades e disponibilidade de recursos, podendo a qualquer momento, com as ferramentas de desenvolvimento disponíveis, considerar a realização de ampliações sem muitas dificuldades.

Nós desenvolvidos pelo usuário, também se constituem em uma alternativa que deverá cada vez mais ganhar destaque. Para atender a necessidades específicas, nós como o PIC-LON podem ser desenvolvidos com rapidez, e incorporados na rede como qualquer nó comercialmente disponível.

Assim, tanto o uso do nó NOSE como o PIC-LON comprovaram as vantagens apregoadas em se usar uma rede de controle padronizada. Isso poderá paulatinamente mudar os paradigmas de projetos de sistemas de automação, comumente baseadas em sistemas e equipamentos com tecnologia proprietária, e que exigem que praticamente tanto o sistema como possíveis ampliações sejam considerados já no início do projeto, sob pena de torná-las inviáveis ou excessivamente custosas no futuro.

\subsection{Análise dos resultados}

De uma maneira geral, o sistema experimental desenvolvido cumpre satisfatoriamente as funções de monitoramento e controle da casa de vegetação. Os recursos nele incorporados puderam comprovar o seu potencial de realizar as mesmas funções de um sistema convencional, como o anteriormente disponível baseado em CLP, além de viabilizar outras funcionalidades.

A análise dos resultados vai além da descrição do sistema concebido e implantado, e da constatação de funcionamento dos recursos incorporados. O potencial para novas abordagens, tanto de projeto como de operação, torna-se um interessante aspecto a se discutir. A seguir apresenta-se a análise da experiência de concepção e experimentação do sistema experimental proposto neste trabalho. 


\section{Informações Coletadas}

Inicialmente, o monitoramento através de um servidor Web possui várias funcionalidades que facilitam a análise do comportamento das medições. A visualização dos dados através de gráficos dinâmicos permite focar e vasculhar facilmente qualquer ponto desejado. A possibilidade de exportação dos dados para tratamento em outras ferramentas possibilita não apenas a manutenção de banco de dados com valores históricos, que podem ser de grande valia futura, como também análises mais sofisticadas.

\section{Interface com o Usuário do Sistema}

Um aspecto que pode ser explorado com mais profundidade do que foi feito neste trabalho foi com relação à interface com o usuário. Embora não estivesse nos objetivos deste trabalho explorar com profundidade tais aspectos, pode-se afirmar que existe um grande potencial para a criação de telas e recursos que tornem a operação do sistema mais simples e segura, além de incorporar informações sobre o próprio funcionamento e operação do sistema (uma espécie de manual eletrônico). A criação das páginas utilizadas para o monitoramento mostrou-se relativamente simples de ser feita, dispondo-se para tal de ferramentas de apoio. Naturalmente há de se considerar os problemas intrínsecos à utilização de navegadores: eventualmente alguns problemas na visualização dos gráficos podem ocorrer caso versões mais recentes do Plug-in Java não estejam instaladas.

\section{Acesso Via Web}

O módulo servidor Web mostrou-se poderoso, abrangendo muitas funcionalidades incluindo administração de usuários, geração de alarmes, envio de $e$ mail, muitas delas não verificadas neste trabalho. Vale ressaltar que o acesso via Web ao sistema de controle aumenta muito a sua disponibilidade de acesso. 


\section{Interface com Sensores e Atuadores Convencionais}

Uma dificuldade encontrada foi com relação ao condicionamento de sinais. O módulo CLP já possuía entradas tanto para o sensor PT-100 a três fios quanto para entrada de corrente a 4/20 mA. No caso dos módulos TAC foram feitos circuitos condicionadores tanto para o sensor resistivo quanto para o de corrente. Os circuitos implementados podem interferir na acurácia das medidas; contudo, o foco deste trabalho não está na instrumentação. Existem módulos da TAC, como o Xenta 471 , que possuem entradas analógicas de corrente $(4 / 20 \mathrm{~mA})$ o que poderia melhorar a exatidão das medidas desses sensores.

\section{O Conceito de Rede de Controle}

O controle dos ventiladores baseado no algoritmo two-step foi executado e foi possível verificar a correta troca de informações entre os módulos através das variáveis de rede. Essa troca de informações também pôde ser verificada através do resultado de duas variáveis de rede que calculam médias feitas utilizando-se medidas de temperatura de todos os módulos.

Com relação à ferramenta de programação dos nós, foi utilizada a Vista Menta. É uma ferramenta gráfica, o que facilita a implementação. Possui blocos funcionais complexos e é possível implementar operações lógicas também complexas utilizando esta ferramenta. Deve-se salientar, no entanto, que ela só pode ser utilizada com os produtos da TAC. Caso se queira construir um nó específico, é necessário usar a linguagem Neuron C (ECHELON, 1995a), exigindo um maior conhecimento de programação, como ocorreu no desenvolvimento do nó PIC-LON. Esse aspecto é comentado em Mahalik (2002), que afirma que o principal problema da implementação de redes de controles distribuídos é a disponibilidade de ferramentas e técnicas para a realização do princípio da descentralização.

A utilização combinada do nó sensor comercialmente disponível NOSE e do sensor desenvolvido no LAA PIC-LON mostrou-se simples de ser feita. Porém, ambos os sensores não estão adequados para utilização no ambiente encontrado em 
uma casa de vegetação. O NOSE, por exemplo, foi projetado para ser utilizado em ambiente bem menos agressivo. Apesar de não se ter detectado qualquer problema durante os testes, sua faixa de operação nominal é restrita: de 0 a $32{ }^{\circ} \mathrm{C}$, não adequada para a casa de vegetação, que poderia atingir temperaturas superiores. $\mathrm{O}$ PIC-LON, que na verdade se trata de um protótipo experimental, apresentou travamento no seu processamento quando a temperatura ficou acima de $40^{\circ} \mathrm{C}$. Ele precisa ser robustecido, selado e receber uma montagem adequada e para que possa ter maior confiabilidade. Apesar disso, conseguiu-se constatar a facilidade de se acrescentar sensores no padrão LonMark ${ }^{\circledR}$ ao sistema e sensores de desenvolvimento específico.

Outra constatação feita foi que o sistema distribuído também permite diminuir o impacto de possíveis alterações, pois apenas os nós envolvidos por uma eventual alteração ficam inoperantes durante o tempo de carregamento dos programas nos respectivos nós. O mesmo não ocorre num CLP. Neste, todo o sistema fica inoperante durante a sua reprogramação. Numa casa de vegetação onde os tempos de respostas não precisam ser muito pequenos, esse aspecto não é tão significativo, mas pode ser muito importante em sistemas de processamento contínuo e de alta disponibilidade.

\section{O Processo de Migração de um Sistema Centralizado para um Sistema Distribuído}

Como conseqüência da realização deste trabalho, pode-se descrever uma sugestão para os passos a serem seguidos no processo de troca de um sistema centralizado por um distribuído baseado na rede de controle LonWorks®, que são:

a) estudo do sistema original: levantamento das entradas e saídas utilizadas e respectivas formas de manipulação, dos algoritmos de controle e intertravamentos requeridos, interfaces com o operador e comunicação com outros sistemas. 
b) substituição do módulo processador do sistema centralizado por um módulo programável da rede de controles, que deverá receber um programa semelhante ao do CLP, exceto no que tange à entradas e saídas, cujo tratamento deverá ser adequado ao novo hardware. Isso possibilita uma transição mais branda para o sistema distribuído, principalmente com relação ao esforço de troca do cabeamento já existente, que será aproveitado.

c) troca dos sensores e atuadores convencionais por sensores inteligentes, e distribuição do intertravamento e funções de controle entre os nós do sistema distribuído.

Uma vantagem que pode ser apontada pela implementação proposta neste trabalho é que ela permite o aproveitamento de boa parte do sistema legado, possibilitando uma migração gradual, pela transferência paulatina dos dispositivos e funções para os nós do novo sistema.

\section{Considerações sobre o Cabeamento do Novo Sistema}

Com relação à redução do tamanho do cabeamento na nova implementação, no Apêndice B apresenta-se um estudo sobre a implementação de uma rede na casa de vegetação. De acordo com o estudo, se todos os sensores e atuadores estivessem conectados a um nó compatível com a rede LonWorks®, haveria uma redução de aproximadamente $60 \%$ (em metros) na quantidade de cabeamento necessário. A redução no cabeamento não somente é uma vantagem do ponto de vista econômico como também auxilia na redução da complexidade da instalação e manutenção do ambiente, bem como mudanças no posicionamento de sensores em cada tipo de utilização da casa de vegetação, o que normalmente não é possível em um sistema convencional. 


\section{Considerações sobre Custos do Novo Sistema}

Sistemas distribuídos levam vantagem em relação ao cabeamento, instalação e manutenção devido à maior simplicidade neste aspecto. Porém, quando se comparam os custos dos módulos programáveis e extensões da solução baseada e dos nós de um rede LonWorks ${ }^{\circledR}$, a última tende a ser mais custosa devido ao maior grau de tecnologia envolvida e número de dispositivos utilizados. Contudo, existe a tendência de redução do preço dessa solução no Brasil, uma vez que se inicia a produção local de dispositivos baseados nessa tecnologia ${ }^{8}$. Isso deve tornar essa solução mais competitiva em relação à solução envolvendo CLPs, quando se considera a solução completa, envolvendo o custo do projeto, equipamentos, programação, software, cabeamento e implantação.

Apenas para se ter uma idéia dos valores envolvidos, comparando-se os custos dos dois sistemas utilizados na casa de vegetação, o original baseado no uso de CLP com a nova solução baseada em rede de controle, e considerando apenas os custos dos módulos programáveis e de entrada/saída, chega-se a valores aproximados de US\$ $1.500,00^{9}$ da solução utilizando CLP contra US\$ $4.800,00^{10}$ na solução de redes controle. O módulo Web utilizado custa cerca de US\$2.500,00 e um módulo de sensor de temperatura no padrão LonWorks ${ }^{\circledR}$ custa cerca de US\$ 250,00 ${ }^{11}$.

Com relação às ferramentas de software necessárias, seguem seus preços aproximados em dólar ${ }^{12}$ : a) Nodebuilder, US\$ 6.595,00 b) LonMaker Integration Tool Professional US\$1.315,00 c) Pacote Vista Server e Explorer US\$11.500,00 d) Menta US\$ 4.500,00 e, e) Xbuilder US\$2.500,00.

Com relação ao tempo e dificuldade de instalação, a utilização de sensores comerciais evita a preocupação com a calibração do sistema de leitura. A

\footnotetext{
${ }^{8}$ Empresa Conceito Tecnologia

${ }^{9}$ Considerou-se o custo de cada módulo por volta de US\$ 500,00 para 8 entradas digitais e 8 analógicas

${ }^{10}$ Considerou-se o preço de US\$ $1.900,00$ para os módulos programáveis e US\$1.000,00 para o módulo de entrada e saída

${ }^{11}$ Valor obtido no site de compras virtuais de produtos padrão LonWorks Engenuity . Disponível em $<$ http://www.engenuity.com> Acesso em 10 Jan 2006.

${ }^{12}$ Valores obtidos no site da empresa EBV Elektronic. Disponível em <http:// .http://www.ebv.com > Acesso em 10 Jan 2006.
} 
acurácia faz parte da especificação do produto. Como no caso do NOSE ou do PICLON percebeu-se que basta configurar a rede, conectar o dispositivo e começar a coletar os dados. Na acurácia de um dispositivo inteligente é levado em consideração o valor medido que o dispositivo está enviando a rede. Um sensor possui sua exatidão, mas para um sistema o que importa é o valor final da medida utilizado pelo sistema. E esse valor envolve deste a acurácia do sensor, dos circuitos condicionadores e seus componentes e da precisão da conversão A/D. Caso a acurácia de um sensor comercial não esteja adequada, basta substituí-lo por outro, inclusive, caso seja utilizado o padrão LonMark ${ }^{\circledR}$ é possível substituí-lo por outro fornecedor. No caso disso ocorrer, quando a medida do sensor é tratada no sistema é necessário investir algum tempo para se verificar e corrigir o problema. Em geral, a solução requer conhecimento experimental.

\section{Considerações Finais}

Em resumo, pode-se dizer que o sistema proposto neste trabalho apresenta como principais vantagens em relação a uma solução convencional:

- Redução de problemas com ruído devido à utilização de sinais digitais (o nó trata sinais analógicos e transforma em digitais).

- Redução no tempo e complexidade na instalação do sistema.

- Redução significativa do cabeamento.

- Facilidade de expansão - colocação de um novo ponto na rede.

- Facilidade na substituição de componentes.

- Redução no tempo de indisponibilidade do sistema devido a alterações: a interrupção do funcionamento pode ser feita apenas nos componentes que estão participando da alteração. 
- Melhoria na confiabilidade por distribuir funções (tratamento de sinal/controle).

- Menor tempo requerido na programação, pelo uso de ferramentas de alto nível e distribuição da complexidade em diversos nós, cada um de implementação normalmente simples; em soluções com CLPs, ao contrário, sistemas de médio e grande porte exigem muitas horas de engenharia para a programação e colocação em operação dos sistemas, normalmente envolvendo o uso de linguagens de concepção antiga (como a de diagrama em escada).

Como desvantagens pode-se citar:

- Alto custo tanto dos módulos quanto das ferramentas de configuração e desenvolvimento da rede, assim como poucas opções de ferramentas encontradas no mercado.

- Custo inicial maior, considerando-se o investimento em ferramentas de desenvolvimento que contudo, pode ser amortizado em vários projetos. 


\section{CONSIDERAÇÕES FINAIS}

Neste trabalho procurou-se dotar uma casa de vegetação experimental de uma nova abordagem aos sistemas de controle normalmente utilizados: a rede de controle distribuído. Essa abordagem mostrou-se de bastante interesse, apresentando vantagens em relação às formas convencionais como flexibilidade, interoperabilidade e escalabilidade. Procurou-se evidenciar uma comparação empírica com os sistemas de controle centralizados, notadamente os baseados em CLP's, com ênfase nos principais aspectos.

O sistema implementado possui a característica de permitir fácil e rápida agregação de novos dispositivos, desde que utilizem o padrão LonMark ${ }^{\circledR}$. Esta característica torna a solução bastante atraente do ponto de vista técnico, constituindo-se também como uma infra-estrutura para futuras linhas de pesquisa.

A exploração máxima do potencial da distribuição de controles ocorre quando cada componente, sensor e atuador, é um nó independente e com inteligência própria. Quando isso ocorre pode-se extrair o máximo de escalabilidade e flexibilidade do sistema implementado. Na implementação experimental desenvolvida utilizou-se quatro nós LonWorks ${ }^{\circledR}$, por razões práticas, o suficiente para a verificação experimental das vantagens da arquitetura distribuída como a redução no cabeamento, a facilidade de expansão e conexão de novos componentes e simplicidade de implementação do sistema. Utilizaram-se tanto componentes de mercado quanto os desenvolvidos em laboratório, o que permitiu a avaliação da interoperabilidade da solução. Embora alguns autores destaquem que pode haver desestímulo para a adoção de uma solução que envolva a tecnologia LonWorks®, devido à possibilidade de se construir componentes que não sigam o padrão designado pelo consórcio LonMark ${ }^{\circledR}$ (LOPES, 2001), deve-se salientar a simplicidade e a eficiência dessa solução ao utilizar o conceito de variáveis de rede (network variables).

Assim como para o CLP, a programação requer do projetista um certo grau de especialização. A ferramenta de programação utilizada no presente trabalho, 
Menta, da empresa TAC, é uma ferramenta gráfica de fácil utilização, pois não exige conhecimentos de programação. Isso the confere um significativo ganho de produtividade, mas seu uso é limitado à programação de módulos deste fabricante. De maneira geral, a linguagem de programação dos nós disponível baseia-se na linguagem C, e é chamada de Neuron C (ECHELON, 1995a). Neste caso, é necessário algum conhecimento mais profundo de programação. De qualquer forma, apesar dessas considerações, é inegável que o aumento da complexidade do sistema de controle requer ferramentas específicas e técnicos melhor treinados para executar a configuração e operação do sistema de controle. Alguns fabricantes possuem a preocupação tanto da comercialização de seus produtos quanto do treinamento dos técnicos e projetistas para a sua correta utilização.

A ferramenta para a construção da rede utilizada, Vista Explorer, mostrou-se adequada tanto para nós de fabricação TAC como para os nós de outros fabricantes como o PureChoice Nose (NOSE, 2003) e PIC-LON (desenvolvido no LAA).

A configuração do módulo servidor Web funcionou adequadamente e sua utilização permitiu a visualização dos dados coletados e manipulação remota dos atuadores. Vale ressaltar que essa funcionalidade permite um potencial de alcance muito grande na utilização do sistema. Traz comodidade, devido ao fato de não ser necessária a presença do operador na casa de vegetação para verificar o funcionamento das suas condições e do estado do sistema de controle, assim como permite a alteração de parâmetros e solução de alguns problemas remotamente.

Embora uma das razões da utilização da tecnologia LonWorks® tenha sido a semelhança entre o tipo de controle necessário para uma casa de vegetação com o envolvido na automação predial, uma das aplicações de maior destaque desta tecnologia, ressalta-se que o ambiente da casa de vegetação é muito mais agressivo aos equipamentos do que na automação predial. A semelhança resume-se apenas ao controle das variáveis ambientais. Para a casa de vegetação torna-se necessária a utilização de componentes robustos e a preocupação com a instalação em armários selados. Com relação ao ruído elétrico, também mais presente, a utilização de comunicação digital reduz significativamente esse tipo de problema. 
A abordagem "sistemas distribuídos de automação baseados em redes de controle" é uma solução que se alinha com as modernas tendências em automação. Utiliza comunicação digital, o que facilita a troca de informações e reduz problemas com ruído. Cada vez mais estão disponíveis no mercado sensores chamados inteligentes, que fornecem a informação na forma digital; tais dispositivos podem facilmente ser convertidos em um nó de uma rede de controle, facilitando a proliferação dessa solução.

Sistemas baseados em redes de controle também possibilitam a sua expansão incremental, com incrementos bem menores do que em uma solução com um CLP: pode-se, por exemplo, dimensionar inicialmente o sistema levando em consideração apenas os recursos estritamente necessários (reduzindo o investimento inicial), pois a expansão é simples, envolvendo o acréscimo de novos módulos.

Devido ao protocolo ser desenvolvido em firmware, a preocupação do desenvolvedor de soluções de automação se concentra muito mais na aplicação do que na comunicação. Isso reduz significativamente o tempo necessário para a implementação de uma solução. No presente trabalho, durante todo o processo de implementação e testes (cerca de seis meses), em apenas duas ocasiões foi necessária a reinicialização do sistema devido a problemas de comunicação entre os componentes. Isso representa um avanço da confiabilidade dos componentes tecnológicos aumentando a produtividade das pessoas envolvidas nesse tipo de solução.

O controle das variáveis ambientais em uma casa de vegetação não é um processo de tempo crítico, não necessita de um acoplamento muito forte entre seus componentes (atuadores e sensores) e nem existe um grande fluxo de dados. Essas são características indicativas para a utilização de sistemas distribuídos, segundo Xie (1998). Portanto pode-se dizer que a utilização do controle distribuído é adequada ao processo de controle das condições climáticas em uma casa de vegetação. Por outro lado, sistemas centralizados são indicados para utilização em processos de tempo crítico, que exigem forte acoplamento entre seus componentes ou onde existe um grande fluxo de dados (XIE, 1998). Outra vantagem da arquitetura distribuída é que 
ela pode ser utilizada para a construção de sistemas (ou subsistemas) de controle centralizados, caso seus requisitos indiquem essa utilização.

Por fim, percebe-se também, na abordagem utilizada, que o sistema possui uma dualidade de funções: pode servir como produto final onde sua função seria a de fazer um controle climático na casa de vegetação, mas também, pode ter a função de um laboratório, explorando as características dinâmicas da casa de vegetação ou criando micro-ambientes na própria casa de vegetação para experimentação de novas formas de controle.

\section{Contribuições}

Uma das maiores contribuições deste trabalho é a disponibilidade de um sistema para experimentação de técnicas de controle ambiental, utilizando redes de controle distribuído. Possibilitou a experimentação prática das vantagens e desvantagens dessa arquitetura, sendo um dos pioneiros na implementação deste tipo de controle em casas de vegetação no Brasil.

Este trabalho também está integrado a outros relacionados com pesquisas associadas a redes de controle em realização no LAA:

- Desenvolvimento de um nó de medição de temperatura utilizando a tecnologia LonWorks® (BURDELIS, 2005): nesse trabalho foi desenvolvido o sensor PIC-LON utilizado na presente implementação.

- Estudo da utilização do padrão IEEE 1451 no desenvolvimento de sensores inteligentes utilizando a tecnologia LonWorks ${ }^{\circledR}$ (TANI; CUGNASCA, 2005; TANI, 2006): o padrão IEEE 1451 propõe uma interface padrão entre os transdutores (sensores e atuadores) e as redes de controle. Visa permitir o projeto dos transdutores independentemente da tecnologia de rede de controle escolhida. Isso possibilita que os transdutores passem a ser intercambiáveis e interoperáveis, reduzindo custos e aumentando a flexibilidade das soluções. Além disso, a especificação de Transducer Electronic Data Sheets (TEDS), 
documentação eletrônica do transdutor que é integrada ao mesmo, promove facilidades plug-and-play, como configuração automática e autocalibração. Pretende-se aplicar o resultado deste trabalho ao sistema de controle da casa de vegetação, avaliando os ganhos da utilização desta abordagem.

- Elaboração de um modelo de sistema de gerenciamento para redes de controle baseado na tecnologia LonWorks ${ }^{13}$. Este trabalho aborda uma pesquisa nas tecnologias existentes para gerenciamento de redes IP e destaca os principais aspectos para a elaboração de um modelo. A infra-estrutura do controle criada na casa de vegetação está sendo usada na elaboração de uma aplicação experimental para o modelo proposto.

- Elaboração de um modelo dinâmico de uma casa de vegetação ${ }^{14}$. Este trabalho pretende definir modelo de comportamento dinâmico para uma casa de vegetação. Na validação do modelo será implementada uma rede de sensores que permita o mapeamento das condições climáticas da casa de vegetação e validação de do modelo proposto. A presente infra-estrutura será utilizada como ferramenta de implementação do modelo em desenvolvimento pelo pesquisador.

- Construção de controle em casas de vegetação baseados na teoria de multiagentes ${ }^{15}$. Neste trabalho é proposta a criação do controle baseado em dois agentes, um regulador de temperatura e outro de umidade que disputam os recursos da estufa para efetuar seu controle. Pretende-se, aplicar o controle utilizando a infra-estrutura criada.

A infra-estrutura montada tem o propósito de servir como um laboratório de acesso remoto via Internet (Web Lab). Através do mesmo, pode-se não somente

\footnotetext{
${ }^{13}$ CHERMONT, M.G. Um modelo de sistema de gerenciamento para redes de controle baseado na tecnologia LonWorks®. Dissertação (Mestrado) - Escola Politécnica, Universidade de São Paulo. São Paulo, 2006. /Em elaboração/

${ }^{14}$ BERNARDO, J.I. Modelagem analítica em casa de vegetação para simulação e controle multivariável otimizado. 2006. Tese (Doutorado) - Escola Politécnica, Universidade de São Paulo. São Paulo. /Em elaboração/

${ }^{15}$ CUNHA, R.A. Utilização de técnicas de sistema multi-agentes para controle de estufas. Dissertação (Mestrado) - Escola Politécnica, Universidade de São Paulo. São Paulo, 2006. /Em elaboração/
} 
ter acesso remotamente aos dados históricos de monitoramento coletados na casa de vegetação, como também é possível fazer alterações nas configurações dos parâmetros de controle (como os pontos de operação da temperatura da casa de vegetação) e nos próprios algoritmos de controle. A flexibilidade para se colocar ou retirar componentes desse sistema torna-se requisito fundamental para que ele seja utilizado com essa finalidade, possibilitando a rápida adaptação do sistema de controle aos requisitos da pesquisa. Este laboratório estará conectado a uma rede de alta velocidade destinada a pesquisa, dentro do contexto do projeto TIDIAKYATERA/ViNCES (TIDIA, 2005; KYATERA, 2005; VINCES, 2005), que disponibilizará seu acesso à outras entidades de pesquisa do Estado de São Paulo (PEREIRA et al, 2005).

\section{Melhorias}

Como sugestões de continuidade do presente trabalho, as seguintes melhorias são propostas:

- Ampliar o número de variáveis medidas através da adição de novos sensores ao sistema como concentração de gás carbônico, intensidade de radiação PAR (Photosyntetically Active Radiation), velocidade e direção do vento e aumento do número de pontos de monitoração das variáveis já existentes (temperatura e umidade) para que seja coberta uma área maior da casa de vegetação.

- Utilização de medidor de freqüência nas pás do ventilador para verificação de funcionamento dos mesmos ao invés da utilização da verificação da tensão nos contatores.

- $\quad$ Elaboração de algoritmos de controle de fotoperíodo e umidade.

- Criação de módulos baseados no padrão LonWorks® para encapsular os sensores da casa de vegetação (PT-100 e EWHS 280), tomando o cuidado de selar a placa de componentes eletrônicos para que ele possa ser utilizado em qualquer parte da casa de vegetação. 
- Elaboração de algoritmos de controle divididos por períodos de tempo (ex. manhã, tarde ou noite).

- $\quad$ Criação e utilização de variáveis de rede com a função específica de disponibilizar o estado de funcionamento de cada componente da rede.

- Criação de alarmes para temperatura excessiva por muito tempo, monóxido de carbono (alarme de incêndios), indicador de necessidade de manutenção periódica dos atuadores, entre outros.

- Implementação de novos atuadores controlados pelo sistema através da colocação de motores nos mecanismos de abertura e fechamento das janelas laterais e zenitais da casa de vegetação.

- Instalação de inversores de freqüência nos ventiladores que já utilizem o padrão LonMark ${ }^{\circledR}$, e utilização de controle PID, possibilitando o controle mais refinado das condições climáticas da casa de vegetação e utilização mais eficiente dos ventiladores.

- $\quad$ Colocação de câmera conectada a Internet para possibilitar o acompanhamento à distância do crescimento de uma determinada planta ou verificar as condições da casa de vegetação, como por exemplo, o funcionamento dos ventiladores, presença de pessoas, etc.

- $\quad$ Colocação de sensores em uma planta piloto para permitir estudos com dados mais apurados da influência dessas grandezas nessa planta.

\section{Potenciais e perspectivas}

Durante a execução deste trabalho foram identificados potenciais e possibilidades de desenvolvimento de novos trabalhos e linhas de pesquisa descritos a seguir: 
- Utilização de sensores baseados em tecnologia sem fio, eliminando a necessidade de cabeamento e permitindo a mobilidade física dos sensores, assim como a exploração da utilização de outros meios físicos como permitidos pela tecnologia LonWorks®, como por exemplo, a rede elétrica para os atuadores como sugerem os trabalhos de Pereira e Cugnasca (2005) e Serôdio et al (2001).

- Exploração e estudos da capacidade de redundância da rede aumentando sua confiabilidade. Podem ser exploradas as redundâncias tanto com relação ao hardware, software assim como de informações (ZHIHAO e JINSHOU, 2002).

- Exploração das características das interfaces homem-computador (IHC) específicas para controle em casas de vegetação levando em consideração as necessidades de interface para o ambiente local e as necessidades de interface para sistemas de acesso remoto, seguindo a linha iniciada por Lopes (2001). A interface local pode ser implementada como mais um nó da rede LonWorks®.

- Criação de um banco de dados de resultados de experiências, parâmetros de controle e dados coletados durante a experiência com disponibilização para comunidade acadêmica via Internet.

- Utilização de métodos de data-mining para identificar padrões, utilizando os dados coletados dos sensores e informações de crescimento e produtividade.

- $\quad$ Estudo do potencial que esse sistema possui para se transformar em consultoria remota. Atualmente a empresa Purechoice fornecedora do nariz eletrônico NOSE (NOSE, 2003) possui serviços de monitoramento de ambientes. Neste serviço os sensores são instalados no local a ser monitorado e os dados são enviados para uma central que disponibiliza um sistema de monitoramento para seus clientes. A mesma idéia poderia ser proposta para o caso das casas de vegetação. Poder-se-ia criar uma 
central que forneceria os serviços de monitoramento para diversas casas de vegetação. Esta central poderia até fazer transferência de programas remotamente de acordo com as solicitações de seus clientes. Isso possibilitaria aos clientes prescindir de pessoal técnico especializado na tecnologia e mesmo assim seria possível ter um serviço ágil, no caso de ser necessária alguma alteração na programação dos nós do sistema. Permitiria também, uma redução nos custos relativos tanto aos acessos físicos às casas de vegetação para alteração de programação, quanto otimizaria os custos necessários para o treinamento de técnicos especializados na tecnologia.

- $\quad$ Estudo e elaboração de interfaces e linguagens que tornem mais simples e padronizadas as formas de configuração e alteração da programação dos sistemas.

- $\quad$ Estudo e implementação de módulos de interconexão entre a rede LonWorks ${ }^{\circledR}$ e soluções proprietárias pré-existentes. Foco deste trabalho poderia ser a utilização de redes de controle para a expansão de sistemas de controle com a manutenção do sistema proprietário anterior.

- $\quad$ Exploração do aspecto segurança dessa rede de controles uma vez que a abertura do acesso ao ambiente da Internet aumenta os riscos de acesso indevido.

- Estudo e implementação de sensores inteligentes com autocalibragem e autodetecção de erro. Correção das grandezas automaticamente em função de temperatura, umidade e altitude. Utilização de sensores para melhorar qualidade sistema.

- Exploração do conhecimento envolvido nos sistemas de controle voltados para a zootecnia de precisão e casas de vegetação, procurando utilizar os avanços de um caso no outro e vice-versa. 
- $\quad$ Pesquisa e exploração de utilização de redes de sensores inteligentes sem fio, a fim de coletar dados mais apurados próximos às plantas.

- $\quad$ Estudo e implementação de algoritmos de controle complexos utilizando, por exemplo, lógica fuzzy, redes neurais, algoritmos genéticos e verificação de seus efeitos, não só com relação ao aumento da produtividade, mas também com relação à otimização dos insumos utilizados no processo produtivo como energia elétrica, água e nutrientes, insumos agrícolas, defensivos agrícolas, necessidades de manutenção dos atuadores, etc.

- $\quad$ Estudo e disponibilização de nós robóticos e veículos operados remotamente a esse sistema.

- Mapeamento das características e comportamentos dinâmicos da casa de vegetação, com o objetivo de se propor alterações na estrutura, nos algoritmos de controle, nas características mais adequadas para os sensores e atuadores e seu posicionamento de maneira a otimizar as respostas dos elementos atuadores às condições climáticas desejáveis.

- Utilização da infra-estrutura como aplicação para o desenvolvimento de um sistema supervisor para redes LonWorks®, seguindo a linha do trabalho desenvolvido por Canovas, Chermont e Cugnasca (2005) e Chermont (2006).

- Criação de sistema de informação como emissor do laudo de produção, onde todos os dados relativos ao cultivo daquela safra pudessem ser armazenados e disponibilizados para os consumidores. Este sistema permitiria o acesso a dados da produção, desde quais produtos foram utilizados como insumos e em quais quantidades, até quais foram as condições climáticas a que foi exposta determinada safra.

Como consideração final, é importante relatar que a evolução tecnológica, apesar de ser motivada na maioria das vezes por motivos econômicos, 
permite ganhos sociais, servindo como agente facilitador na implementação de linhas de pensamento voltadas para a melhoria da qualidade de vida das pessoas. No caso de sua aplicação na agricultura e em particular nas casas de vegetação, permite o rastreamento das condições de produção, a produção de alimentos com menor quantidade de elementos nocivos à saúde (defensivos agrícolas) e, sobretudo, a utilização mais racional dos recursos naturais à disposição do homem na produção de alimentos. Representa um alinhamento à preservação do ambiente, e utilização racional dos recursos naturais. 


\section{REFERÊNCIAS}

ALVES FILHO, M.S. Aplicação de redes de controle distribuído em processo de pesagem automatizado e informatizado. 2001. 216p. Dissertação (Mestrado) Escola Politécnica, Universidade de São Paulo. São Paulo, 2001.

ATARASSI, R.T. Modelagem do microclima em casa-de-vegetação. 2000. Dissertação (Mestrado) - Escola Superior de Agricultura "Luiz de Queiroz", Universidade de São Paulo. Piracicaba, 2000.

BLOM, T.J. The Science of growing - air temperature or plant temperature. Ontario: Priva, s.d. Disponível em: <http://www.prica.ca/newsletter/news-scienceairtemp.htm>. Acesso em: 30 de jul. 2005.

BRYAN, L.A; BRYAN, F.A. Programmable controllers: theory and implementation. Industrial Text, 1997, Georgia, EUA.

BURDELIS, M.J.P. Desenvolvimento de sistema de instrumentação inteligente aplicado a estufas utilizando rede LonWorks®. São Paulo: Laboratório de Automação Agrícola da EPUSP, 2005. (Documento interno).

CANOVAS, S.R.M. Integração entre redes LonWorks® e redes IP: aplicações, requisitos e soluções. Dissertação (Mestrado) - Escola Politécnica, Universidade de São Paulo. São Paulo, 2006. /No prelo/

CANOVAS, S.R.M.; CHERMONT, M.G. ; CUGNASCA, C.E. Remote monitoring and actuation based on LonWorks ${ }^{\circledR}$ technology. In: EFITA/WCCA 2005 JOINT CONFERENCE, Vila Real, Portugal. Proceedings. Vila Real: EFITA, 2005. 
CANSADO, J.C.A. Agrilogic sistema para experimentação de controle de casas de vegetação. 2003. 118p. Dissertação (Mestrado) - Escola Politécnica, Universidade de São Paulo. São Paulo, 2003.

CORDER, R. Web-Enabled Communication Applications for Remote Access and Equipment Monitoring. Sensorsmag. Peterborough, NH, EUA. Abril de 2004. Disponível em: <http://www.sensorsmag.com/articles/0404/14>. Acesso em: 15 de mar. 2005.

ECHELON CORPORATION. The LonWorks ${ }^{\circledR}$ network platform - a technology overview. Disponível em: $<$ http://www.echelon.com/developers/lonworks/default.htm>. Acesso em: 30 de jul. 2005.

Echelon technology adopted as European building control standard. (b) Disponível em: <http://www.echelon.com/about/press/ahr2005.htm> Acesso em: 30 de jul. 2005.

Introduction to the LonWorks ${ }^{\circledR}$ system. Palo Alto: Echelon, 1999 (Relatório 78-0183-01A).

Lonmaker user's guide. Palo Alto: Echelon, 2001 (Relatório 078-016802E).

Neuron C programmer's guide. Palo Alto: Echelon, 1995 (a). (Relatório 078-0002-02G)

Nodebuilder user's guide, Revision 3. Palo Alto, Echelon, 1995 (b). (Relatório 078-0141-01D)

Site. Disponível em: <http://www.echelon.com > Acesso em: 10 de jan. 2006. 
ENGENUITY. Portal de comercialização de produtos LonWorks. Disponível em $<$ http://www.engenuity.com> Acesso em 10 de jan. 2006.

FELSER M. The fieldbus standards: history and structures. Berna: University of Applied Science, 2002.

FISCHER, D. M. BACnet® \& LonWorks®: A White Paper. 1996. Disponível em:

http://www.alerton.com/Products/BACtalk/About_Bacnet/Articles/whitepaper.asp>. Acesso em: 31 de jan. 2006.

FRANCO, L.R.H.R. Uma visão geral sobre fieldbuses. Eletricidade Moderna, Disponível em: http://www.labfield.unifei.edu.br/pub.htm Acesso em: 02 de fev. 2006.

GOLDSCHMIDT, I. Development of BACnet. Strategic planning for energy and the environment, v. $18, \quad$ n. 2, p. 16-24, 1998. Disponível em: <http://www.BACnet.org/Bibliography/SPEE-11-98.html>. Acesso em: $12 \mathrm{de} \mathrm{dez.}$ 2004.

GRAHAM CONTROLS CONSULTING. A short history and a technology overview. Disponível em: <http://www.grahamcontrols.com/lwoverview.htm> Acesso em: 10 de jan. 2006.

GUIMARÃES, A.A.; SARAIVA, A.M. O Protocolo CAN: entendendo e implementando uma rede de comunicação serial de dados baseada no barramento "Controller Area Network". In: CONGRESSO SAE BRASIL, 11., São Paulo, 2002. Anais. São Paulo: SAE, 2002. Artigo SAE 2002-01-3569, 2002.

HANAN, J.J. Greenhouses: advanced technology for protected horticulture. Florida, CRC Press, 1998.

HORTITEC. Holambra, Feira jun 2003. /Entrevistas pessoais/ 
INVENSYS CONTROLS Site. Disponível em: <http://www.invensys.com> Acesso em: 10 de jan. 2006.

KYATERA Project. Disponível em: <http://www.kyatera.fapesp.br> Acesso em: 25 de out. 2005 .

LEE, K.B.; SCHNEEMAN, R.D. Internet-Based Distributed Measurement and Control Applications. IEEE Instrumentation \& Measurement Magazine, p.23-27, Junho de 1999.

LIBERTY CONTROL NETWORKS. Portal de comercialização de produtos LonWorks. Disponível em <http://www.libertycontrolnetworks.co.uk > Acesso em 10 de jan. 2006.

LONMARK ASSOCIATION. Site. Disponível em: < http://www.lonmark.org/>. Acesso em: 10 de fev. 2006.

LOPES, A.A. Interface remota para monitoração e controle de processos via Internet: uma aplicação para ambientes agrícolas. 2001. 115p. Dissertação (Mestrado) - Escola Politécnica, Universidade de São Paulo. São Paulo, 2001.

MAHALIK, N. G. P. C.; LEE, S. K. A study on production line automation with LonWorks ${ }^{\circledR T M}$ control networks. Computer Standards \& Interfaces, v. 24, Issue 1, p. 21-27, Mar 2002.

MICROCHIP Site. Disponível em: <http://www.microchip.com> Acesso em: 10 de jan. 2006.

MIYAGI, P.E. Controle programável: fundamentos do controle de sistemas e eventos discretos. São Paulo: Edgard Blücher,1996. 
NELSON, P.V. Greenhouse operation and management. 4.ed. New Jersey: Prentice Hall, 1991.

NOSE DataSheets, 2003. Disponível em: <http://www.purechoice.com>. Acesso em: 30 de jul. 2005.

OVERSTREET, J.W.; TZES, A. An Internet-Based Real-Time Control Engineering Laboratory. IEEE Control Systems Magazine, v.19, n.5, p. 19-34, Outubro de 1999.

PEREIRA, G.A.; CUGNASCA, C.E. Application of LonWorks ${ }^{\circledR}$ distributed control technology in greenhouses. In: EFITA/WCCA 2005 JOINT CONFERENCE, Vila Real, Portugal. Proceedings. Vila Real: EFITA, 2005.

PEREIRA, G.A. et al. Greenhouse Weblab. In: WORKSHOP TIDIA, 2. São Paulo, 2005. Anais. São Paulo: FAPESP, 2005.

RAJI, R.S. Control Networks and the Internet. In: MAHALIK, N.P. (Ed.) Fieldbus technology: the digital control networking system for automation and control applications. Berlin: Springer-Verlag, 2002. p. 171-182.

RATTIN, J. E.; ANDRIOLO, J. L.; WITTER, M. Acumulação de massa seca e rendimento de frutos de tomateiro cultivado em substrato com cinco doses de solução nutritiva. Horticultura Brasileira, v.21, n.1, p. 26-30, Jan./Mar. 2003.

SCHIMANSKI, A. Application experiences with fieldbus instruments. ISA Transactions, v.35, p.137-145, 1996.

SENSIRION. SHT1x/SHT7x humidity \& temperature sensor datasheet. Staefa: Sensirion, 2003. Disponível em:<http://www.sensirion.com> Acesso em: 01 de nov. 2005 . 
SERÔDIO, C. et al. A networked platform for agricultural management systems. Computers and Electronics in Agriculture, Amsterdam, v.31, p.75-90, 2001.

SHICKHUBER, G.; MCCARTHY, O. Distributed fieldbus and control network systems. Computing \& Control Engineering Journal, v. 1, p. 21-32, Feb. 1997.

TAC. DataSheets. North Andover: TAC, 2001(a). Disponível em:<http://www.tac.com> Acesso em: 01 de jul. 2005.

Engineering applications in TAC menta. North Andover: TAC, 2004.

TAC Menta. North Andover: TAC, 2001 (b). Disponível em:< http://www.tac-global.com/pub/products/default.asp?NP=vista/menta.asp\&ID=> Acesso em: 12 de fev. 2006.

TAC vista. North Andover: TAC, 2001(d). Disponível em:< http://www.tac-global.com/pub/products/default.asp?NP=vista/vista.asp\&ID=> Acesso em: 12 de fev. 2006.

TAC XBuilder® programming tool for TAC Xenta 511. North Andover: TAC, 2003 (b). Disponível em:<http://www.tac.com> Acesso em: 01 de jul. 2005.

Xenta 511 - operating dataSheet. North Andover: TAC, 2003(a). Disponível em:<http://www.tac.com> Acesso em: 01 de jul. 2005.

Xenta - network guide. North Andover: TAC, 2001 (c). Disponível em:<http://www.tac.com> Acesso em: 01 de jul. 2005.

TANENBAUM, A.S. Computer networks. 3.ed. Upper Saddle River: Prentice Hall, 1996. 813p. 
TANI, F. Proposta de desenvolvimento de transdutores inteligentes baseados na norma IEEE 1451 aplicados a redes. 2006. Dissertação em elaboração (Mestrado) Escola Politécnica, Universidade de São Paulo. São Paulo, 2006. /Em elaboração/

TANI, F.; CUGNASCA, C.E. Agriculture and the IEEE 1451 smart transducer interface standard. In: In: EFITA/WCCA 2005 JOINT CONFERENCE, Vila Real, Portugal. Proceedings. Vila Real: EFITA, 2005.

TIDIA - Tecnologia da Informação no Desenvolvimento da Internet Avançada. Disponível em: <http://www.tidia.fapesp.br> Acesso em: 25 de out. 2005.

TOSHIBA. Neuron chip data book. Toshiba, EUA, 1995.

VIDA, J.B. et al. Manejo de doenças de plantas em cultivo protegido. Fitopatologia Brasileira, v.29, p. 355-372, 2004.

ViNCES - Virtual Networking Center of Ecosystem Services. Disponível em: <http://www.ib.usp.br/vinces> Acesso em: 25 de out. 2005.

XIE, C. et al. A case study on the development of intelligent actuator components for distributed control systems using LONWORK neuron chips. Mechatronics, v.8, n. 2, p.103-119, Mar. 1998.

ZHIHAO, L.,JINSHOU Y. The research and realization of full redundancy technology in LON motoring and control network. In: WORLD CONGRESS ON INTELLIGENT CONTROL AND AUTOMATION, 4., Shangai, 2002. Proceedings. Piscataway: IEEE, 2002. v.4, p. 3035-3038. 


\section{APÊNDICE A - CIRCUITOS CONDICIONADORES DE SINAL}

Este apêndice tem por objetivo fornecer detalhes da implementação e formas de conexão, com a finalidade de facilitar a continuidade deste trabalho.

\section{CIRCUITOS CONDICIONADORES DE SINAL}

a) PT-100

Nos módulos da TAC foi utilizado um circuito condicionador de sinal utilizando o amplificador operacional LM 358 e resistores de precisão 1\% (Figura 62). Seu objetivo é transformar as variações de resistência em tensões de 0 a $10 \mathrm{~V}$. Foi projetado para atender à seguinte faixa de operação: $-259,74{ }^{\circ} \mathrm{C}$ quando $\mathrm{VI}_{\mathrm{PT} 100}=0 \mathrm{~V}$ a $82,04{ }^{\circ} \mathrm{C}$ quando $\mathrm{VI}_{\mathrm{PT} 100}=10 \mathrm{~V}$, pois a entrada dos módulos TAC está preparada para tensões de $0 \mathrm{Va} 10 \mathrm{~V}$.

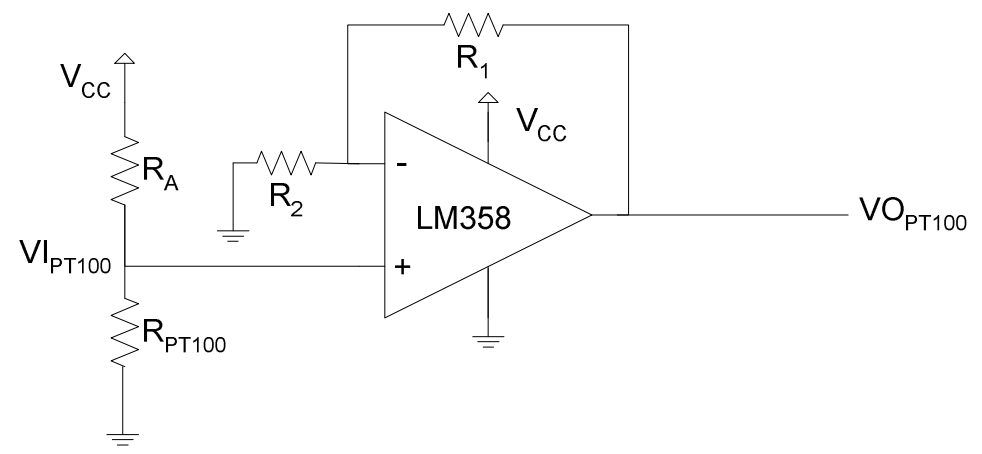

Figura 62 - Circuito condicionador utilizado para o sensor de temperatura PT-100

Do circuito acima têm-se que:

$$
R_{P T 100}=\frac{R_{A}}{\frac{\left(1+R_{1} / R_{2}\right) * V_{C C}}{V O_{P T 100}}-1}
$$


da equação característica do PT-100 têm-se que:

$\mathrm{R}_{\mathrm{PT} 100}=0,385 T+100$

Fazendo (2) em (1) vem:

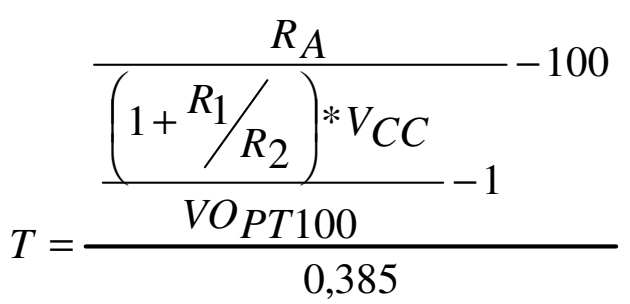

que é a equação utilizada para a obtenção do valor da temperatura

Para o sistema implementado foram utilizados os seguintes valores:

$\mathrm{R} 1=3.000$

$\mathrm{R} 2=470$

$\mathrm{RA}=2.200$

$\mathrm{VCC}=24$

b) EHWS 280

Para a sua utilização nos módulos da TAC foi utilizado um circuito condicionador de sinal utilizando o amplificador operacional LM 358 e resistores de precisão 1\% (Figura 63). Sua função é transformar a saída em corrente do EWHS 280 em tensões de 0 a $10 \mathrm{~V}$. Foi projetado para atender à seguinte faixa de operação: $0 \%$ quando $\mathrm{I}_{\mathrm{EWHS}}=0 \mathrm{~V}$ e $\mathrm{V}_{\mathrm{EWHS}}=0 \mathrm{~V}$ a $100 \%$ quando $\mathrm{I}_{\mathrm{EWHS}}=20 \mathrm{~mA}$ e $\mathrm{V}_{\mathrm{EWHS}}=9,4 \mathrm{~V}$.

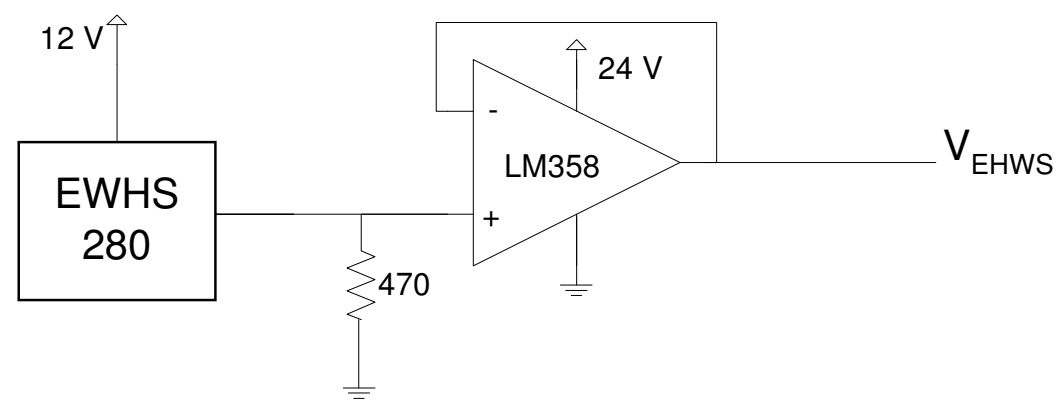

Figura 63 - Circuito condicionador utilizado para o sensor de umidade EWHS 280 
Do circuito temos que:

$\mathrm{V}_{\text {EWHS }}=470 * \mathrm{I}_{\text {EWHS }}(1)$

Umidade Relativa $\%=50 * \mathrm{I}_{\text {EWHS }}(2)$

de (1) em (2) vem :

$\mathrm{V}_{\text {EWHS }}=470 *$ Umidade Relativa $\% / 50$

Logo:

Umidade Relativa $\%=V_{\text {EWHS }} * \mathbf{5 0 / 4 7 0}$

que é a equação utilizada para a obtenção do valor da umidade relativa.

Inntervalo de funcionamento do circuito:

PARA I $I_{\text {EWHS }}=0 \mathrm{~mA}$ a Umidade Relativa $=0 \%$ e $\mathrm{V}_{\mathrm{EWHS}}=0=0 \mathrm{~V}$

PARA $\mathrm{I}_{\mathrm{EWHS}}=20 \mathrm{~mA}$ a Umidade Relativa $=100 \%$ e $\mathrm{V}_{\mathrm{EWHS}}=470 * 0,020=9,4 \mathrm{~V}$ 


\section{APÊNDICE B - ESTUDO SOBRE A REDUÇÃO NO CABEAMENTO NA CASA DE VEGETAÇÃ̃O}

Uma das vantagens da utilização de uma rede de controles distribuída é a redução do cabeamento. Para se ter uma idéia desse potencial de redução aplicado a casa de vegetação utilizada, considerou-se o tamanho dos cabos que ligam os sensores PT-100 e EWHS 280 e os dois ventiladores em duas situações: a) situação atual, onde os cabos vão dos sensores até o quadro com o CLP. b) implementação de uma rede de controle onde cada sensor e cada atuador seria um nó LonWorks®. Neste caso, não haveria um ponto centralizador e considerou-se que a necessidade de cabos seria para implementação de uma rede com a topologia "Daisy Chain" (um componente ligado ao outro). Considerou-se que a alimentação dos ventiladores seria feita da mesma forma nos dois casos e não foi considerada no cálculo. Com relação a alimentação dos sensores, no caso b) está sendo considerada uma rede com quatro fios, sendo dois para a rede propriamente dita e dois para alimentação dos módulos. Considerou-se também que o PT-100 possui três fios e o sensor EWHS 280 possui dois fios. A Figura 64 mostra as dimensões da casa de vegetação e o posicionamento dos componentes utilizados no cálculo. 


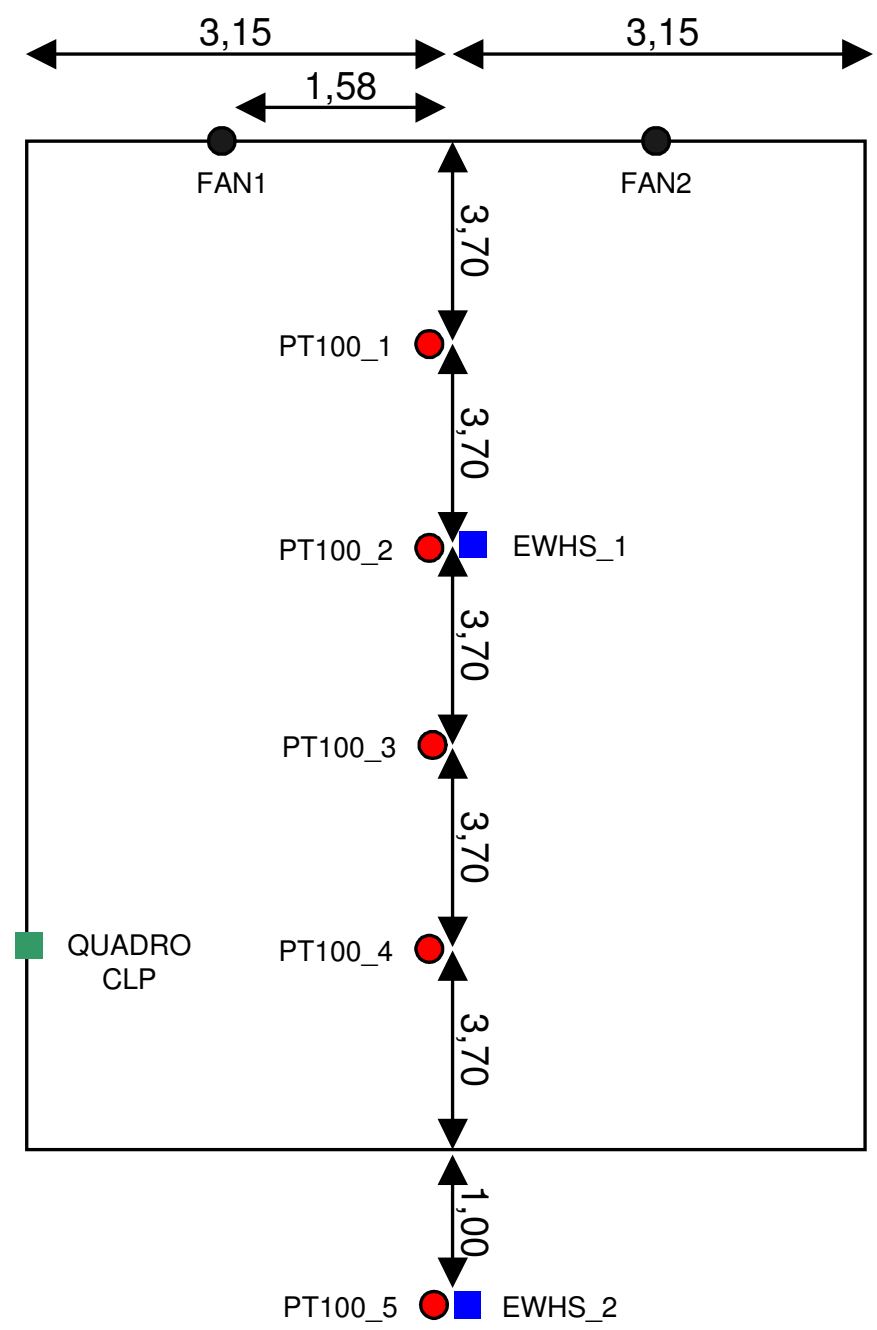

Figura 64 - Dimensões da casa de vegetação e posicionamento dos sensores e atuadores utilizadas no cálculo do tamanho do cabeamento necessário

Para a situação a) descrita acima foi elaborada a Tabela 7 chegando-se a um total de 236,6 metros de cabos necessários. Para a situação b) houve uma redução para 96,9 metros, conforme detalhado na Tabela 8 . Isso equivale a uma redução de $(236,6-96,9) / 236,6=59,0 \%$ em comprimento de cabos quando se utiliza uma rede de controles ao invés da arquitetura centralizada neste caso específico. Considerando-se que se trata de uma casa de vegetação com pequenas dimensões $(18,6 \mathrm{~m}$ x 6,3m) pode-se considerar como bem expressiva a redução. Caso esse cálculo fosse feito para casas de maiores dimensões a tendência seria uma redução ainda maior. 
Tabela 7 - Comprimentos dos cabos dos sensores e atuadores até o quadro de CLP

\begin{tabular}{lr}
\hline COMPONENTE & $\begin{array}{r}\text { COMPRIMENTO } \\
\text { DOS CABOS (m) }\end{array}$ \\
\hline FAN1 & 28,5 \\
FAN2 & 39,1 \\
PT-100_1 & 42,8 \\
PT-100_2 & 31,7 \\
PT-100_3 & 20,6 \\
PT-100_4 & 9,5 \\
PT-100_5 & 36,3 \\
EWHS_1 & 21,1 \\
EWHS_2 & 24,2 \\
TOTAL & $\mathbf{2 3 6 , 6}$ \\
\hline
\end{tabular}

Tabela 8 - Distância dos componentes para o caso de ser montada uma rede de controle

\begin{tabular}{lr}
\hline COMPONENTES & $\begin{array}{r}\text { COMPRIMENTO } \\
\text { DOS CABOS (m) }\end{array}$ \\
\hline FAN1-FAN2 & 12,6 \\
FAN2-PT100_1 & 21,1 \\
PT100_1 - PT100_2 & 14,8 \\
PT_100_2 - EWHS_16 & 0,0 \\
EWHS_1 - PT100_3 & 14,8 \\
PT_100_3 - PT100_4 & 14,8 \\
PT100_4 - PT100_5 & 18,8 \\
PT_100_5 - EWHS_216 & 0,0 \\
TOTAL & $\mathbf{9 6 , 9}$ \\
\hline
\end{tabular}

${ }^{16}$ Como os dois sensores estão no mesmo ponto, considerou-se nula a distância entre eles. 


\section{APÊNDICE C - MEDIDAS DE TEMPERATURA COLETADAS}

Este apêndice apresenta uma tabela com os dados coletados para os sensores de temperatura PT-100 e NOSE no dia 07 de fevereiro de 2006 (Tabela 9).

Tabela 9 - Dados de temperatura coletados na casa de vegetação

\begin{tabular}{|c|c|c|c|c|c|c|c|c|c|}
\hline HORA & NOSE & HORA & PT-100_1 & HORA & PT-100_2 & HORA & PT-100_3 & HORA & PT-100_4 \\
\hline $00: 16: 10$ & 30,35 & 00:05:52 & 24,00 & $00: 19: 52$ & 24,31 & 01:15:06 & 22,89 & $00: 26: 06$ & 21,30 \\
\hline 01:10:40 & 30,04 & $00: 05: 52$ & 24,00 & 01:08:22 & 24,66 & $01: 40: 36$ & 22,55 & $00: 34: 36$ & 21,65 \\
\hline $02: 40: 40$ & 29,73 & $00: 14: 52$ & 24,35 & $02: 10: 52$ & 24,31 & 02:19:06 & 22,14 & $01: 26: 36$ & 21,99 \\
\hline 05:00:40 & 29,42 & 00:20:22 & 24,00 & 02:39:52 & 23,96 & 02:23:06 & 22,49 & $01: 26: 36$ & 21,99 \\
\hline $05: 11: 40$ & 29,10 & $00: 50: 52$ & 24,35 & 03:01:22 & 24,31 & $02: 29: 36$ & 22,14 & $01: 42: 36$ & 21,65 \\
\hline $05: 28: 40$ & 28,79 & 01:57:22 & 24,00 & $04: 46: 22$ & 23,96 & 02:54:06 & 22,49 & 02:19:06 & 21,30 \\
\hline $06: 14: 40$ & 29,10 & 02:32:22 & 23,66 & $04: 49: 52$ & 23,62 & 03:02:06 & 22,14 & $02: 56: 06$ & 21,65 \\
\hline $06: 31: 40$ & 29,42 & 02:52:22 & 24,06 & 04:58:22 & 23,21 & 03:06:36 & 22,49 & 03:01:06 & 21,30 \\
\hline $06: 50: 40$ & 29,73 & $02: 54: 52$ & 23,72 & 05:38:22 & 22,87 & 03:08:06 & 22,14 & 03:16:36 & 21,65 \\
\hline 07:15:40 & 30,04 & 02:59:22 & 24,06 & $05: 41: 52$ & 23,21 & 03:12:36 & 22,49 & 04:45:06 & 21,30 \\
\hline $07: 41: 40$ & 30,35 & 03:02:22 & 23,72 & $05: 47: 22$ & 23,85 & 04:46:06 & 22,08 & $04: 47: 36$ & 20,90 \\
\hline 08:00:10 & 30,67 & $03: 14: 52$ & 24,12 & $05: 54: 52$ & 24,20 & 04:49:06 & 21,68 & $04: 53: 36$ & 20,55 \\
\hline $08: 14: 10$ & 30,98 & 03:28:22 & 23,77 & $06: 04: 22$ & 23,85 & 04:56:06 & 21,33 & $04: 58: 36$ & 20,21 \\
\hline 08:28:40 & 30,67 & 03:30:22 & 24,18 & $06: 07: 52$ & 24,25 & 05:32:06 & 20,99 & 04:59:36 & 20,55 \\
\hline 08:36:10 & 30,35 & 03:33:22 & 23,83 & $06: 12: 52$ & 23,91 & $05: 42: 36$ & 21,39 & 05:08:36 & 20,21 \\
\hline 08:47:10 & 30,04 & 03:40:22 & 24,18 & $06: 14: 22$ & 24,37 & $05: 42: 36$ & 21,39 & 05:15:06 & 20,55 \\
\hline 09:38:40 & 30,35 & 04:43:22 & 23,83 & $07: 24: 52$ & 24,77 & 05:43:36 & 21,74 & 05:16:36 & 20,21 \\
\hline 09:44:40 & 30,67 & 04:48:52 & 23,37 & $07: 25: 22$ & 24,43 & $05: 46: 36$ & 22,08 & $05: 42: 36$ & 20,55 \\
\hline $09: 52: 10$ & 30,98 & $04: 55: 52$ & 23,02 & $07: 30: 22$ & 24,77 & $05: 57: 36$ & 22,43 & $05: 44: 06$ & 20,90 \\
\hline $10: 06: 10$ & 31,29 & $05: 22: 52$ & 22,68 & $07: 30: 22$ & 24,77 & $06: 28: 06$ & 22,78 & $05: 47: 06$ & 21,25 \\
\hline $10: 32: 40$ & 31,60 & $05: 42: 22$ & 23,02 & 07:53:22 & 25,12 & 07:34:06 & 23,12 & 05:52:36 & 21,59 \\
\hline $10: 39: 40$ & 31,92 & $05: 43: 22$ & 23,43 & 08:06:22 & 25,47 & 07:50:06 & 23,47 & 06:10:36 & 21,94 \\
\hline $10: 39: 40$ & 31,92 & $05: 45: 52$ & 23,83 & $08: 13: 52$ & 25,82 & $08: 01: 36$ & 23,82 & $06: 56: 36$ & 22,28 \\
\hline $10: 44: 40$ & 32,23 & $05: 53: 52$ & 24,18 & 08:15:52 & 25,12 & 08:13:06 & 24,16 & 07:37:06 & 22,63 \\
\hline $10: 49: 40$ & 32,54 & $06: 27: 22$ & 24,58 & 08:16:22 & 24,72 & 08:15:36 & 23,12 & 07:56:06 & 23,03 \\
\hline $10: 55: 40$ & 32,85 & $07: 41: 22$ & 24,93 & $08: 16: 52$ & 24,20 & 08:16:06 & 22,43 & 08:08:06 & 23,43 \\
\hline $11: 02: 10$ & 33,17 & 07:53:52 & 25,27 & 08:17:52 & 23,85 & $08: 16: 36$ & 21,85 & $08: 15: 36$ & 22,45 \\
\hline $11: 07: 10$ & 33,48 & 08:03:52 & 25,62 & 09:08:22 & 24,20 & $08: 21: 06$ & 21,51 & 08:16:06 & 21,71 \\
\hline $11: 11: 10$ & 33,79 & 08:14:22 & 25,97 & 09:18:22 & 24,54 & $08: 24: 06$ & 21,85 & $08: 16: 36$ & 21,13 \\
\hline $11: 15: 10$ & 34,10 & $08: 15: 22$ & 25,04 & $09: 21: 22$ & 24,95 & $08: 25: 06$ & 21,51 & 08:18:06 & 20,79 \\
\hline $11: 21: 10$ & 34,42 & 08:15:52 & 24,47 & 09:27:52 & 25,29 & 08:30:36 & 21,85 & 08:49:36 & 21,13 \\
\hline $11: 30: 10$ & 34,73 & $08: 16: 22$ & 23,89 & $09: 35: 22$ & 25,76 & 08:32:06 & 21,51 & 09:16:06 & 21,59 \\
\hline $12: 14: 10$ & 35,04 & 08:17:22 & 23,48 & $10: 28: 22$ & 26,16 & $08: 45: 36$ & 21,85 & 09:18:06 & 22,05 \\
\hline $12: 17: 10$ & 35,35 & 08:28:22 & 23,08 & $10: 31: 22$ & 26,57 & 09:07:36 & 22,20 & $09: 21: 06$ & 22,40 \\
\hline $12: 20: 10$ & 35,67 & 08:38:22 & 23,43 & $10: 37: 22$ & 26,91 & 09:18:06 & 22,60 & $09: 24: 36$ & 22,80 \\
\hline $12: 22: 40$ & 35,98 & 09:10:22 & 23,83 & 10:43:22 & 27,38 & 09:19:06 & 22,95 & 09:30:06 & 22,34 \\
\hline $12: 26: 10$ & 36,29 & 09:18:52 & 24,24 & 10:59:22 & 27,73 & $09: 21: 06$ & 23,30 & 09:31:06 & 21,99 \\
\hline $12: 28: 40$ & 36,60 & 09:27:52 & 24,75 & $11: 02: 22$ & 28,07 & 09:27:06 & 23,70 & 09:33:36 & 22,51 \\
\hline $12: 31: 40$ & 36,92 & $09: 35: 52$ & 25,16 & $11: 03: 22$ & 28,42 & $09: 29: 36$ & 23,35 & 09:38:36 & 22,86 \\
\hline $12: 35: 10$ & 37,23 & $10: 27: 22$ & 25,51 & $11: 06: 52$ & 28,88 & $09: 32: 36$ & 22,95 & $09: 43: 36$ & 22,51 \\
\hline $12: 38: 10$ & 37,54 & $10: 30: 52$ & 25,85 & $11: 08: 52$ & 29,23 & 09:34:06 & 23,35 & 09:51:06 & 22,86 \\
\hline $12: 46: 40$ & 37,85 & $10: 34: 22$ & 26,20 & $11: 11: 22$ & 28,77 & 09:38:06 & 23,76 & 09:52:06 & 22,51 \\
\hline $13: 08: 40$ & 38,17 & $10: 39: 52$ & 26,55 & $11: 14: 22$ & 28,47 & $09: 43: 36$ & 23,41 & 09:54:06 & 22,86 \\
\hline 13:14:10 & 38,48 & 10:43:52 & 26,95 & 11:16:22 & 28,13 & 09:59:06 & 23,82 & 10:06:36 & 22,45 \\
\hline $13: 18: 10$ & 38,79 & $11: 01: 52$ & 27,41 & $11: 28: 22$ & 27,72 & $10: 06: 36$ & 23,47 & $10: 07: 06$ & 22,80 \\
\hline $13: 24: 40$ & 39,10 & $11: 04: 52$ & 27,93 & $11: 29: 22$ & 28,07 & $10: 24: 36$ & 23,87 & $10: 25: 36$ & 23,26 \\
\hline $13: 51: 40$ & 38,79 & $11: 16: 52$ & 27,35 & $11: 34: 22$ & 27,38 & $10: 31: 06$ & 24,22 & $10: 30: 36$ & 23,61 \\
\hline $14: 14: 40$ & 39,10 & $11: 19: 52$ & 27,70 & $11: 34: 52$ & 27,78 & $10: 35: 06$ & 24,57 & $10: 31: 06$ & 23,26 \\
\hline $14: 24: 10$ & 39,42 & $11: 28: 52$ & 27,29 & $11: 39: 22$ & 27,43 & $10: 42: 06$ & 24,97 & 10:32:06 & 23,61 \\
\hline $14: 30: 10$ & 39,73 & $11: 36: 52$ & 26,83 & $11: 44: 52$ & 27,03 & $10: 51: 06$ & 25,32 & $10: 39: 36$ & 23,95 \\
\hline
\end{tabular}




\begin{tabular}{|c|c|c|c|c|c|c|c|c|c|}
\hline HORA & NOSE & HORA & PT-100_1 & HORA & PT-100_2 & HORA & PT-100_3 & HORA & PT-100_4 \\
\hline $14: 35: 10$ & 40,04 & $11: 38: 52$ & 27,18 & $11: 49: 52$ & 27,38 & $10: 55: 06$ & 24,97 & $10: 43: 36$ & 24,36 \\
\hline $14: 41: 40$ & 40,35 & $11: 40: 52$ & 26,83 & $11: 55: 22$ & 27,72 & $10: 55: 36$ & 25,38 & 10:48:06 & 24,01 \\
\hline 14:48:10 & 40,67 & 11:57:22 & 27,29 & 12:07:22 & 28,07 & 11:03:06 & 25,90 & 10:50:06 & 24,59 \\
\hline $14: 56: 10$ & 40,98 & $12: 08: 52$ & 27,87 & $12: 09: 52$ & 28,47 & $11: 07: 36$ & 26,53 & $10: 51: 36$ & 24,13 \\
\hline $15: 15: 10$ & 40,67 & $12: 08: 52$ & 27,87 & $12: 10: 22$ & 28,88 & $11: 09: 36$ & 26,19 & $10: 53: 36$ & 24,53 \\
\hline $15: 20: 40$ & 40,35 & $12: 10: 22$ & 28,28 & $12: 11: 52$ & 29,46 & $11: 15: 06$ & 25,78 & $11: 02: 36$ & 24,88 \\
\hline $15: 26: 10$ & 40,04 & $12: 11: 22$ & 28,68 & 12:13:22 & 29,86 & $11: 34: 36$ & 25,44 & $11: 02: 36$ & 24,88 \\
\hline $15: 30: 10$ & 39,73 & $12: 13: 52$ & 29,20 & $12: 14: 22$ & 30,39 & $11: 43: 36$ & 25,09 & 11:03:06 & 25,22 \\
\hline $15: 34: 10$ & 39,42 & 12:16:52 & 29,55 & 12:15:22 & 30,73 & 11:52:06 & 25,44 & 11:06:36 & 25,68 \\
\hline 15:38:10 & 39,10 & $12: 24: 22$ & 29,95 & 12:17:52 & 30,39 & 12:08:06 & 25,78 & 11:15:36 & 25,22 \\
\hline $15: 51: 40$ & 39,42 & $12: 28: 22$ & 30,42 & $12: 22: 22$ & 30,73 & $12: 08: 36$ & 26,13 & $11: 28: 06$ & 24,82 \\
\hline $15: 54: 40$ & 39,73 & $12: 29: 52$ & 29,72 & $12: 26: 22$ & 31,20 & $12: 11: 06$ & 26,65 & $11: 41: 36$ & 24,47 \\
\hline 15:58:10 & 40,04 & $12: 34: 52$ & 30,24 & $12: 30: 22$ & 30,68 & $12: 11: 36$ & 27,23 & $11: 54: 36$ & 24,82 \\
\hline $16: 01: 10$ & 40,35 & $12: 38: 52$ & 29,78 & $12: 34: 52$ & 31,31 & $12: 12: 06$ & 26,88 & $12: 04: 06$ & 25,16 \\
\hline $16: 04: 10$ & 40,67 & 12:42:52 & 29,43 & $12: 41: 22$ & 30,68 & 12:13:06 & 27,29 & $12: 05: 06$ & 24,82 \\
\hline $16: 06: 40$ & 40,98 & 12:57:22 & 29,03 & $12: 42: 22$ & 30,33 & $12: 14: 06$ & 27,81 & 12:08:06 & 25,40 \\
\hline $16: 09: 40$ & 41,29 & 13:03:22 & 29,43 & 12:44:52 & 29,98 & $12: 16: 36$ & 28,21 & $12: 10: 06$ & 25,74 \\
\hline $16: 13: 40$ & 41,60 & 13:04:52 & 30,18 & $12: 49: 52$ & 30,33 & $12: 19: 36$ & 27,87 & $12: 12: 06$ & 26,43 \\
\hline $16: 22: 40$ & 41,29 & $13: 06: 52$ & 30,59 & $12: 54: 52$ & 29,98 & $12: 19: 36$ & 27,87 & $12: 13: 06$ & 26,84 \\
\hline $16: 27: 10$ & 40,98 & $13: 10: 52$ & 31,17 & $12: 56: 52$ & 29,63 & $12: 20: 36$ & 28,27 & $12: 14: 36$ & 27,30 \\
\hline $16: 31: 40$ & 40,67 & $13: 12: 22$ & 30,76 & $12: 57: 52$ & 30,04 & $12: 22: 36$ & 28,68 & $12: 15: 36$ & 27,76 \\
\hline $16: 36: 10$ & 40,35 & 13:14:22 & 31,28 & $12: 59: 22$ & 29,63 & $12: 23: 06$ & 28,33 & $12: 24: 36$ & 28,57 \\
\hline $16: 48: 40$ & 40,04 & $13: 15: 22$ & 30,88 & $12: 59: 22$ & 29,63 & $12: 26: 06$ & 28,68 & $12: 28: 36$ & 28,98 \\
\hline $16: 53: 40$ & 39,73 & $13: 20: 52$ & 30,36 & $13: 00: 52$ & 30,04 & $12: 28: 06$ & 29,08 & $12: 30: 06$ & 28,11 \\
\hline $16: 57: 10$ & 39,42 & $13: 23: 22$ & 29,95 & $13: 04: 22$ & 30,73 & $12: 29: 36$ & 28,68 & $12: 30: 36$ & 27,65 \\
\hline $16: 57: 10$ & 39,42 & $13: 29: 52$ & 29,43 & 13:05:52 & 31,20 & $12: 30: 06$ & 28,16 & $12: 31: 36$ & 28,11 \\
\hline $17: 00: 40$ & 39,10 & 13:32:22 & 29,90 & $13: 07: 22$ & 31,54 & $12: 31: 36$ & 28,56 & $12: 34: 06$ & 28,57 \\
\hline 17:03:10 & 38,79 & $13: 35: 52$ & 29,55 & $13: 10: 52$ & 32,01 & $12: 35: 06$ & 28,97 & $12: 35: 36$ & 28,98 \\
\hline $17: 06: 40$ & 38,48 & 13:40:22 & 29,14 & 13:14:22 & 32,41 & 12:38:36 & 28,62 & $12: 38: 36$ & 28,63 \\
\hline 17:09:40 & 38,17 & 13:41:22 & 29,49 & 13:15:22 & 32,07 & $12: 41: 36$ & 28,21 & $12: 41: 36$ & 27,88 \\
\hline $17: 12: 10$ & 37,85 & $13: 42: 22$ & 29,14 & $13: 16: 22$ & 31,72 & $12: 42: 36$ & 27,81 & $12: 43: 06$ & 27,42 \\
\hline 17:19:10 & 37,54 & $13: 44: 22$ & 29,49 & 13:18:52 & 32,12 & $12: 50: 36$ & 28,21 & $12: 44: 36$ & 26,95 \\
\hline $17: 23: 10$ & 37,23 & $13: 50: 52$ & 29,95 & $13: 19: 22$ & 31,72 & 12:52:06 & 27,75 & $12: 45: 06$ & 27,53 \\
\hline $17: 28: 10$ & 36,92 & 13:51:52 & 29,61 & $13: 21: 22$ & 31,08 & $12: 56: 06$ & 27,29 & $12: 47: 06$ & 27,07 \\
\hline $17: 33: 10$ & 36,60 & $13: 56: 22$ & 29,95 & $13: 24: 22$ & 30,68 & 13:00:36 & 27,69 & $12: 49: 06$ & 27,59 \\
\hline 17:39:10 & 36,29 & 14:02:22 & 29,61 & $13: 27: 52$ & 30,27 & 13:01:06 & 27,29 & $12: 50: 36$ & 27,94 \\
\hline $17: 46: 40$ & 35,98 & 14:03:22 & 30,18 & 13:32:22 & 30,62 & 13:03:36 & 28,10 & $12: 51: 06$ & 27,59 \\
\hline $17: 56: 10$ & 35,67 & $14: 10: 52$ & 30,65 & $13: 37: 22$ & 30,15 & $13: 05: 36$ & 29,14 & $12: 54: 06$ & 27,18 \\
\hline $18: 07: 10$ & 35,35 & $14: 11: 52$ & 30,99 & $13: 40: 52$ & 29,81 & $13: 14: 36$ & 29,90 & $12: 56: 06$ & 26,78 \\
\hline 18:18:10 & 35,04 & $14: 16: 22$ & 30,59 & $13: 44: 52$ & 30,21 & $13: 16: 06$ & 29,37 & $12: 56: 36$ & 26,43 \\
\hline $18: 27: 10$ & 34,73 & $14: 17: 22$ & 30,24 & $13: 54: 52$ & 30,56 & $13: 20: 06$ & 28,97 & 12:59:06 & 26,90 \\
\hline 18:38:40 & 34,42 & 14:19:52 & 30,59 & 14:03:52 & 30,96 & $13: 21: 06$ & 28,56 & 13:03:36 & 27,47 \\
\hline $18: 48: 40$ & 34,10 & $14: 20: 52$ & 30,94 & 14:05:22 & 30,62 & 13:23:06 & 27,98 & 13:05:06 & 27,88 \\
\hline 18:56:10 & 33,79 & 14:22:22 & 31,28 & 14:06:22 & 30,96 & $13: 25: 36$ & 28,39 & 13:06:06 & 28,40 \\
\hline 19:05:10 & 33,48 & $14: 25: 22$ & 31,69 & 14:10:52 & 31,54 & $13: 26: 36$ & 27,87 & 13:08:36 & 28,74 \\
\hline 19:11:10 & 33,17 & $14: 43: 22$ & 32,04 & $14: 11: 52$ & 32,01 & 13:39:06 & 27,46 & 13:09:36 & 29,15 \\
\hline $19: 16: 40$ & 32,85 & $14: 48: 52$ & 31,63 & $14: 12: 22$ & 32,41 & $13: 44: 06$ & 27,92 & 13:12:06 & 28,80 \\
\hline $19: 20: 40$ & 32,54 & $14: 50: 22$ & 32,04 & $14: 13: 52$ & 32,01 & $13: 44: 36$ & 27,58 & 13:14:06 & 29,21 \\
\hline $19: 25: 10$ & 32,23 & $14: 51: 22$ & 31,63 & $14: 14: 52$ & 31,54 & $13: 52: 06$ & 27,92 & $13: 15: 06$ & 29,55 \\
\hline $19: 29: 40$ & 31,92 & $14: 54: 22$ & 31,28 & $14: 17: 52$ & 30,96 & 13:58:36 & 28,27 & $13: 15: 36$ & 29,15 \\
\hline $19: 34: 40$ & 31,60 & $14: 55: 22$ & 30,71 & $14: 20: 22$ & 31,31 & 13:59:06 & 27,87 & 13:19:36 & 28,51 \\
\hline $19: 39: 10$ & 31,29 & $14: 56: 52$ & 30,07 & $14: 20: 52$ & 31,83 & 14:03:06 & 28,27 & $13: 21: 06$ & 28,17 \\
\hline $19: 44: 40$ & 30,98 & 14:58:22 & 30,42 & $14: 22: 52$ & 32,24 & $14: 04: 06$ & 27,92 & 13:23:06 & 27,76 \\
\hline 19:51:10 & 30,67 & 14:59:22 & 30,90 & $14: 25: 52$ & 32,65 & $14: 06: 06$ & 28,33 & 13:27:36 & 27,24 \\
\hline $19: 59: 10$ & 30,35 & $15: 00: 22$ & 31,30 & $14: 41: 52$ & 32,99 & $14: 10: 36$ & 28,74 & $13: 34: 06$ & 27,59 \\
\hline $20: 07: 40$ & 30,04 & 15:03:22 & 30,96 & $14: 48: 52$ & 32,65 & $14: 11: 36$ & 29,55 & $13: 35: 06$ & 27,24 \\
\hline $20: 37: 40$ & 30,35 & 15:04:52 & 30,61 & 14:50:22 & 33,05 & $14: 13: 36$ & 29,08 & 13:38:36 & 26,84 \\
\hline $20: 54: 10$ & 30,67 & 15:04:52 & 30,61 & 14:51:22 & 32,70 & 14:16:06 & 28,62 & 13:48:06 & 27,18 \\
\hline $21: 16: 40$ & 30,98 & $15: 06: 22$ & 30,26 & $14: 54: 22$ & 32,18 & 14:18:06 & 28,27 & $13: 48: 36$ & 26,67 \\
\hline $21: 54: 10$ & 31,29 & 15:08:52 & 29,92 & $14: 55: 22$ & 31,72 & $14: 19: 36$ & 28,62 & 13:48:36 & 26,67 \\
\hline $22: 46: 10$ & 30,98 & $15: 10: 52$ & 29,45 & $14: 55: 52$ & 31,31 & $14: 20: 06$ & 28,97 & $13: 49: 36$ & 27,24 \\
\hline $22: 47: 40$ & 30,67 & $15: 13: 22$ & 29,11 & $14: 56: 52$ & 30,79 & $14: 22: 36$ & 29,43 & 13:53:36 & 27,65 \\
\hline $22: 48: 40$ & 30,35 & $15: 23: 22$ & 28,64 & $14: 58: 52$ & 31,10 & $14: 24: 36$ & 29,84 & $13: 54: 06$ & 27,30 \\
\hline $22: 50: 10$ & 29,92 & $15: 27: 22$ & 28,18 & $14: 59: 52$ & 31,62 & 14:33:06 & 30,19 & $14: 02: 36$ & 27,70 \\
\hline $22: 51: 10$ & 29,60 & $15: 35: 22$ & 27,84 & $15: 00: 22$ & 32,08 & $14: 34: 36$ & 29,61 & $14: 07: 36$ & 27,36 \\
\hline
\end{tabular}




\begin{tabular}{|c|c|c|c|c|c|c|c|c|c|}
\hline HORA & NOSE & HORA & PT-100_1 & HORA & PT-100_2 & HORA & PT-100_3 & HORA & PT-100_4 \\
\hline $22: 55: 40$ & 29,92 & $15: 39: 22$ & 28,24 & 15:03:22 & 31,68 & $14: 40: 36$ & 30,19 & 14:08:06 & 27,94 \\
\hline $22: 59: 10$ & 30,23 & $15: 39: 52$ & 28,70 & 15:04:22 & 31,33 & 14:42:06 & 30,77 & 14:10:06 & 27,47 \\
\hline 23:03:40 & 30,54 & $15: 40: 52$ & 29,22 & $15: 06: 22$ & 30,81 & $14: 42: 36$ & 30,30 & $14: 10: 36$ & 27,88 \\
\hline $23: 10: 40$ & 30,85 & $15: 41: 52$ & 29,86 & 15:08:22 & 30,46 & $14: 45: 36$ & 29,90 & $14: 11: 36$ & 28,74 \\
\hline \multirow[t]{61}{*}{$23: 38: 40$} & 31,17 & $15: 42: 52$ & 30,38 & $15: 09: 52$ & 30,06 & $14: 46: 06$ & 30,24 & $14: 15: 06$ & 28,22 \\
\hline & & $15: 43: 22$ & 30,78 & $15: 11: 52$ & 29,71 & $14: 46: 36$ & 29,90 & $14: 15: 36$ & 28,57 \\
\hline & & $15: 45: 22$ & 31,48 & $15: 13: 52$ & 29,31 & $14: 46: 36$ & 29,90 & $14: 16: 06$ & 28,22 \\
\hline & & $15: 47: 52$ & 31,88 & $15: 24: 52$ & 28,79 & $14: 50: 36$ & 30,24 & $14: 17: 36$ & 27,53 \\
\hline & & $15: 50: 22$ & 31,42 & $15: 34: 22$ & 28,38 & $14: 51: 36$ & 29,90 & $14: 20: 06$ & 28,11 \\
\hline & & 15:53:22 & 31,77 & $15: 39: 52$ & 29,13 & $14: 52: 36$ & 29,37 & $14: 21: 06$ & 28,57 \\
\hline & & 16:01:52 & 32,11 & 15:39:52 & 29,13 & 14:55:36 & 28,74 & $14: 22: 36$ & 28,98 \\
\hline & & $16: 07: 22$ & 32,52 & $15: 40: 52$ & 29,77 & 14:56:36 & 28,21 & $14: 25: 36$ & 29,38 \\
\hline & & 16:09:22 & 31,82 & $15: 41: 52$ & 30,41 & 14:59:06 & 28,74 & $14: 27: 06$ & 28,98 \\
\hline & & 16:09:52 & 31,36 & $15: 42: 52$ & 30,93 & 15:00:06 & 29,43 & $14: 28: 36$ & 29,32 \\
\hline & & $16: 10: 52$ & 30,72 & 15:43:22 & 31,39 & 15:00:36 & 29,78 & 14:42:06 & 29,79 \\
\hline & & $16: 11: 22$ & 30,38 & $15: 44: 22$ & 31,79 & $15: 01: 36$ & 30,24 & $14: 45: 36$ & 29,32 \\
\hline & & $16: 12: 22$ & 29,86 & $15: 45: 22$ & 32,26 & 15:02:06 & 29,61 & 14:49:06 & 29,73 \\
\hline & & $16: 14: 22$ & 29,40 & $15: 46: 22$ & 32,72 & 15:03:36 & 29,20 & $14: 52: 06$ & 28,98 \\
\hline & & $16: 16: 52$ & 28,93 & $15: 47: 52$ & 33,07 & $15: 05: 06$ & 28,85 & $14: 53: 06$ & 29,32 \\
\hline & & $16: 21: 22$ & 28,59 & $15: 49: 52$ & 32,61 & $15: 06: 36$ & 28,45 & $14: 54: 06$ & 28,92 \\
\hline & & $16: 24: 22$ & 28,93 & $15: 51: 52$ & 32,14 & 15:08:06 & 28,10 & 14:55:36 & 28,17 \\
\hline & & $16: 30: 22$ & 28,59 & $15: 52: 52$ & 32,49 & $15: 10: 36$ & 27,52 & $14: 57: 06$ & 27,76 \\
\hline & & $16: 35: 22$ & 29,05 & $15: 55: 22$ & 32,90 & $15: 15: 36$ & 27,17 & 14:59:36 & 28,28 \\
\hline & & $16: 35: 52$ & 29,40 & 16:00:22 & 33,24 & $15: 17: 36$ & 27,58 & 15:00:06 & 28,69 \\
\hline & & $16: 37: 22$ & 29,80 & 16:03:52 & 33,71 & $15: 23: 36$ & 27,00 & $15: 00: 36$ & 29,09 \\
\hline & & 16:38:52 & 30,26 & 16:08:52 & 33,30 & $15: 30: 06$ & 26,65 & 15:03:36 & 28,51 \\
\hline & & $16: 39: 22$ & 30,61 & $16: 09: 22$ & 32,90 & $15: 39: 36$ & 27,29 & 15:06:06 & 28,17 \\
\hline & & $16: 41: 52$ & 30,26 & 16:09:52 & 32,26 & $15: 41: 06$ & 27,63 & $15: 07: 36$ & 27,82 \\
\hline & & $16: 42: 52$ & 29,57 & 16:10:22 & 31,68 & $15: 41: 36$ & 28,10 & 15:09:06 & 27,47 \\
\hline & & $16: 45: 22$ & 29,05 & 16:11:22 & 31,10 & 15:42:36 & 28,45 & 15:10:06 & 27,01 \\
\hline & & $16: 46: 52$ & 28,53 & $16: 11: 52$ & 30,64 & $15: 43: 36$ & 29,26 & $15: 14: 36$ & 26,67 \\
\hline & & 16:48:22 & 28,13 & $16: 12: 52$ & 30,23 & 15:45:06 & 29,61 & 15:19:06 & 27,01 \\
\hline & & $16: 50: 22$ & 27,55 & $16: 14: 52$ & 29,88 & $15: 46: 06$ & 29,95 & $15: 21: 36$ & 26,67 \\
\hline & & $16: 52: 52$ & 27,20 & $16: 17: 22$ & 29,31 & $15: 51: 36$ & 29,61 & $15: 24: 06$ & 26,32 \\
\hline & & $16: 59: 52$ & 26,86 & $16: 24: 52$ & 29,88 & 15:54:06 & 30,07 & 15:33:36 & 25,86 \\
\hline & & 17:09:22 & 27,29 & $16: 26: 52$ & 29,42 & $15: 59: 06$ & 30,48 & 15:39:36 & 26,49 \\
\hline & & $17: 21: 52$ & 26,83 & 16:30:22 & 29,02 & $16: 05: 36$ & 29,95 & $15: 41: 36$ & 27,36 \\
\hline & & 17:43:52 & 26,49 & $16: 35: 22$ & 29,48 & $16: 06: 36$ & 30,77 & 15:43:06 & 28,05 \\
\hline & & 18:06:52 & 26,14 & $16: 35: 52$ & 29,88 & 16:07:36 & 30,30 & $15: 44: 06$ & 28,51 \\
\hline & & 18:34:22 & 25,79 & 16:37:22 & 30,29 & 16:09:06 & 29,95 & 15:45:06 & 29,21 \\
\hline & & $18: 44: 22$ & 25,39 & $16: 38: 52$ & 30,81 & $16: 10: 06$ & 29,61 & $15: 46: 36$ & 29,84 \\
\hline & & 19:06:52 & 24,93 & 16:39:22 & 31,16 & $16: 10: 36$ & 29,14 & 15:47:06 & 29,50 \\
\hline & & 19:07:52 & 24,24 & $16: 39: 52$ & 31,68 & $16: 11: 06$ & 28,79 & $15: 55: 36$ & 29,90 \\
\hline & & 19:09:22 & 23,66 & $16: 41: 22$ & 31,04 & $16: 11: 36$ & 28,45 & 15:56:06 & 29,55 \\
\hline & & 19:11:52 & 23,08 & $16: 41: 52$ & 30,69 & 16:13:06 & 27,92 & 16:00:06 & 29,96 \\
\hline & & 19:11:52 & 23,08 & $16: 42: 52$ & 30,23 & $16: 15: 06$ & 28,33 & $16: 03: 06$ & 30,48 \\
\hline & & 19:18:52 & 22,68 & $16: 43: 52$ & 29,83 & $16: 16: 06$ & 27,75 & 16:04:06 & 30,02 \\
\hline & & 19:38:22 & 23,02 & $16: 45: 52$ & 29,36 & $16: 17: 36$ & 27,23 & 16:04:06 & 30,02 \\
\hline & & 19:39:22 & 22,68 & 16:47:22 & 28,84 & $16: 24: 36$ & 27,63 & 16:09:06 & 29,67 \\
\hline & & $19: 45: 52$ & 23,02 & 16:49:22 & 28,50 & $16: 26: 36$ & 27,29 & $16: 10: 06$ & 29,27 \\
\hline & & 19:49:52 & 22,68 & $16: 49: 52$ & 28,15 & $16: 35: 36$ & 27,87 & $16: 10: 36$ & 28,80 \\
\hline & & $20: 06: 52$ & 23,08 & $16: 52: 52$ & 27,75 & 16:39:06 & 28,68 & 16:11:36 & 28,40 \\
\hline & & 20:07:52 & 23,48 & 17:00:22 & 27,40 & $16: 40: 06$ & 29,32 & 16:13:06 & 27,99 \\
\hline & & 20:09:22 & 23,83 & $17: 10: 52$ & 27,72 & $16: 41: 36$ & 28,62 & $16: 14: 06$ & 27,47 \\
\hline & & $20: 10: 52$ & 24,18 & 17:18:52 & 27,38 & $16: 42: 36$ & 28,16 & 16:14:36 & 27,88 \\
\hline & & 20:11:52 & 24,52 & $17: 38: 52$ & 27,03 & $16: 44: 06$ & 27,81 & 16:15:06 & 28,22 \\
\hline & & $20: 17: 52$ & 24,87 & 18:05:52 & 26,57 & $16: 45: 36$ & 27,35 & $16: 16: 06$ & 27,65 \\
\hline & & 20:28:22 & 25,22 & 18:34:52 & 26,22 & $16: 47: 36$ & 27,00 & $16: 16: 36$ & 27,01 \\
\hline & & $20: 37: 22$ & 25,56 & 18:43:22 & 25,87 & $16: 48: 36$ & 26,59 & $16: 17: 36$ & 26,67 \\
\hline & & $21: 03: 52$ & 25,16 & 19:03:22 & 25,47 & $16: 48: 36$ & 26,59 & $16: 24: 36$ & 27,30 \\
\hline & & $21: 10: 22$ & 25,51 & 19:07:22 & 25,06 & $16: 50: 36$ & 26,19 & $16: 26: 36$ & 26,95 \\
\hline & & $22: 31: 22$ & 25,16 & 19:07:52 & 24,66 & $16: 52: 36$ & 25,84 & 16:31:06 & 26,61 \\
\hline & & $23: 27: 22$ & 24,81 & 19:09:22 & 24,20 & $16: 57: 06$ & 25,49 & $16: 35: 36$ & 27,01 \\
\hline & & & & 19:09:22 & 24,20 & 17:08:36 & 25,84 & 16:36:06 & 27,53 \\
\hline & & & & 19:10:22 & 23,79 & $17: 20: 06$ & 25,49 & $16: 37: 06$ & 27,18 \\
\hline
\end{tabular}




\begin{tabular}{|c|c|c|c|c|c|c|c|c|c|}
\hline HORA & NOSE & HORA & PT-100_1 & HORA & PT-100_2 & HORA & PT-100_3 & HORA & PT-100_4 \\
\hline & & & & 19:12:22 & 23,39 & 17:38:06 & 24,97 & 16:38:36 & 27,76 \\
\hline & & & & $19: 22: 52$ & 22,99 & 18:07:06 & 24,57 & $16: 39: 36$ & 28,34 \\
\hline & & & & $19: 34: 52$ & 23,33 & $18: 25: 36$ & 24,22 & $16: 42: 36$ & 27,94 \\
\hline & & & & $19: 51: 22$ & 22,98 & $18: 50: 06$ & 23,87 & $16: 43: 36$ & 27,53 \\
\hline & & & & 20:08:22 & 23,33 & 19:06:36 & 23,24 & $16: 44: 06$ & 27,18 \\
\hline & & & & $20: 09: 22$ & 23,68 & 19:07:36 & 22,66 & $16: 45: 36$ & 26,84 \\
\hline & & & & $20: 10: 22$ & 24,02 & $19: 08: 36$ & 22,26 & $16: 47: 06$ & 26,49 \\
\hline & & & & $20: 13: 52$ & 24,43 & 19:09:36 & 21,91 & $16: 48: 36$ & 26,09 \\
\hline & & & & $20: 19: 22$ & 24,77 & 19:11:36 & 21,45 & $16: 50: 06$ & 25,74 \\
\hline & & & & 20:32:22 & 25,18 & 19:23:06 & 21,04 & $16: 53: 36$ & 25,34 \\
\hline & & & & $22: 34: 22$ & 24,77 & 19:54:06 & 20,70 & $16: 59: 06$ & 24,88 \\
\hline & & & & $23: 27: 52$ & 24,43 & 20:06:36 & 21,16 & $17: 13: 36$ & 25,28 \\
\hline & & & & $23: 38: 22$ & 24,83 & 20:08:06 & 21,68 & $17: 17: 06$ & 24,93 \\
\hline & & & & $23: 46: 52$ & 24,49 & 20:09:36 & 22,08 & $17: 21: 36$ & 24,59 \\
\hline & & & & & & 20:12:06 & 22,43 & $17: 42: 06$ & 24,18 \\
\hline & & & & & & $20: 15: 36$ & 22,78 & $17: 43: 06$ & 24,53 \\
\hline & & & & & & $20: 20: 06$ & 23,12 & $17: 50: 06$ & 24,07 \\
\hline & & & & & & $20: 40: 36$ & 23,58 & $17: 55: 06$ & 24,41 \\
\hline & & & & & & 22:04:06 & 23,24 & $17: 56: 36$ & 23,95 \\
\hline & & & & & & $23: 11: 06$ & 22,89 & $17: 57: 36$ & 24,30 \\
\hline & & & & & & & & $18: 05: 06$ & 23,95 \\
\hline & & & & & & & & $18: 12: 06$ & 23,61 \\
\hline & & & & & & & & $18: 14: 36$ & 23,95 \\
\hline & & & & & & & & $18: 15: 06$ & 23,55 \\
\hline & & & & & & & & 18:16:06 & 23,95 \\
\hline & & & & & & & & $18: 22: 06$ & 23,55 \\
\hline & & & & & & & & $18: 31: 06$ & 23,90 \\
\hline & & & & & & & & 18:32:06 & 23,49 \\
\hline & & & & & & & & 18:33:36 & 23,84 \\
\hline & & & & & & & & 18:38:36 & 23,43 \\
\hline & & & & & & & & 18:53:06 & 23,09 \\
\hline & & & & & & & & $19: 06: 36$ & 22,34 \\
\hline & & & & & & & & $19: 07: 36$ & 21,76 \\
\hline & & & & & & & & 19:09:36 & 21,13 \\
\hline & & & & & & & & $19: 12: 06$ & 20,73 \\
\hline & & & & & & & & $19: 12: 06$ & 20,73 \\
\hline & & & & & & & & $19: 14: 06$ & 20,38 \\
\hline & & & & & & & & 19:32:36 & 19,92 \\
\hline & & & & & & & & 19:40:36 & 20,38 \\
\hline & & & & & & & & $19: 41: 06$ & 19,98 \\
\hline & & & & & & & & $20: 06: 36$ & 20,38 \\
\hline & & & & & & & & 20:08:06 & 20,84 \\
\hline & & & & & & & & 20:09:36 & 21,19 \\
\hline & & & & & & & & $20: 11: 06$ & 21,53 \\
\hline & & & & & & & & $20: 13: 36$ & 21,88 \\
\hline & & & & & & & & $20: 16: 36$ & 22,34 \\
\hline & & & & & & & & $20: 28: 06$ & 22,69 \\
\hline & & & & & & & & $21: 33: 36$ & 23,03 \\
\hline & & & & & & & & $22: 24: 06$ & 22,69 \\
\hline & & & & & & & & $22: 47: 06$ & 22,28 \\
\hline & & & & & & & & $23: 46: 36$ & 22,63 \\
\hline & & & & & & & & $23: 48: 06$ & 22,28 \\
\hline
\end{tabular}

Medidas em graus Celsius 